Portland State University

PDXScholar

Fall 11-19-2019

\title{
Investigating the Origins of Toxins Present in Electronic Cigarette Aerosols
}

Shawna Vreeke

Portland State University

Follow this and additional works at: https://pdxscholar.library.pdx.edu/open_access_etds

Part of the Chemistry Commons

Let us know how access to this document benefits you.

\section{Recommended Citation}

Vreeke, Shawna, "Investigating the Origins of Toxins Present in Electronic Cigarette Aerosols" (2019). Dissertations and Theses. Paper 5338.

https://doi.org/10.15760/etd.7211

This Dissertation is brought to you for free and open access. It has been accepted for inclusion in Dissertations and Theses by an authorized administrator of PDXScholar. Please contact us if we can make this document more accessible: pdxscholar@pdx.edu. 
Investigating the Origins of Toxins Present in Electronic Cigarette Aerosols

by

Shawna Vreeke

A dissertation submitted in partial fulfillment of the requirements for the degree of

Doctor of Philosophy

in

Chemistry

Dissertation Committee:

Robert M. Strongin, Chair

David H. Peyton

David R. Stuart

Raj Solanki

Portland State University

2019 
(C) 2019 Shawna Vreeke 


\begin{abstract}
The purported safety of electronic cigarettes has come under scrutiny with the significant increase of lung related illnesses starting in the summer of 2019. Public view has started to shift towards understanding the potential negative health impact associated with these devices. While many investigations indicate probable hazards present in e-cigarette aerosols, inter-laboratory assessments are wide ranging and can be contradictory. Due to the novelty of this field, relatively little is known about these products. In this work, the identification and quantification of inhalation toxicants such as formaldehyde, acrolein, acetaldehyde and dihydroxyacetone are reported. Results of the investigation of the ability of various e-cigarette components to modulate levels of toxins are also described. Upon identifying that inter-device power settings did not correlate well with toxin production, the relationships between wicking efficiency and coil parameters were studied. A simple model was developed that performed in the moderate to substantial range as a predictor of the relative carbonyl levels produced upon vaping twelve different e-cigarettes. It can thus be used to predict the relative harm of devices across varying styles. Related investigations showed that additives in the electronic cigarette liquid promote the formation of toxicants upon aerosolization. The addition of triacetin, an additive found in both e-cigarettes and combustible cigarettes, led to a significant increase in the levels of formaldehyde, acrolein and acetaldehyde. By using ${ }^{13} \mathrm{C}$ labeled triacetin and a combination of ${ }^{1} \mathrm{H}$ NMR and ${ }^{13} \mathrm{C} N M R$, the ester hydrolysis of triacetin to form acetic acid was identified. The released acetic
\end{abstract}


acid acted as a catalyst to promote the degradation of propylene glycol and glycerol upon heating. Carbon-13 labeling thus enabled the precise identification of the mechanistic pathway whereby triacetin addition to e-liquid leads to elevated levels of aldehyde toxins in e-cigarette aerosols. The elucidation of the physical and chemical origins of e-cigarette aerosol toxins will aid efforts to mitigate harm. 


\section{Table of Contents}

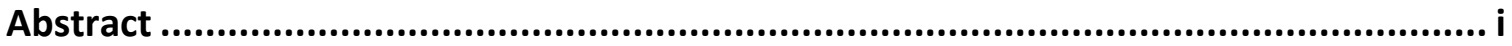

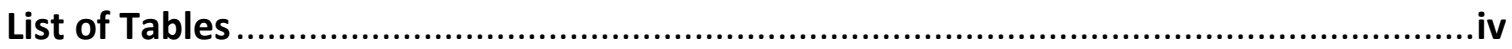

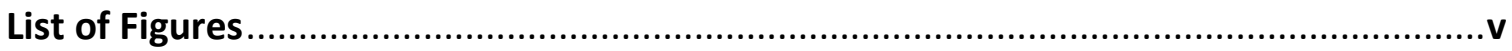

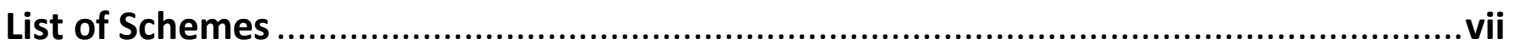

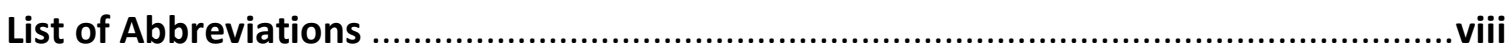

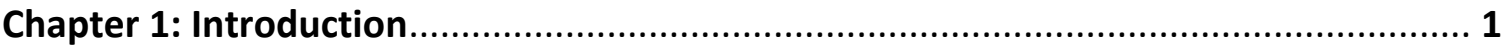

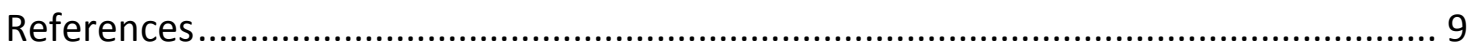

Chapter 2: Dihydroxyacetone Levels in Electronic Cigarettes: Wick Temperature and

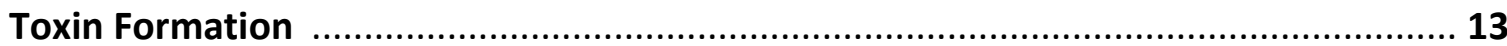

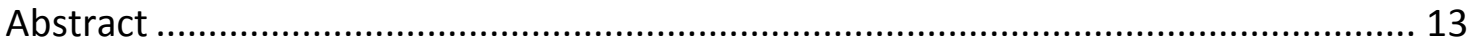

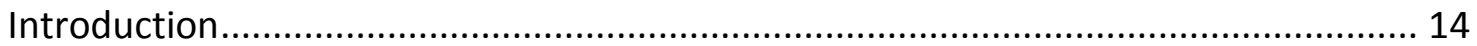

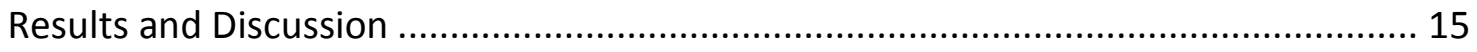

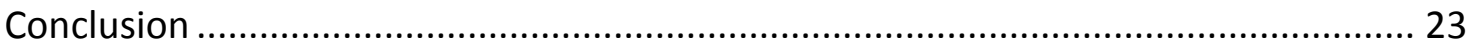

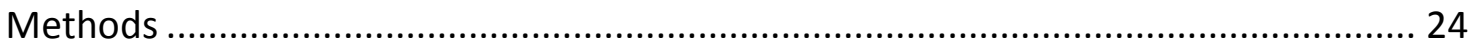

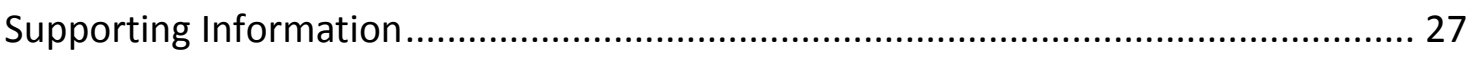

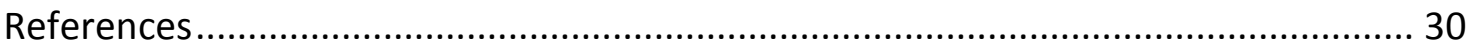

\section{Chapter 3: A Simple Predictive Model for Estimating Relative E-Cigarette Toxic}

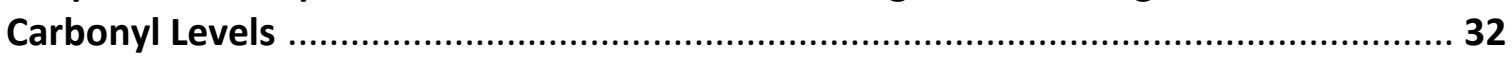

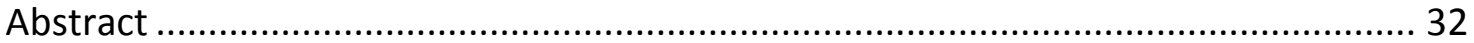

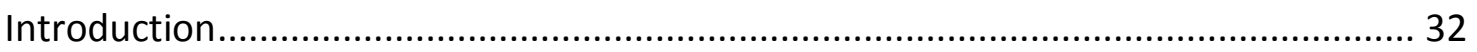

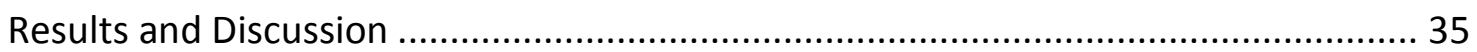

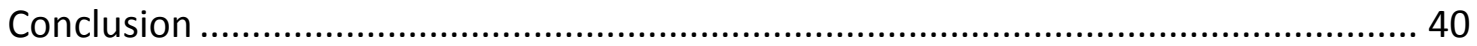

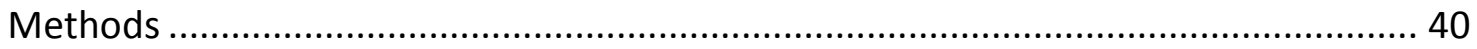

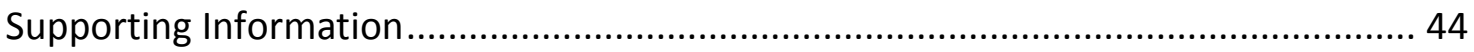

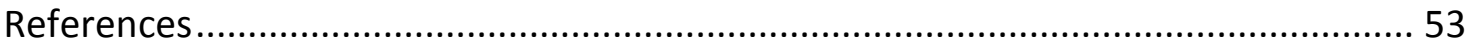

Chapter 4: Triacetin Enhances Levels of Acrolein, Formaldehyde Hemiacetals, and

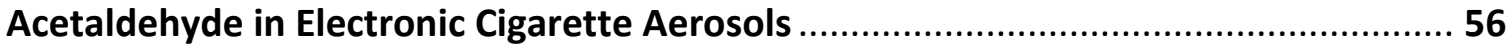

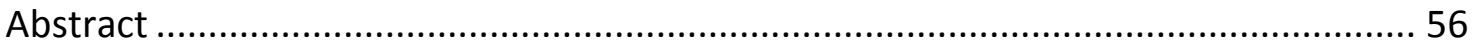

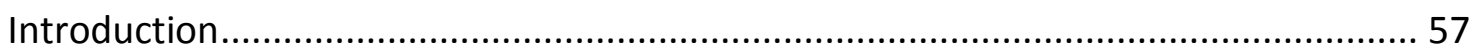

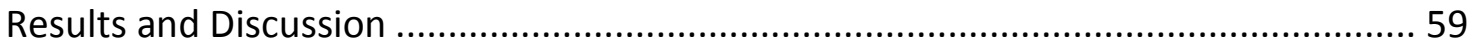

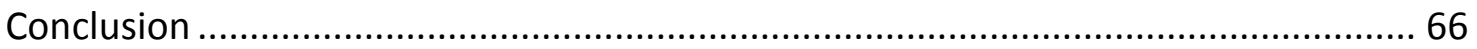

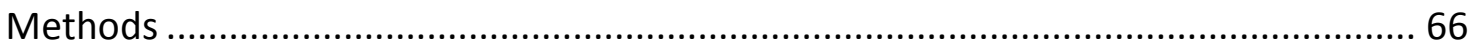

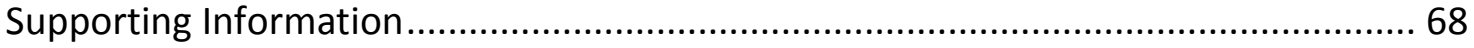

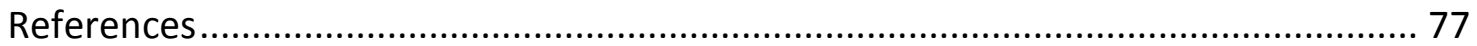

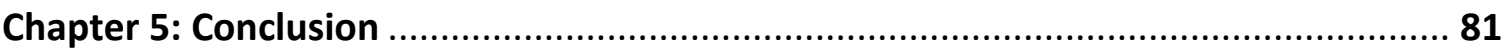

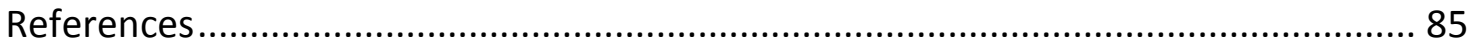




\section{Chapter 2 Tables}

List of Tables

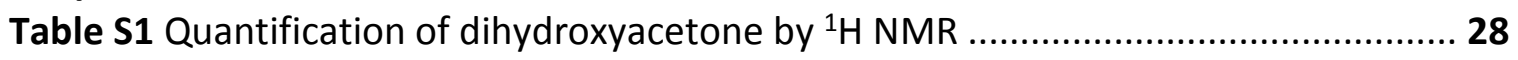

Table S2 Quantification of dihydroxyacetone by GC/MS .......................................... 28

Table S3 Maximum temperature recorded of the wicking wet layer ............................ 29

\section{Chapter 3 Tables}

Table S1 E-cigarette identification and coil style of twelve different coils

Table S2 Coil and wick measurements of twelve different e-cigarettes..........................45

Table S3 Average concentrations of six target carbonyls generated from twelve ecigarettes tested

Table S4 Average mass e-liquid consumed during each independent collection from

twelve coils tested

\section{Chapter 4 Tables}

Table 1 TA reported in various e-liquid flavors

Table S1 Quantification of compounds $\mathbf{1 a - b}, \mathbf{2}$ and $\mathbf{3}$ by ${ }^{1} \mathrm{H}$ NMR

Table S2 Mass of e-liquid consumed for each sample collected

Table S3 Reported concentration range of triacetin in e-liquid 


\section{Chapter 1 Figures}

\section{List of Figures}

Figure 1 The exponential increased use of e-cigarettes use among youth...................... 1

Figure 2 Comparison of combustible cigarette and e-cigarette advertisements.............. 2

Figure 3 Illustration of a general design of an electronic cigarette................................. 4

Figure 4 Depiction of horizontal and vertical coil orientations .................................... 5

\section{Chapter 2 Figures}

Figure $1^{1} \mathrm{H}$ NMR spectra highlighting a representative PG/GL aerosol sample showing peak assignment of the hydroxyl proton of hydroxyacetone and dihydroxyacetone ..... 16 Figure 2 Global spectrum deconvolution of the hydroxyl region of the aerosolized PG/GL using the program MNova

Figure 3 Quantitative results from ${ }^{1} \mathrm{H}$ NMR of EC1-2 and quantitative results from GC/MS of EC1-3.

Figure 4 DHA concentration compared to the mass of PG/GL consumption as a function of device power for EC1-3.

Figure 5 Representation of the inner structure of electronic cigarettes showing a horizontal coil configuration and a vertical coil configuration...

Figure 6 Normalized recorded temperature changes over increasing battery power output

Figure S1 Maximum temperature recordings of the wet layer of the saturated wick during puff activation

\section{Chapter 3 Figures}

Figure 1 Depiction of horizontal and vertical coil orientations

Figure 2 Illustration of single, parallel and dual coils ....

Figure 3 Total carbonyl emissions as a function of coil length per the product of surface area of wick and coil wraps.

Figure 4 Experimental versus predicted values of the regression analysis of EC1-12 .... 38

Figure 5 Analyzing alternative models as predictors of measured toxins...................... 39

Figure S1 Formaldehyde-DNPH calibration curve for HPLC analysis.............................. 46

Figure S2 Acetaldehyde-DNPH calibration curve for HPLC analysis .............................. 46

Figure S3 Acetone-DNPH calibration curve for HPLC analysis ................................... 47

Figure S4 Propanal-DNPH calibration curve for HPLC analysis................................. 47

Figure S5 Butyraldehyde-DNPH calibration curve for HPLC analysis ............................47 47

Figure S6 Benzaldehyde-DNPH calibration curve for HPLC analysis ............................. 48

Figure S7 Regression analysis of alternative model (SA coil/SA wick*wraps) and subsequent predictability

Figure S8 Regression analysis of alternative model (coil*wraps/SA wick) and subsequent predictability

Figure S9 Regression analysis of alternative model (Watts/SA coil) and subsequent predictability 
Figure S10 Regression analysis of alternative model (Volts/SA coil) and subsequent predictability

Figure S11 Regression analysis of alternative model (Watts*SA wick/coil length) and subsequent predictability....

Figure S12 Regression analysis of alternative model (SA coil*Watts/SA wick) and subsequent predictability .

Figure S13 Regression analysis of alternative model (Volts/SA wick) and subsequent predictability

Figure S14. Regression analysis of alternative model (ohms*Watts/SA wick) and subsequent predictability.

Figure S15. Regression analysis of alternative model (ohms*Watts/coil length) and subsequent predictability .

Figure S16. Regression analysis of alternative model (ohms/SA wick) and subsequent predictability

\section{Chapter 4 Figures}

Figure 1 Isotopically-labeled triacetin ....

Figure 2 Overlay of ${ }^{1} \mathrm{H}$ NMR spectra of aerosolized PG/GL e-liquid and 10\% TA/PG/GL e-

liquid 61

Figure 3 Concentrations of compounds $\mathbf{1 a}-\mathbf{3}$ in the aerosolization of PG/GL and increased levels with the addition of $10 \%$ TA. 63

Figure 4 Overlay of ${ }^{1} \mathrm{H}$ NMR spectra of aerosolized PG/GL e-liquid and 0.5\% HOAc/PG/GL

e-liquid..... 65

Figure $\mathrm{S} 1{ }^{1} \mathrm{H}$ NMR spectra of compound $4\left({ }^{13} \mathrm{C}_{3}-\mathrm{TA}\right)$ 70

Figure S2 ${ }^{13} \mathrm{C}$ NMR spectra of compound $4\left({ }^{13} \mathrm{C}_{3}-\mathrm{TA}\right)$ 71

Figure S3 ${ }^{1} \mathrm{H}$ NMR spectra of compound $5\left({ }^{13} \mathrm{C}_{6}-\mathrm{TA}\right)$ 72

Figure $\$ 4{ }^{13} \mathrm{C}$ NMR spectra of compound $5\left({ }^{13} \mathrm{C}_{6}-\mathrm{TA}\right)$ 73 


\section{List of Schemes}

\section{Chapter 2 Schemes}

Scheme 1 Oxidation of glycerol affords DHA and its tautomer glyceraldehyde......

\section{Chapter 4 Schemes}

Scheme 1 Two pathways of triacetin proposed thermal degradation...........................60 Scheme 2 Triacetin in e-cigarettes leads to HOAc formation and subsequent protonation of PG/GL to catalyze the formation of products such as 1-3 
List of Abbreviations

\begin{tabular}{|c|c|}
\hline$\% \mathrm{v} / \mathrm{v}$ & percent by volume \\
\hline ACS & American Chemical Society \\
\hline DHA & dihydroxyacetone \\
\hline DMSO & dimethyl sulfoxide \\
\hline DNPH & 2,4-dinitrophenylhydrazine \\
\hline EC & electronic cigarette \\
\hline e-cigarette/s & electronic cigarette/s \\
\hline e-liquid & electronic cigarette liquid \\
\hline EPA & Environmetal Protection Agency \\
\hline EtOAc & ethyl acetate \\
\hline FDA & Federal Drug Administration \\
\hline GC/MS & gas chromotagraphy mass spectrometry \\
\hline GL & glycerol \\
\hline GRAS & generally recognized as safe \\
\hline GSD & global spectrum deconvolution \\
\hline $\mathrm{HA}$ & hydroxyacetone \\
\hline HOAc & acetic acid \\
\hline HPLC & high performance liquid chromatography \\
\hline IARC & International Agency for Research on Cancer \\
\hline IPA & isopropanol \\
\hline LOD & level of detection \\
\hline LOQ & level of quantification \\
\hline $\mathrm{MeCN}$ & acetonitrile \\
\hline N/A & not available \\
\hline$N / R$ & not reported \\
\hline $\mathrm{Na}_{2} \mathrm{SO}_{4}$ & sodium sulfate \\
\hline $\mathrm{NIH}$ & National Institutes of Health \\
\hline NMR & nuclear magnetic resonance \\
\hline PG & propylene glycol \\
\hline SA & surface area \\
\hline SCSM-STEP & single cigarette smoking machine \\
\hline SI & supporting information \\
\hline SNR & signal to noise ratio \\
\hline TA & triacetin \\
\hline UV & ultraviolet \\
\hline VV/VW & variable voltage/variable wattage \\
\hline VV/VW/TC & variable voltage/variable wattage/temperature control \\
\hline W & watts \\
\hline$\Omega$ & ohms (resistance) \\
\hline
\end{tabular}




\section{Chapter 1: Introduction}

Electronic cigarettes are one of the most controversial topics of 2019. More than 1800 accounts of lung injury from vaping (nicotine and/or THC-containing products) have been reported as of this writing. ${ }^{1} 36 \%$ of all cases are of patients under 21 years of age, even though the minimum age to purchase e-cigarettes is 18 federally and up to 21 in many states. ${ }^{2}$ The number of youth who use e-cigarettes continues to rise (see Figure 1), increasing the percentage of overall tobacco use to levels higher than pre-e-cigarette years ( $27 \%$ in 2018 vs $20 \%$ in 2007$).^{3-4}$ This is concerning because tobacco use is the leading cause of preventable death and disease.

\section{SURGE IN YOUTH CURRENT E-CIGARETTE USE}

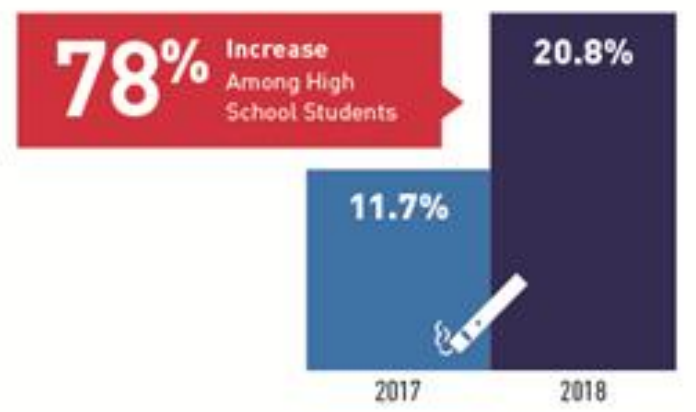

Figure 1. The exponential increased use of e-cigarettes among youth has been deemed an epidemic. From 2017 to 2018 use among high school students increase by $78 \%{ }^{4}$

However, many people, including some researchers believe e-cigarettes to be safe. ${ }^{5-7}$ This has led to a sense of security among users, and an opportunity for ecigarette manufacturers. The lack of regulations has enabled the implementation of tactics similar to those previously used by traditional cigarette companies..$^{8-9}$ 
Throughout history, tobacco companies used advertisements to source new smokers, often times targeting youth and young adults. ${ }^{10}$ Additionally, they "falsely denied, distorted and minimized the significant adverse health consequences of smoking for decades."11 E-cigarette manufactures may be using similar tactics with their advertisements.

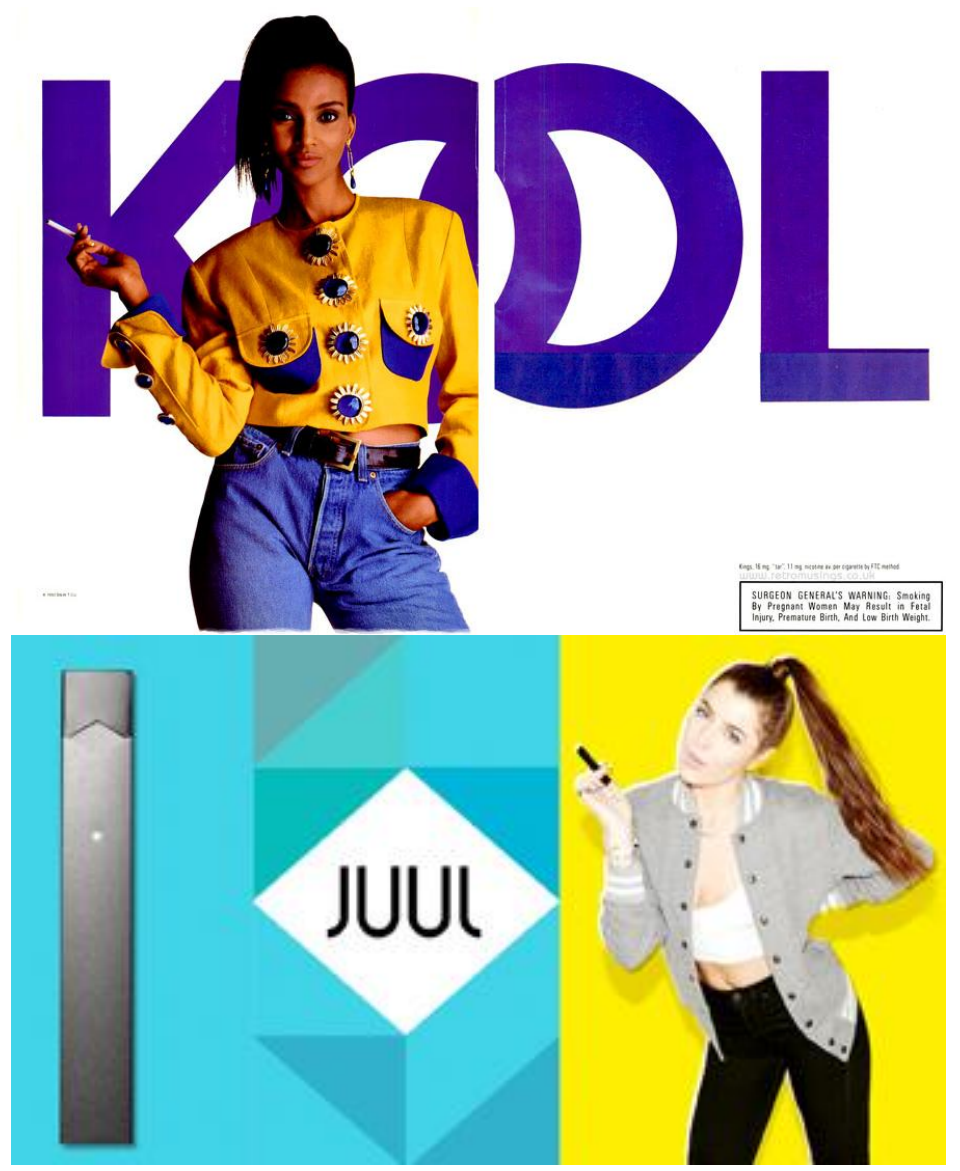

Figure 2. Comparison of combustible cigarette and e-cigarette advertisements. The KOOL ad (top) was published in a series of magazines in 1992. The JUUL ad (bottom) was published on various webpages and social media in 2015.

With the current epidemic of increased e-cigarette use, coupled with the sharp rise of vaping related illness, it is imperative for the scientific community to investigate the health effects of e-cigarettes. With evidence based data on the toxicity of specific e- 
cigarettes and e-liquid formulations, regulatory agencies can make more informed decisions and increase public awareness of risks. Ultimately, there is a known latency period before we will begin to see the long term health effects of these products.

\section{History of Electronic Cigarettes}

Modern e-cigarettes were first sold in the United States in 2007. At that time, they were not under the same regulations as traditional cigarettes. It was not until 2016 that the FDA began to regulate e-cigarettes as a tobacco product. This regulation included restricting the age to purchase and use e-cigarettes to 18 and enforcing public health standards for these products. ${ }^{12}$ The popularity of e-cigarettes has increased throughout the years among all age ranges. E-cigarettes are branded as a means to quit combustible cigarettes. ${ }^{13}$ However, reported data of e-cigarette use as a smoking cessation have been contradictory. ${ }^{14-15}$ More importantly, this purpose would not apply to the $34 \%$ of e-cigarette users whom have never used a traditional cigarette. ${ }^{16-17}$ The attraction of the never use population to initiate e-cigarette use could be attributed to their perception of safety, ${ }^{18}$ with many believing the aerosols contained only water vapor $^{19}$ or was nicotine free. ${ }^{20}$ In 2015 , Public Health England concluded that ecigarettes were $95 \%$ less harmful than smoking. ${ }^{21}$ Since then, many researches have disagreed, stating that while there may be significantly less chemicals produced by ecigarettes, there are different chemicals present, such as flavorings and solvents, which can contribute to the overall health impact of the product. 


\section{Electronic Cigarette Components}

E-cigarettes are battery powered devices that deliver nicotine to the user in an aerosol. The aerosol is a mixture of liquid particles and gaseous vapor. The devices are constantly evolving; however, the main components have not changed. Each device contains a battery, a metal coil, wicking material, a reservoir to hold the e-liquid, an air tube and mouthpiece.

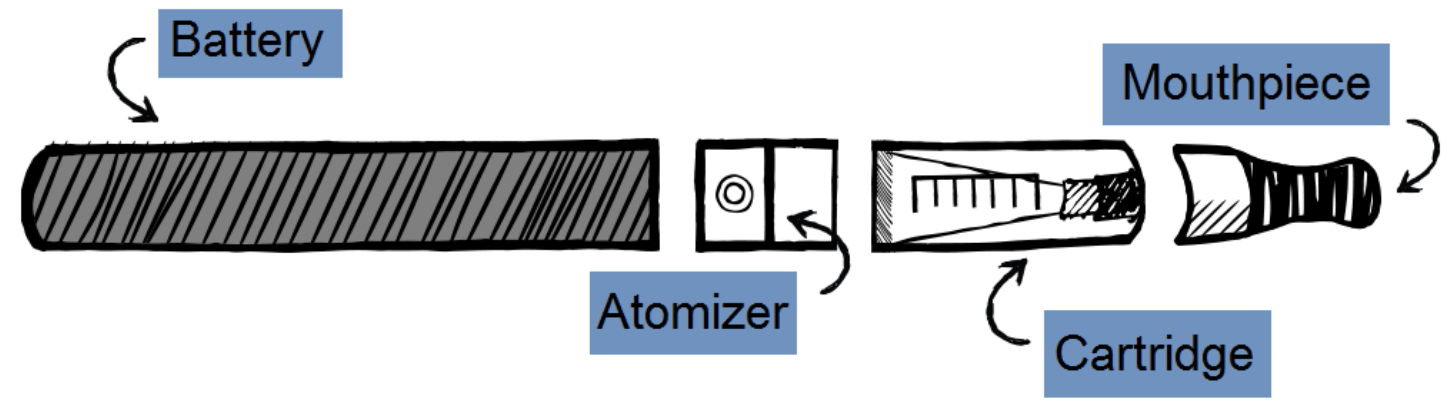

Figure 3. Illustration of a general design of an electronic cigarette. Graphic from the 2019 US Surgeon General's report entitled "How an E-cigarette works." 22

There are four common types of devices: $1^{\text {st }}, 2^{\text {nd }}, 3^{\text {rd }}$ generation and pod systems. ${ }^{23}$ First generation devices encompass the cig-a-likes, which are disposable small devices which resembled a cigarette. The device does not allow the user to change power settings or e-liquid. Second generation devices are larger with an e-liquid reservoir which allows the user to change and refill the e-liquid. These devices do not allow the user to change power settings and contain button activation. Third generation devices are the battery mod and tank systems. Many tanks are interchangeable, allowing the user greater options for coil resistance, coil style and power settings. The user is able to change and refill the e-liquid. Pod systems are the newest device. These 
are lower power devices with compact batteries which the user does not have control over the power setting. For single use pod structures, manufacturers often offer a variety of e-liquid flavors and nicotine concentrations.

Each device contains a coil and wick system. The coil releases heat energy from the battery and aerosolizes the e-liquid which has saturated into the wick. Two orientations exist, vertical and horizontal, and varying coil styles with single, dual and parallel among the most common.
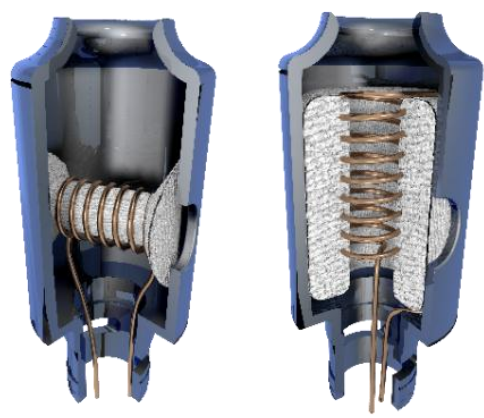

Figure 4. Depiction of horizontal (left) and vertical (right) coil orientations. The vertical coil has a surrounding wick. Illustrations by Tetiana Korzun.

The e-liquid contains propylene glycol (PG), glycerol (GL), nicotine, flavorants and other additives such as benzoic acid. It has been reported that the labeled levels of nicotine can be incorrect, ${ }^{24-25}$ and individual flavor compounds do not need to be reported on the product. Commonly, the ingredients used have been deemed "generally recognized as safe" (GRAS); however, this status only applies to use in food and most have no known inhalation toxicity. Despite this, some vaping industry websites misleadingly claim that e-liquids are safe for inhalation due to their GRAS rating. ${ }^{26}$ 
Additionally, e-liquid can be heated to high temperatures $\left(\geq 334^{\circ} \mathrm{C}\right)^{27}$ which can cause thermal degradation reactions of various components.

\section{Potential Health Hazards Found in Electronic Cigarette Aerosols}

The degradation of propylene glycol and glycerol is well known and can occur within the e-cigarette heating vessel. ${ }^{28}$ Jensen et al. identified fifteen dehydration and oxidation products from the aerosolization of $\mathrm{PG} / \mathrm{GL}$, some of which are toxic and carcinogenic. For example, formaldehyde and acetaldehyde are carcinogens that are present in the aerosols. ${ }^{29}$ Acrolein and acetone are also present and are classified as toxins ${ }^{30}$ and VOCs (volatile organic compounds). ${ }^{31}$ Both formaldehyde and acrolein are known cardiovascular toxins at low concentrations. ${ }^{32}$ While the concentrations of these harmful compounds are generally lower in e-cigarettes than in combustible cigarettes, users may be exposed to levels higher than OSHA safe workplace levels. ${ }^{33}$

Furthermore, e-liquid contains chemicals that are not present in cigarettes or are at significantly higher levels compared to traditional cigarettes, which may cause unique health hazards. Korzun and coworkers ${ }^{34}$ have reported that larger aerosol producing devices can expose users to levels of PG that are in range with GRAS exposure threshold. Most flavor additives' inhalation toxicity has not been extensively studied. Sassano et al. ${ }^{35}$ found that vanillin and cinnamaldehyde levels correlated with cytotoxicity. Behar et al. ${ }^{36}$ reported 26 of 36 refill fluids were cytotoxic to stem cells. Fetterman and coworkers $^{37}$ found that e-cigarette flavorings increased inflammation in endothelial cells. Moreover, flavorants may be interacting with each other and/or the solvents, 
leading to new or elevated levels of toxin formation. Ultimately, there is a known latency period before we will begin to see the long term health effects. Meanwhile, it is imperative to continue fundamental scientific research in order to better inform regulators, manufacturers, and the public about the possible health effects of ecigarettes.

\section{Research Focus}

In order to understand the health hazards of e-cigarettes, I have focused on quantifying the degradation products from e-liquid solvents and analyzing how the different components of an e-cigarette and e-liquid effect toxin production.

"All things are poison, and nothing is without poison, the dosage alone makes it so a thing is not a poison. ${ }^{138}$ Every chemical has the ability to produce harmful effects on the body only if it is present above a specific concentration, or dose. In order to assess the hazards of e-cigarettes, each compound must be quantified individually and analyzed based on its permissible exposure limits. However, due to the complexity of ecigarettes and the ongoing development of new products, the levels of reported toxins have varied greatly among laboratories and methods, from as little as $2 \mathrm{ng} / \mathrm{puff}$ up to $\sim 340,000 \mathrm{ng} / \mathrm{puff}$ of formaldehyde in the aerosol..$^{39}$ Understanding what variables contribute to the large inter-laboratory differences is imperative in protecting ecigarette users and for developing evidence based policies.

Large variations of reported toxin levels can be affected by the puffing protocol, method of analysis, e-liquid formulation and e-cigarette device. My work focuses on the 
latter two. While many researchers have found that different devices produce significantly different results, there had been only two reports of attempts to develop a relationship between the different devices and components in modulating aerosol toxin levels. ${ }^{40-41}$ Although flavored e-liquids have shown to increase aldehyde levels ${ }^{42-43}$ and increase oxidative stress, ${ }^{44-45}$ only three studies have identified the effects of individual flavorants. ${ }^{46-48}$ With over 150 different flavor chemicals present in e-liquids, ${ }^{49}$ work is in its infancy.

\section{Research Value}

The outcome of my research will contribute to the evidence based data on individual components of e-liquids and e-cigarettes, their relationship to toxin production and their subsequent health concern. Scientific evidence has afforded a better understanding of the health risks of e-cigarettes. This has begun to alter the public's perception of their overall safety ${ }^{50}$ and my data will further communicate those risks. With the rapidly evolving market, the fundamental understanding which my work will contribute can be applied to new devices. The significant increase in users' hospitalization has attracted the attention of regulatory agencies from the state and federal level. States have proposed and successfully passed measures to ban or greatly limit flavored e-liquids. ${ }^{51}$ The flavor ban has two purposes: discourage youth from using the devices and lower the health risks. However, many adults who use e-cigarettes as a less harmful alternative to combustible cigarettes prefer flavored e-liquids. ${ }^{52}$ Without sufficient scientific data on the individual flavors, regulators are unable to determine if 
specific flavors should be allowed, and bans may potentially drive adult users to return to cigarettes. ${ }^{53-54} \mathrm{My}$ work will contribute to creating policies that are based on evidence and inform the public of the associated risks.

In Chapter 2 I report the e-cigarette aerosol levels of dihydroxyacetone (DHA), the active ingredient in sunless tanner. Dihydroxyacetone's inhalation safety has been questioned and studied more recently due to its presence in e-cigarettes. ${ }^{55} \mathrm{I}$ also describe a study of wicking temperature stability as a factor in determining the aerosol levels of DHA.

In Chapter 3 I expand on the concept of wick stability by introducing coil characteristics. I investigate how the relationship of the coil and wick may lead to increased levels of carbonyls in the aerosols, and develop a model that can be used to predict relative carbonyl levels among a variety of devices.

In Chapter 4 I investigate the additive triacetin (TA) on the production of three target aldehydes: formaldehyde, acrolein and acetaldehyde. I synthesized TA with isotopically labeled carbons in order to identify the pathway of degradation. This is the first study to conclusively demonstrate the mechanism of formation of enhanced toxic aldehyde levels in e-cigarette aerosols from a common flavor additive.

Chapter 5 summarizes the results and discusses the direction for future work.

\section{REFERENCES}

1. CDC. Outbreak of Lung Injury Associated with E-Cigarette Use, or Vaping. https://www.cdc.gov/tobacco/basic_information/e-cigarettes/severe-lung-disease.html (accessed 10/14/19). 
2. Youth Access to E-Cigarettes. States with Laws Restricting Youth Access to E-Cigarettes. Mitchell Hamline School of Law. Public Health Law Center: 2019.

3. CDC, Cigarette Use among High School Students--United States, 1991-2007. MMWR; Morbidity and Mortality Weekly Report 2008, 57 (25), 686-8.

4. Karen A. Cullen; Bridget K. Ambrose; Andrea S. Gentzke; Benjamin J. Apelberg; Ahmed Jamal; King, B. A., Notes from the Field: Increase in Use of Electronic Cigarettes and Any Tobacco Product among Middle and High School Students - United States, 2011-2018. MMWR Morbid Mortal Wkly Rep 2018, 67 (45), 1276-1277.

5. Kennedy, C. D.; van Schalkwyk, M. C. I.; McKee, M.; Pisinger, C., The Cardiovascular Effects of Electronic Cigarettes: A Systematic Review of Experimental Studies. Preventive Medicine 2019, 127, 105770.

6. Erku, D. A.; Gartner, C. E.; Do, J. T.; Morphett, K.; Steadman, K. J., Electronic Nicotine Delivery Systems (E-Cigarettes) as a Smoking Cessation Aid: A Survey among Pharmacy Staff in Queensland, Australia. Addictive Behaviors 2019, 91, 227-233.

7. Alcalá, H. E.; Shimoga, S. V., It Is About Trust: Trust in Sources of Tobacco Health Information, Perceptions of Harm, and Use of E-Cigarettes. Nicotine and Tobacco Research 2019.

8. Sri Kantha, S., III Health from Tobacco Cigarettes and Electronic Cigarettes: An Overview. 2019, 282287.

9. Sheila Kaplan, M. R., Juul Illegally Marketed E-Cigarettes, F.D.A Says. 09/09/2019 ed.; The New York Times, 2019.

10. Institute of Medicine (Us) Committee on Preventing Nicotine Addiction in Children and Youths, Tobacco Advertising and Promotion. In Growing up Tobacco Free: Preventing Nicotine Addiction in Children and Youths., Barbara S. Lynch; Bonnie, R. J., Eds. National Academies Press (US): Washington (DC), 1994.

11. United States V. Philip Morris USA Inc., Et AI. U.S. District Court for the District of Columbia: 2006.

12. FDA. The Facts on the Fda's New Tobacco Rule. fda.gov https://www.fda.gov/consumers/consumerupdates/facts-fdas-new-tobacco-rule (accessed 10/03/19).

13. Alexander, C., Misconceptions About E-Cigarette Safety Might Be Stopping Smokers Using Them to Quit. In Science blog, Cancer Research UK, 2018.

14. Berry, K. M.; Reynolds, L. M.; Collins, J. M.; Siegel, M. B.; Fetterman, J. L.; Hamburg, N. M.; Bhatnagar, A.; Benjamin, E. J.; Stokes, A., E-Cigarette Initiation and Associated Changes in Smoking Cessation and Reduction: The Population Assessment of Tobacco and Health Study, 2013-2015. Tobacco Control 2019, 28 (1), 42-49.

15. Lesueur, F. E. K.; Bolze, C.; Melchior, M., Factors Associated with Successful Vs. Unsuccessful Smoking Cessation: Data from a Nationally Representative Study. Addictive Behaviors 2018, 80, 110-115.

16. Mirbolouk, M.; Charkhchi, P.; Kianoush, S.; Uddin, S. M. I.; Orimoloye, O. A.; Jaber, R.; Bhatnagar, A.; Benjamin, E. J.; Hall, M. E.; DeFilippis, A. P.; Maziak, W.; Nasir, K.; Blaha, M. J., Prevalence and Distribution of E-Cigarette Use among U.S. Adults: Behavioral Risk Factor Surveillance System, 2016. Annals of Internal Medicine 2018, 169 (7), 429-438.

17. Fulton, E.; Gokal, K.; Griffiths, S.; Wild, S., More Than Half of Adolescent E-Cigarette Users Had Never Smoked a Cigarette: Findings from a Study of School Children in the Uk. Public Health 2018, 161, 33-35.

18. Amrock, S. M.; Lee, L.; Weitzman, M., Perceptions of E-Cigarettes and Noncigarette Tobacco Products among Us Youth. Pediatrics 2016, 138 (5), e20154306.

19. Alexander, J. P.; Williams, P.; Lee, Y. O., Youth Who Use E-Cigarettes Regularly: A Qualitative Study of Behavior, Attitudes, and Familial Norms. Preventive medicine reports 2018, 13, 93-97.

20. Boykan, R.; Messina, C. R.; Chateau, G.; Eliscu, A.; Tolentino, J.; Goniewicz, M. L., Self-Reported Use of Tobacco, E-Cigarettes, and Marijuana Versus Urinary Biomarkers. Pediatrics 2019, 143 (5), e20183531.

21. McNeill A; Brose LS; Calder R; SC, H. E-Cigarettes: An Evidence Update. A Report Commissioned by Public Health England; Public Health England: 2015. 
22. How an E-Cigarette Works. Surgeon General of the United States https://ecigarettes.surgeongeneral.gov/getthefacts.html (accessed 10/04/19).

23. Williams, M.; Talbot, P., Design Features in Multiple Generations of Electronic Cigarette Atomizers. International Journal of Environmental Research and Public Health 2019, 16 (16), 2904.

24. Vasudha Bansala, K.-H. K., Review on Quantitation Methods for Hazardous Pollutants Released by ECigarette (EC) Smoking. TrAC Trends in Analytical Chemistry 2016, 78, 120-133.

25. Jurgen Hahn; Yulia B Monakhova; Julia Hengen; Matthias Kohl-Himmelseher; etc., Electronic Cigarettes: Overview of Chemical Compositon and Exposure Estimation. Tobacco Induced Diseases 2014, 12(1)

26. Hallagan, J., The Safety Assessment and Regulatory Authority to Use Flavors - Focus on E-Cigarettes 2015.

27. Chen, W.; Wang, P.; Ito, K.; Fowles, J.; Shusterman, D.; Jaques, P. A.; Kumagai, K., Measurement of Heating Coil Temperature for E-Cigarettes with a "Top-Coil” Clearomizer. PLoS ONE 2018, 13 (4), e0195925.

28. Jensen, R. P.; Strongin, R. M.; Peyton, D. H., Solvent Chemistry in the Electronic Cigarette Reaction Vessel. Scientific Reports 2017, 7, 42549.

29. Iarc Monographs on the Identification of Carcinogenic Hazards to Humans. In List of Classifications Agents classified by the IARC Monographs, Volumes 1-124.

30. Toxic Substances Portal. 03/03/2011 ed.; Agency for Toxic Substances and Disease Registry: 2011.

31. World Health, O., Indoor Air Quality: Organic Pollutants. Environmental Technology Letters 1989, 10 (9), 855-858.

32. Bhatnagar, A., E-Cigarettes and Cardiovascular Disease Risk: Evaluation of Evidence, Policy Implications, and Recommendations. Current Cardiovascular Risk Reports 2016, 10, 24.

33. Salamanca, J. C.; Meehan-Atrash, J.; Vreeke, S.; Escobedo, J. O.; Peyton, D. H.; Strongin, R. M., ECigarettes Can Emit Formaldehyde at High Levels under Conditions That Have Been Reported to Be Non-Averse to Users. Scientific Reports 2018, 8 (1), 7559.

34. Korzun, T.; Lazurko, M.; Munhenzva, I.; Barsanti, K. C.; Huang, Y.; Jensen, R. P.; Escobedo, J. O.; Luo, W.; Peyton, D. H.; Strongin, R. M., E-Cigarette Airflow Rate Modulates Toxicant Profiles and Can Lead to Concerning Levels of Solvent Consumption. ACS Omega 2018, 3 (1), 30-36.

35. Sassano, M. F.; Davis, E. S.; Keating, J. E.; Zorn, B. T.; Kochar, T. K.; Wolfgang, M. C.; Glish, G. L.; Tarran, R., Evaluation of E-Liquid Toxicity Using an Open-Source High-Throughput Screening Assay. PLoS Biology 2018, 16 (3), e2003904.

36. Behar, R. Z.; Luo, W.; McWhirter, K. J.; Pankow, J. F.; Talbot, P., Analytical and Toxicological Evaluation of Flavor Chemicals in Electronic Cigarette Refill Fluids. Scientific Reports 2018, 8 (1), 8288.

37. Fetterman, J. L.; Weisbrod, R. M.; Feng, B.; Bastin, R.; Tuttle, S. T.; Holbrook, M.; Baker, G.; Robertson, R. M.; Conklin, D. J.; Bhatnagar, A.; Hamburg, N. M., Flavorings in Tobacco Products Induce Endothelial Cell Dysfunction. Arteriosclerosis, Thrombosis, and Vascular Biology 2018, 38 (7), 1607-1615.

38. Grandjean, P., Paracelsus Revisited: The Dose Concept in a Complex World. Basic \& Clinical Pharmacology \& Toxicology 2016, 119 (2), 126-32.

39. Beauval, N.; Verrièle, M.; Garat, A.; Fronval, I.; Dusautoir, R.; Anthérieu, S.; Garçon, G.; Lo-Guidice, J.M.; Allorge, D.; Locoge, N., Influence of Puffing Conditions on the Carbonyl Composition of E-Cigarette Aerosols. International Journal of Hygiene and Environmental Health 2019, 222 (1), 136-146.

40. Malek, N.; Nakkash, R.; Talih, S.; Lotfi, T.; Salman, R.; Karaoghlanian, N.; El-Hage, R.; Saliba, N.; Eissenberg, T.; Shihadeh, A., A Transdisciplinary Approach to Understanding Characteristics of Electronic Cigarettes. Tobacco Regulatory Science 2018, 4 (3), 47-72.

41. Talih, S.; Salman, R.; Karaoghlanian, N.; El-Hellani, A.; Saliba, N.; Eissenberg, T.; Shihadeh, A., "Juice Monsters": Sub-Ohm Vaping and Toxic Volatile Aldehyde Emissions. Chemical Research in Toxicology 2017, 30 (10), 1791-1793.

42. Qu, Y.; Kim, K.-H.; Szulejko, J. E., The Effect of Flavor Content in E-Liquids on E-Cigarette Emissions of Carbonyl Compounds. Environmental Research 2018, 166, 324-333. 
43. Khlystov, A.; Samburova, V., Flavoring Compounds Dominate Toxic Aldehyde Production During ECigarette Vaping. Environmental Science \& Technology 2016, 50 (23), 13080-13085.

44. Cirillo, S.; Vivarelli, F.; Turrini, E.; Fimognari, C.; Burattini, S.; Falcieri, E.; Rocchi, M. B. L.; Cardenia, V.; Rodriguez-Estrada, M. T.; Paolini, M.; Canistro, D., The Customizable E-Cigarette Resistance Influences Toxicological Outcomes: Lung Degeneration, Inflammation, and Oxidative Stress-Induced in a Rat Model. Toxicological Sciences 2019.

45. Chatterjee, S.; Tao, J.-Q.; Johncola, A.; Guo, W.; Caporale, A.; Langham, M. C.; Wehrli, F. W., Acute Exposure to E-Cigarettes Causes Inflammation and Pulmonary Endothelial Oxidative Stress in Nonsmoking, Healthy Young Subjects. American Journal of Physiology-Lung Cellular and Molecular Physiology 2019, 317 (2), L155-L166.

46. Duell, A. K.; McWhirter, K. J.; Korzun, T.; Strongin, R. M.; Peyton, D. H., Sucralose-Enhanced Degradation of Electronic Cigarette Liquids During Vaping. Chemical Research in Toxicology 2019, 32 (6), 1241-1249.

47. El-Hage, R.; El-Hellani, A.; Haddad, C.; Salman, R.; Talih, S.; Shihadeh, A.; Eissenberg, T.; Aoun Saliba, N., Toxic Emissions Resulting from Sucralose Added to Electronic Cigarette Liquids. Aerosol Science and Technology 2019, 53 (10), 1197-1203.

48. Soussy, S.; EL-Hellani, A.; Baalbaki, R.; Salman, R.; Shihadeh, A.; Saliba, N. A., Detection of 5Hydroxymethylfurfural and Furfural in the Aerosol of Electronic Cigarettes. Tobacco Control 2016, 25, ii88-ii93.

49. Omaiye, E. E.; McWhirter, K. J.; Luo, W.; Tierney, P. A.; Pankow, J. F.; Talbot, P., High Concentrations of Flavor Chemicals Are Present in Electronic Cigarette Refill Fluids. Scientific Reports 2019, 9 (1), 2468.

50. Huang, J.; Feng, B.; Weaver, S. R.; Pechacek, T. F.; Slovic, P.; Eriksen, M. P., Changing Perceptions of Harm of E-Cigarette Vs Cigarette Use among Adults in 2 Us National Surveys from 2012 to 2017. JAMA Network Open 2019, 2 (3), e191047-e191047.

51. DUCHARME, J., As the Number of Vaping-Related Deaths Climbs, These States Have Implemented ECigarette Bans. Time 09/25/19, 2019.

52. Landry, R. L.; Groom, A. L.; Vu, T.-H. T.; Stokes, A. C.; Berry, K. M.; Kesh, A.; Hart, J. L.; Walker, K. L.; Giachello, A. L.; Sears, C. G.; McGlasson, K. L.; Tompkins, L. K.; Mattingly, D. T.; Robertson, R. M.; Payne, T. J., The Role of Flavors in Vaping Initiation and Satisfaction among U.S. Adults. Addictive Behaviors 2019, 99, 106077.

53. Pacek, L. R.; Rass, O.; Sweitzer, M. M.; Oliver, J. A.; McClernon, F. J., Young Adult Dual Combusted Cigarette and E-Cigarette Users' Anticipated Responses to Hypothetical E-Cigarette Market Restrictions. Substance Use and Misuse 2019, 10.

54. G. B. D. Tobacco Collaborators, Smoking Prevalence and Attributable Disease Burden in 195 Countries and Territories, 1990-2015: A Systematic Analysis from the Global Burden of Disease Study 2015. Lancet (London, England) 2017, 389 (10082), 1885-1906.

55. Wang, Y. Y.; Wu, Q. G.; Muskhelishvili, L.; Davis, K.; Bryant, M.; Cao, X. F., Assessing the Respiratory Toxicity of Dihydroxyacetone Using an in Vitro Human Airway Epithelial Tissue Model. Toxicology In Vitro 2019, 59, 78-86. 
Chapter 2: Dihydroxyacetone Levels in Electronic Cigarettes: Wick Temperature and Toxin Formation

Vreeke, S.; Korzun, T.; Luo, W.; Jensen, R. P.; Peyton, D. H.; Strongin, R. M., Dihydroxyacetone Levels in Electronic Cigarettes: Wick Temperature and Toxin Formation. Aerosol Science and Technology 2018, 52 (4), 370-376. The following paper has been modified.

\section{ABSTRACT}

Recently, we reported the presence of dihydroxyacetone (DHA), the active ingredient in sunless tanners, in the aerosols of an electronic cigarette. DHA has been shown to react with DNA in vitro. The FDA restricts the use of DHA to external application only. It states that it should not be inhaled, ingested, or come into contact with any areas containing mucous membranes, due to unknown risk. Herein, the quantification of DHA in the aerosols of three brands of e-cigarettes has been carried out. These included two devices with horizontal heating coil configurations as well as one with a sub-ohm resistance vertical heating coil. In order to understand and begin to address the origin of DHA and related aerosol products, the wicking properties of the three e-cigarettes were compared. DHA levels were analyzed by a combination of GS/MS and ${ }^{1} \mathrm{H}$ NMR. DHA was found in all three e-cigarettes, with substantially less in the sub-ohm, vertical coil device as compared to the horizontal coil devices (e.g., $0.088 \mu \mathrm{g} /$ puff vs. $2.29 \mu \mathrm{g} /$ puff, respectively). Correspondingly, the temperature of the wet layer of the wick for the vertical coil was relatively stable, compared to the wicks for the horizontal coils, upon increasing battery power output. This result is in agreement with prior studies of e-cigarette wicking efficiency and aerosol toxin formation. The 
temperature measurements reported are a simple means for comparing devices with different design properties during operation.

\section{INTRODUCTION}

Electronic cigarettes (e-cigarettes) have increased exponentially in popularity since their introduction a decade ago. ${ }^{1}$ Their usage among children and adolescents, which grew by $900 \%$ between 2011 and 2015, has been recognized as a major public health concern by the US Surgeon General. ${ }^{2}$ One in six US high school students currently uses e-cigarettes. In addition, the CDC reports that one in four middle school and high school students were exposed to secondhand e-cigarette aerosols. ${ }^{3}$ Although the longterm health effects of e-cigarettes may not be known for many years, understanding the chemical profiles of their aerosols affords current insight into their potential toxicity. Recently, we identified 15 e-cigarette aerosol products formed upon aerosolization of the e-cigarette solvents propylene glycol (PG) and glycerol (GL). ${ }^{4}$ Among these was dihydroxyacetone (DHA), the active ingredient in spray tanning products. Although DHA is approved by the FDA for external use in cosmetics, its use is restricted due to unknown inhalation risks. ${ }^{5}$ Research has shown that DHA can cause DNA damage. ${ }^{6}$ DHA can be formed in e-cigarette aerosols via the free radical oxidation of glycerol followed by $\mathrm{C}-\mathrm{H}$ cleavage (Scheme 1). ${ }^{4,7} \mathrm{DHA}$ is well-known to tautomerize to glyceraldehyde. ${ }^{8}$

Due to potential genotoxicity concerns, understanding the conditions that lead to DHA (as well as related aerosol products) formation can aid users, regulatory agencies, and manufacturers in addressing possible e-cigarette health risks. Herein, we 
investigated three devices, two with horizontal coils and one with a vertical sub-ohm coil. Each was tested at varying power settings. Analysis of the aerosols by ${ }^{1} \mathrm{H}$ NMR and GC/MS enabled determination of DHA levels. The concentrations of DHA were not only proportional to increasing wattage settings, but were also influenced by the individual e-cigarette coil design.

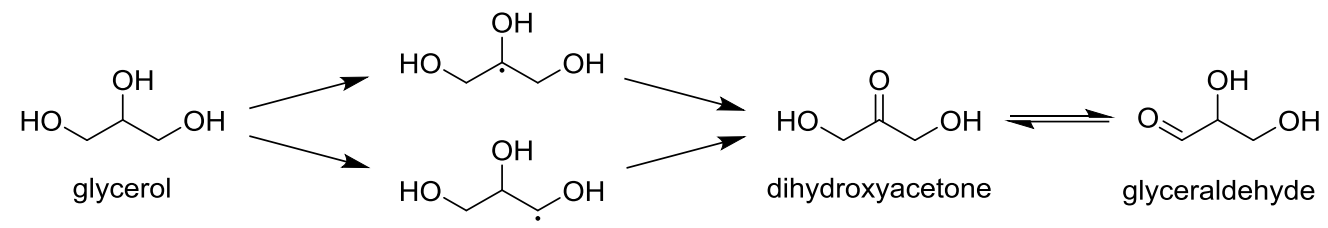

Scheme 1. Oxidation of glycerol affords DHA and its tautomer glyceraldehyde. Glyceraldehyde was also identified in our prior study. ${ }^{4}$

\section{RESULTS AND DISCUSSION}

Identification of DHA. The spectral analysis of the PG/GL aerosol products for DHA is challenging due to peak overlap of the DHA hydroxyl protons and those of the more abundant hydroxyacetone (HA) (Figure 1). However, the presence of DHA was confirmed via spiking the aerosol sample with a standard of the monomer prepared from the commercially available DHA dimer. This revealed the four equivalent DHA methylene protons (d, $4.16 \mathrm{ppm}$ ) split by the adjacent hydroxyl proton (t, $5.03 \mathrm{ppm})$. The mass spectra of samples displayed the expected molecular ion peak at $90 \mathrm{~m} / \mathrm{z}$ as well as prominent fragments at 72 and $43 \mathrm{~m} / \mathrm{z}$ at retention 10 to 11 minutes, confirmed by DHA external standard. Solvent blanks for both IPA and acetone contained no detectable DHA. 
DHA is a constituent of the particulate phase. We hypothesized that DHA would be a particulate phase component of the aerosol due to its ability to form multiple hydrogen bonds to PG and GL. As expected, DHA was found exclusively in the cold trap of the experimental setup. None was found in the impinger connected in series that collects gas-phase components not retained in the cold trap. This is consistent with our prior related studies employing a tandem cold trap impinger sample collection method. ${ }^{9}$

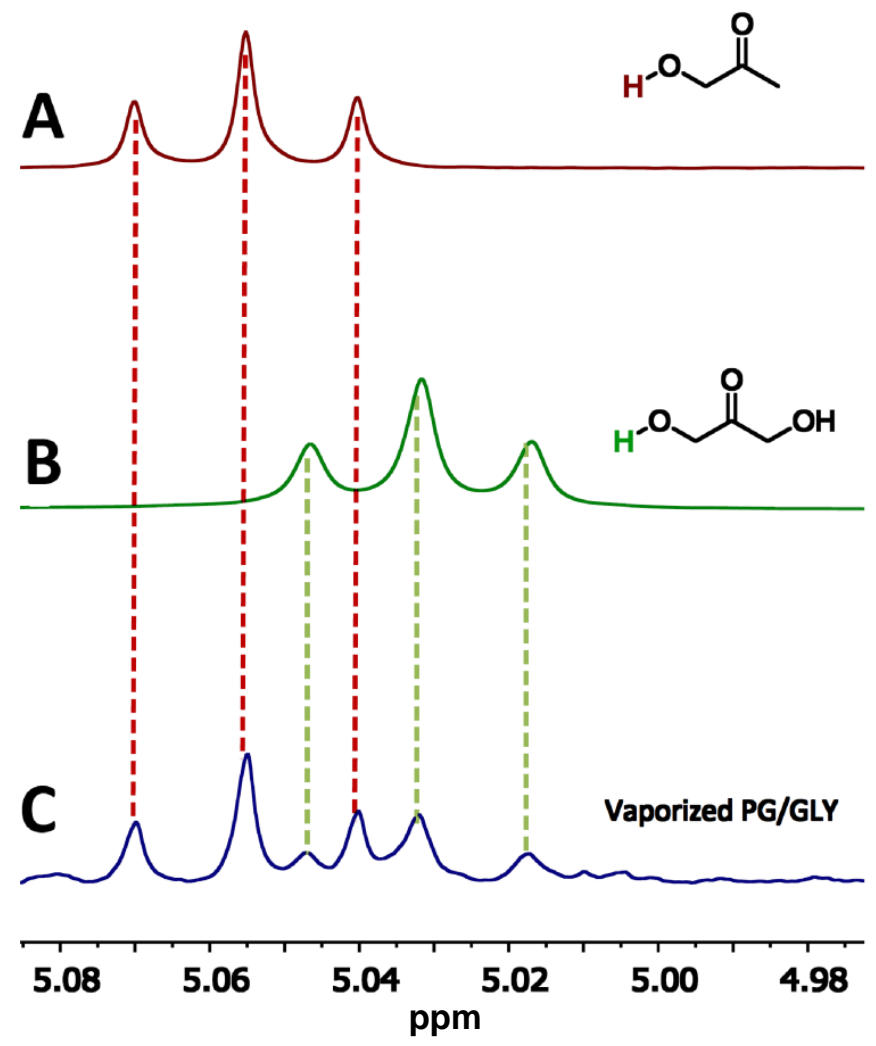

Figure 1. ${ }^{1} \mathrm{H}$ NMR spectra highlighting $(\mathbf{A})$ the hydroxyl proton resonance of a commercial hydroxyacetone (HA) standard, (B) hydroxyl proton peak of a DHA monomer standard, (C) a representative PG/GL aerosol sample showing peak assignment.

Determination of DHA levels. DHA quantification was carried out by ${ }^{1} \mathrm{H} N M R$ and GC/MS. Utilizing MNova's global spectrum deconvolution (GSD) algorithm, ${ }^{10}$ 
concentrations were calculated by comparing ${ }^{1} \mathrm{H}$ NMR relative peak integrations with the internal standard, 2,3,5,6-tetrachloro-4-nitrobenzene. Due to the peak overlap of DHA and HA, the individual fit peaks of the hydroxyl protons were integrated (Figure 2).

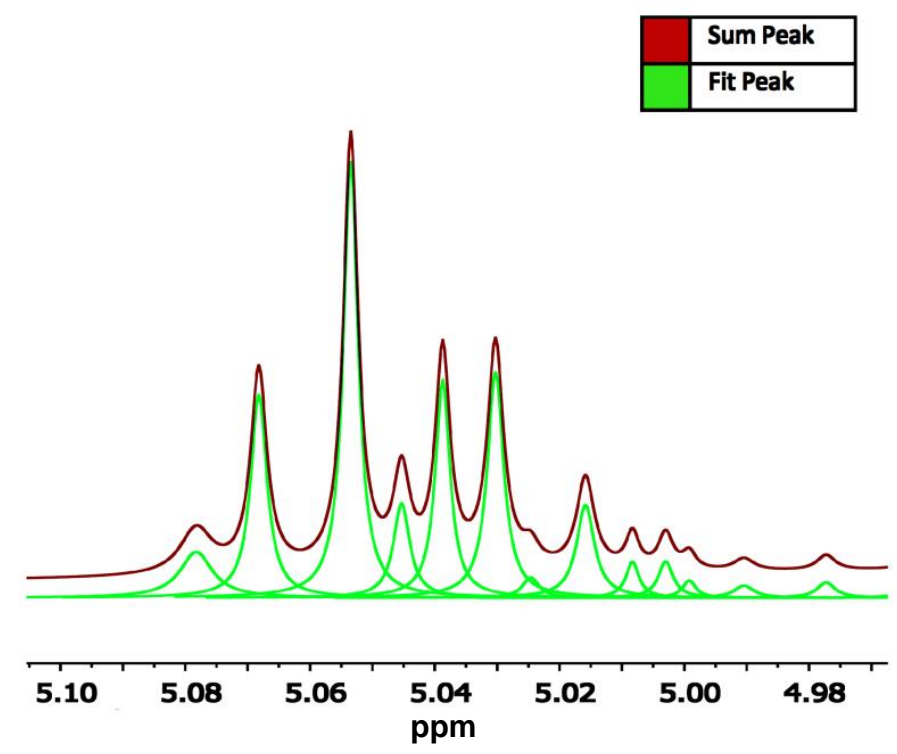

Figure 2. Global spectrum deconvolution (GSD) of the hydroxyl region of the aerosolized PG/GL using the program MNova. The red spectrum is the experimental spectrum. The green spectrum is the "fit," generated using the Savitsky-Golay (SG) deconvolution algorithm. ${ }^{10}$

Quantifying DHA at the lowest wattages for EC1 and EC2, as well as all wattages for EC3, proved challenging due to the relatively low sensitivity of NMR. We thus used GC/MS to identify and quantify DHA at these low levels. Examination of Figure 3 by comparing the data shown in $\mathbf{A}$ (NMR-derived levels of DHA) to that displayed in $\mathbf{B}$ (GC/MS-derived levels of DHA) reveals that DHA concentrations obtained by ${ }^{1} \mathrm{H}$ NMR and GC/MS are in excellent agreement. 
A

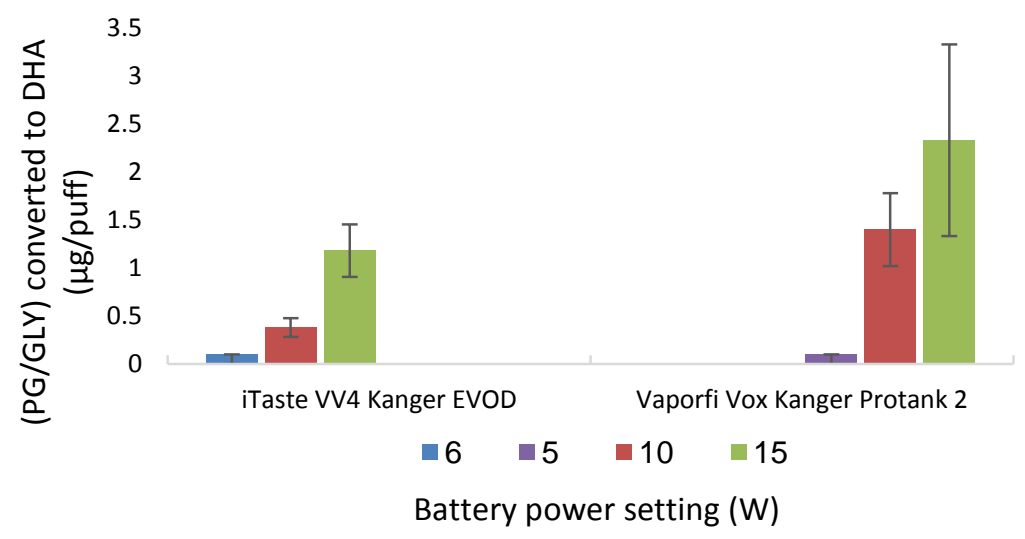

B

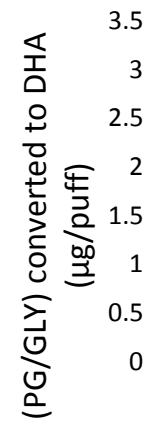

3.5

3

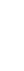

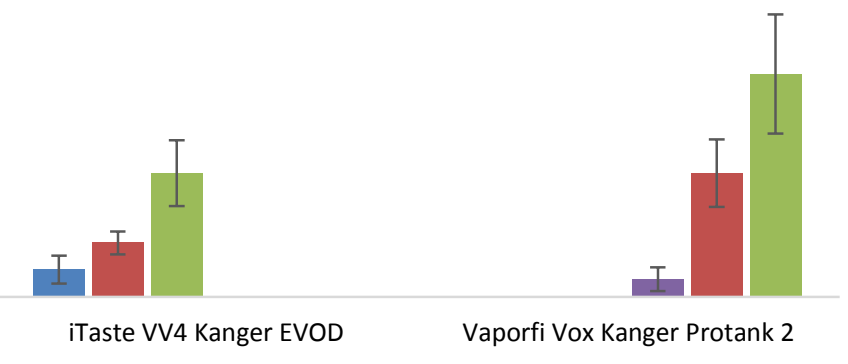

6
$-5 \square 10 \square 15$

Battery power setting (W)

C

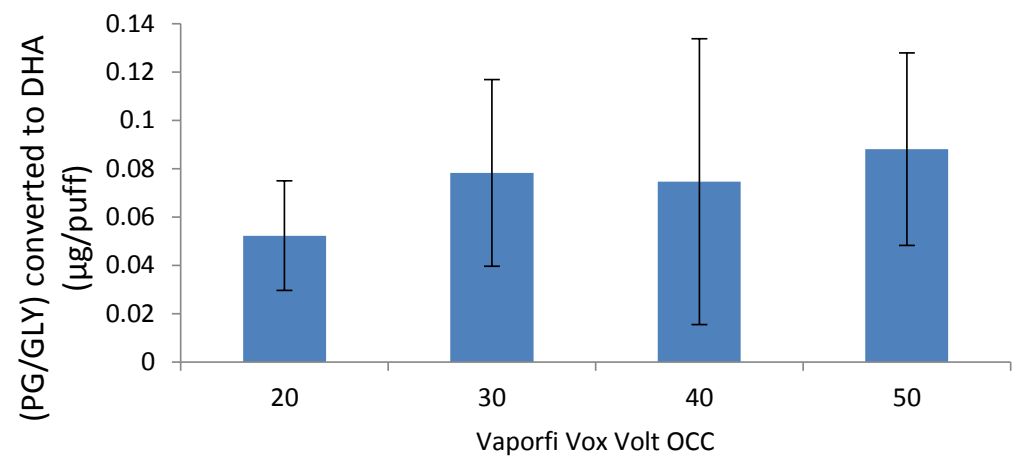

Battery power setting (W)

Figure 3. (A) Quantitative results from ${ }^{1} \mathrm{H} N \mathrm{NMR}$ of $\mathrm{EC} 1$ and $\mathrm{EC} 2$ with standard deviation and varying wattages. (B) Quantitative results from GC/MS of EC1 and EC2 with standard deviation and varying wattages. It is important to note that while EC1 and EC2 utilize the same coil, they produce varying DHA concentrations. (C) Quantitative results from GC/MS of EC3 with standard deviation and varying wattages. $\mathrm{GC} / \mathrm{MS}$ is relatively less accurate at very low concentrations which may contribute to non-linearity in concentration level vs. wattage trends. Error bars represent the standard deviation. 
Aerosol Production. Figure 4 illustrates that DHA concentration levels are directly proportional to the mass of aerosolized PG/GL in each device. As illustrated in Figure 4 , the most PG/GL was consumed by EC3, and EC3 produced $48 \%$ less DHA than EC1 and EC2, at the lowest power levels. However, EC1 consumed less PG/GL than EC2, but produced $55 \%$ less DHA at the highest power setting. These results suggest that factors in addition to power output and e-liquid consumption influence the chemical reactions taking place in e-cigarettes. An alternative explanation is that low DHA production could be caused by the larger surface area of the coil. ${ }^{11}$ 


\section{A: EC1}

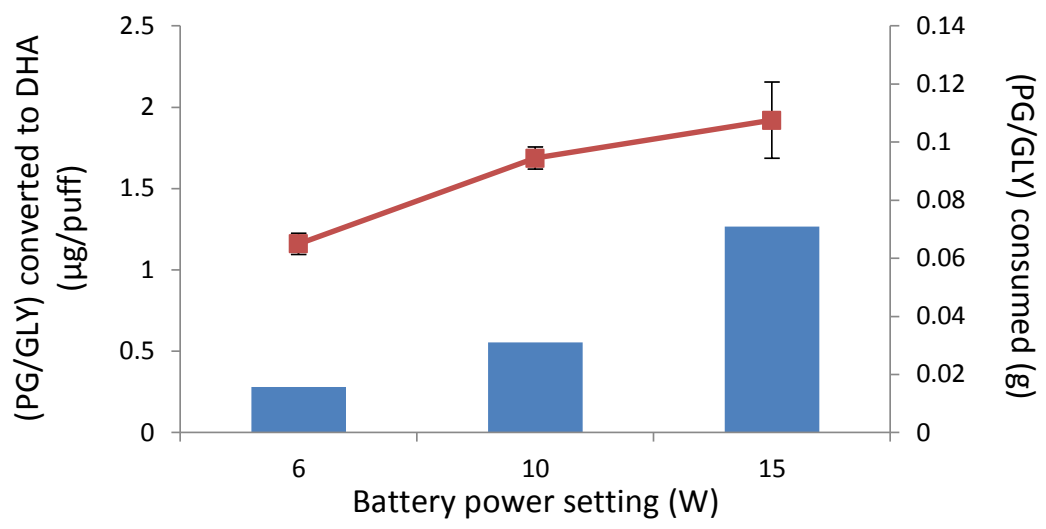

\section{B: EC2}

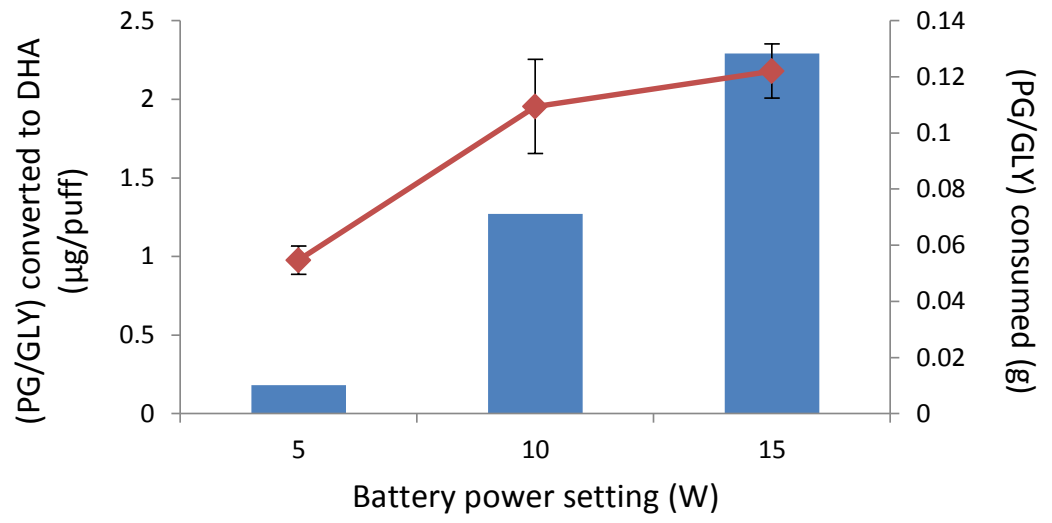

\section{C: EC3}

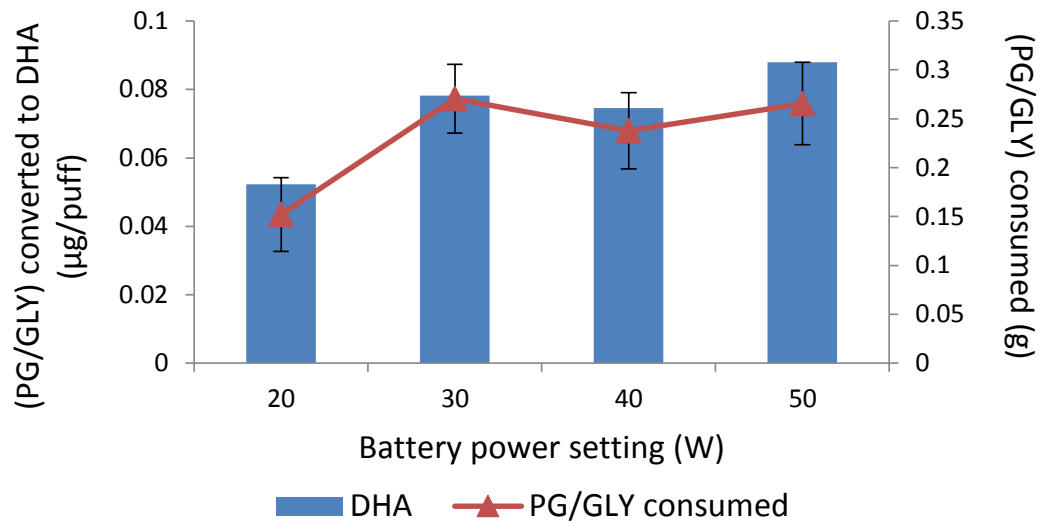

Figure 4. (A) DHA concentration reported in $\mu \mathrm{g} /$ puff compared to the mass of $P G / G L$ consumption as a function of device power for EC1. (B) DHA concentration reported in $\mu \mathrm{g} /$ puff compared to the mass of PG/GL consumption as a function of device power for EC2. (C) DHA concentration reported in $\mu \mathrm{g} / \mathrm{puff}$ compared to the mass of PG/GL consumption as a function of device power for EC3. Errors bars represent the standard deviation. 
Wick Temperature. Many prior reports in the e-cigarette literature have noted the correlation of PG/GL degradation product levels relative to wattage and heating coil temperature. ${ }^{12-13}$ Wang et al. ${ }^{14}$ have also recently reported the temperature dependence of carbonyl formation from PG/GL in the absence of an e-cigarette device. Optimal aerosol production depends on the efficient supply of solvent to the heating coil, which is limited by wicking rate. ${ }^{15}$ When power levels are applied that causes the rate of aerosolization to exceed the rate of solvent supply to the coil, overheating of the e-liquid can occur. This can lead to not only reduced aerosolization but also over-heated e-solvents and faster chemical degradation. ${ }^{15}$

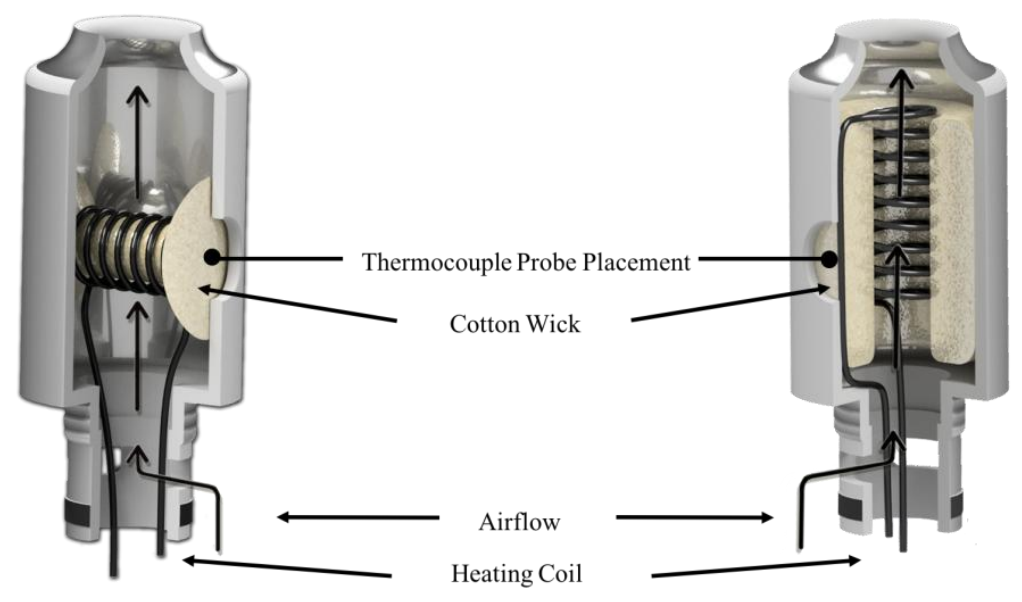

Figure 5. Representation of the inner structure of electronic cigarettes showing a horizontal coil configuration (EC1, EC2, left) and a vertical coil configuration (EC3, right). Temperature readings were taken within the wet layer of the cotton wick, as labeled, at the solvent inlet. 
Wicking action often takes place in conjunction with evaporation. ${ }^{16}$ A porous material, such as the wick in an e-cigarette (Figure 5), can be envisioned as containing both a wet layer and an evaporative surface layer. ${ }^{17}$ We placed a thermocouple probe at the area of the wick in each device corresponding to regions of the wet layer, and recorded the highest temperature during puffing. Figure 6 shows that the wick in EC3 afforded the smallest temperature increase with increasing power level, followed by EC2 and EC1. As wicking efficiency diminishes, and drying begins to occur in a porous solid, the area of the evaporative layer increases while that of the wet layer contracts. ${ }^{17}$ The relatively steady wet layer temperature of EC3 is thus indicative of a more stable wet layer, and thus more efficient wicking, as compared to EC1 and EC2. This can account for the lower yields of DHA attained via EC3 as compared to EC1 and EC2, despite the relatively higher operating power levels used with EC3.

Wicking efficiency in term of aerosol amount produced was correlated previously to mg total analyte produced per puff, per Watt. No trend in aerosol amount per Watt vs analyte production was found, for instance, such as plotted in Figure $4 .{ }^{15}$ However, the data shown in Figure 6, which correlates the change of temperature vs. the change of power level (Watts), correlates directly to DHA production. Further validation of this potentially simple and reproducible (Figure S1) method and its application to determining wicking efficiency is ongoing. Potential limitations under study are possible variability of temperature readings at the wick/reservoir intersection 
due to the distance of the probe from the coil, wick thickness differences between devices and probe placement consistency.

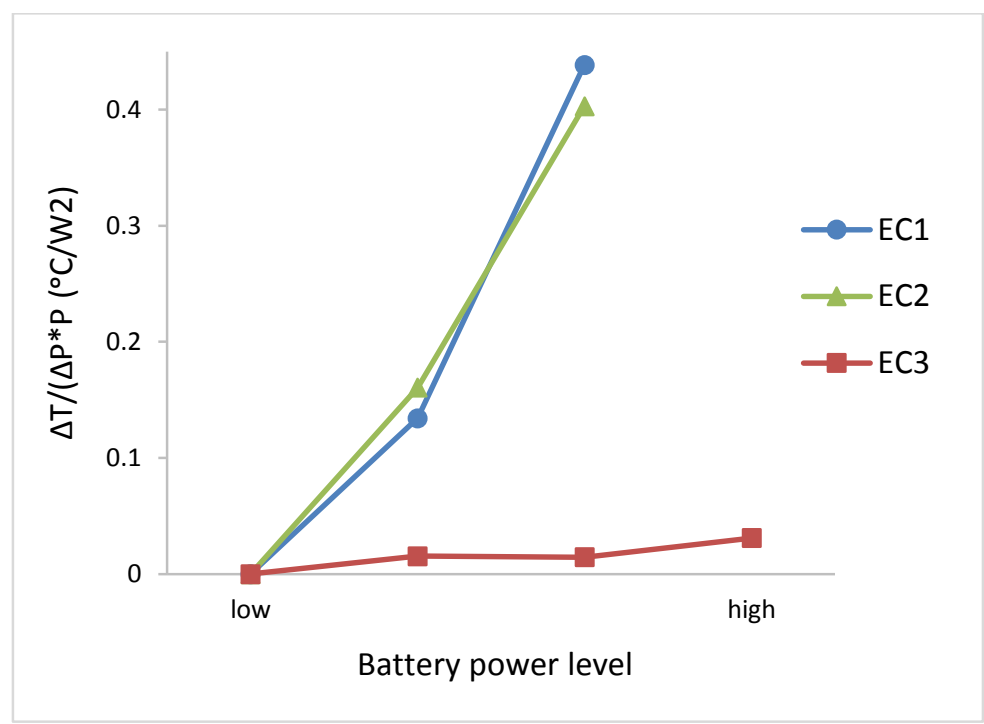

Figure 6. Normalized recorded temperature changes over increasing battery power output. Each data point was calculated using $\Delta T /\left(\Delta P^{*} P\right)$. Temperatures were recorded within the wet layer of the saturated wick during a 10 second battery activation period. Wattages used for EC1 and EC2 were 5,10 and $15 \mathrm{~W}$ $(n=3)$. For EC3, the four power levels were 20, 30, 40, and $50 \mathrm{~W}(n=5)$. See Table S3 for raw temperature data.

\section{CONCLUSION}

DHA levels in e-cigarette aerosols were determined for the first time. Three different devices were studied, and DHA was quantified via a combination of ${ }^{1} \mathrm{H}$ NMR and GC/MS. The range of DHA production among the three e-cigarettes was $0.0523-$ $2.33 \mu \mathrm{g} /$ puff. The inhalation toxicity of DHA is currently unknown, despite recent concern about its use in spray tan products ${ }^{5}$ as well as evidence that it reacts with DNA. ${ }^{6}$ As expected, DHA levels increased with increasing power levels within each of the individual e-cigarettes investigated (Figure 3). However, nominal power settings were not directly correlated to DHA production when comparing different e-cigarette devices. 
Efficient heat transfer and wicking are critical properties intrinsic to the proper function of current e-cigarettes. Relatively facile measurements of wet layer wick region temperatures during vaping enabled us to explain how the lowest yields of DHA were obtained via the relatively "hottest" device. Further related investigations involving additional e-cigarette aerosol products and e-liquid formulations are currently under study in our labs.

\section{METHODS}

Electronic cigarette devices. Three e-cigarette devices (ECs 1-3) were chosen to represent a range of e-cigarette user preferences. EC1: An Innokin ${ }^{\circledR}$ iTaste VV4 variable voltage/variable wattage (VV/VW) battery was fitted with a Kanger ${ }^{\circledR}$ EVOD clearomizer containing a $2.2 \Omega$ single horizontal coil. EC2: A Vaporfi ${ }^{\circledR}$ VOX TC VV/VW battery was fitted with a Kanger ${ }^{\circledR}$ Protank-2 clearomizer containing a $2.2 \Omega$ single horizontal coil. EC3: A Vaporfi ${ }^{\circledR}$ VOX TC VV/VW battery was fitted with a Vaporfi ${ }^{\circledR}$ Volt hybrid tank containing a $0.5 \Omega$ single vertical coil. EC1 and EC2 utilize the same MT32 $2.2 \Omega$ single horizontal coil.

E-liquid and avoidance of dry coils and burnt e-liquid. Each device was filled completely with e-liquid based on manufacturer's recommendation. For this study, a 1:1 ratio (by volume) of PG/GL was mixed in house from ACS-grade PG and GL. EC1 and EC2 were filled with a mixture of $1.0 \mathrm{~mL}$ PG and $1.0 \mathrm{~mL} \mathrm{GL}$. EC3 was filled with a mixture 2.0 $\mathrm{mL}$ PG and $2.0 \mathrm{~mL} \mathrm{GL}$. Throughout the session (see Collecting the aerosol), ample e- 
liquid was maintained to cover the wicking material. After each session, the e-liquid was disposed of and a new solution was made before the start of the next session.

Collecting the aerosol. The e-cigarette aerosol consists of aerosol droplets suspended in the gas phase. ${ }^{18}$ The aerosol produced from the e-cigarette was passed through a dry cold trap $\left(-76^{\circ} \mathrm{C} \pm 2{ }^{\circ} \mathrm{C}\right)$, followed by an impinger of solvent, a $0.45 \mu \mathrm{m}$ pore size syringe filter and a $\mathrm{CH}$ Technologies single cigarette smoking machine (SCSMSTEP). Each vaping session consisted of 10 puffs. The SCSM-STEP was set to the CORESTA program, which has a square shape puff profile, 3 second (s) puff period, $30 \mathrm{~s}$ puff interval, and a $55 \mathrm{~mL}$ puff volume. For this study (vide supra), the puff interval was set to 3 minutes by disconnecting the filter from the smoking machine after each puff. Each device was set at varying wattages, within manufacturer's recommendations. EC1 was tested (at a minimum) in triplicate at 6 watts, 10 watts and 15 watts. EC2 was tested (at a minimum) in triplicate at 5 watts, 10 watts and 15 watts. EC 3 was tested (at a minimum) in triplicate at 20 watts, 30 watts, 40 watts, and 50 watts. After each puff, the solvent from the impinger was used to collect and rinse the aerosols that had condensed inside the cold trap. For analysis by NMR, the impinger was filled with $0.6 \mathrm{~mL}$ DMSO- $d_{6}$. Post aerosolization, $0.425 \mathrm{~mL}$ of the DMSO- $d_{6}$ rinse was collected into a Wilmad $^{\circledR} 400 \mathrm{MHz}$ NMR tube. $20 \mu \mathrm{L}$ of $9.7 \mathrm{mM}$ 2,3,5,6-tetrachloro-4-nitrobenzene prepared in DMSO- $d_{6}$ was added as an internal standard. For analysis by GC/MS the impinger was filled with $2.0 \mathrm{~mL}$ HPLC-grade acetone. Post aerosolization, $1.5 \mathrm{~mL}$ of acetone from the impinger was used to rinse the cold trap, and $1.0 \mathrm{~mL}$ of the rinse was 
collected into an amber glass screw top vial. $20 \mu \mathrm{L}$ of $11 \mathrm{mM}$ 1,2,3-trichlorobenzene prepared in HPLC grade isopropanol (IPA) was added as an internal standard.

Calculating the exact droplet growth rate is outside the scope of this study, but we hypothesize it has a minimal effect on the accurate quantification of DHA. Effective aerosol collection and analysis relies on rapid sampling and decreased droplet growth prior to reaching the collection site. ${ }^{19}$ To optimize aerosol collection, the tubing used to connect the mouthpiece of the e-cigarette and the glassware was kept minimal and any tube bending was avoided. ${ }^{20}$ We suspect there was minimal aerosol loss within the relatively small mouthpiece of the e-cigarette. Furthermore, rapid collection and analysis by NMR and GC/MS of the aerosol was performed to help reduce potential loss.

Analysis by NMR. ${ }^{1} \mathrm{H}$ NMR spectra were obtained on a Bruker ${ }^{\circledR} 400 \mathrm{MHz}$ AVANCE II+ spectrometer, with a $30^{\circ}$ pulse angle, a 60 second relaxation delay and 256 acquisitions. Data was processed and analyzed by $\mathrm{MNova}^{\circledR}$; integrations were performed using MNova's ${ }^{\circledast}$ global spectrum deconvolution (GSD) algorithm. To verify the presence of DHA within the collected aerosol, each sample was spiked with DHA standard. This standard was prepared by dissolving solid DHA dimer in DMSO- $d_{6}$ to a concentration of 1.4 M. DHA was allowed to monomerize in DMSO- $d_{6}$ solution for three days before use.

Analysis by GC/MS. Chromatograph spectra were obtained on an Agilent ${ }^{\circledR} 7890$ gas chromatograph with a 5975 mass spectrometer fitted with a Restek RXi-624Sil MS column. Oven temperature was $40^{\circ} \mathrm{C}$ for 2 minutes and then programed to $250^{\circ} \mathrm{C}$ at 
$15^{\circ} \mathrm{C} / \mathrm{min}$. To aid in calculating the concentration of DHA within the collected aerosol an external standard was prepared by dissolving DHA in HPLC-grade acetone over the concentration range of $0.25 \mu \mathrm{g} / \mathrm{mL}$ to $100 \mu \mathrm{g} / \mathrm{mL}$. Quantification was performed by peak area integration of the $72 \mathrm{~m} / \mathrm{z}$ fragment of DHA at 10 to 11 minutes retention time. The external standard response factor was then used to calculate DHA concentrations in each sample.

Wick temperature recording. Temperature readings were observed using a Tektronix ${ }^{\circledR}$ digital thermometer. The probe was placed at the surface of the wicking material, where the e-liquid soaks into the wick (see Figure 5). All three devices were tested in at least triplicate at the varying wattages used for the DHA measurements. The temperatures were recorded every second for 10 seconds of activation and complete cool down. The highest values were normalized and reported graphically (see Figure 6).

\section{SUPPORTING INFORMATION}

Quantification of dihydroxyacetone. Table S1 reports the quantification of DHA by ${ }^{1} \mathrm{H}-\mathrm{NMR}$ using relative integrations against an internal standard. Values are presented as an average $\mu \mathrm{g} / \mathrm{puff}$ for wattages tested. Table $\mathrm{S} 2$ is the quantification of DHA by GC/MS using relative peak area against an external standard. Values are presented as an average $\mu \mathrm{g} /$ puff for wattages tested. 
Table S1. Quantification of dihydroxyacetone by ${ }^{1} \mathrm{H}-\mathrm{NMR}$.

\begin{tabular}{|c|c|c|}
\hline \multicolumn{3}{|c|}{ iTaste VV4 Kanger EVOD } \\
\hline $\begin{array}{c}\text { Power } \\
(\mathrm{W})\end{array}$ & $\begin{array}{c}\text { Average DHA } \\
(\mu \mathrm{g} / \mathrm{puff})\end{array}$ & $\begin{array}{c}\text { Standard } \\
\text { Deviation }\end{array}$ \\
\hline 6 & $<$ LOQ & N/A \\
\hline 10 & 0.380 & 0.0986 \\
\hline 15 & 1.18 & 0.275 \\
\hline \multicolumn{3}{|c|}{ Vaporfi Vox Kanger Protank 2} \\
\hline 5 & $<$ LOQ & N/A \\
\hline 10 & 1.40 & 0.381 \\
\hline 15 & 2.33 & 0.1310 \\
\hline
\end{tabular}

Table S2. Quantification of dihydroxyacetone by GC/MS.

\begin{tabular}{|c|c|c|}
\hline \multicolumn{3}{|c|}{ iTaste VV4 Kanger EVOD } \\
\hline $\begin{array}{c}\text { Power } \\
(\mathrm{W})\end{array}$ & $\begin{array}{c}\text { Average DHA } \\
(\mu \mathrm{g} / \text { puff })\end{array}$ & $\begin{array}{c}\text { Standard } \\
\text { Deviation }\end{array}$ \\
\hline 6 & 0.279 & 0.145 \\
\hline 10 & 0.554 & 0.119 \\
\hline 15 & 1.27 & 0.340 \\
\hline \multicolumn{3}{|c|}{ Vaporfi Vox Kanger Protank 2} \\
\hline 5 & 0.18 & 0.122 \\
\hline 10 & 1.27 & 0.348 \\
\hline 15 & 2.29 & 0.612 \\
\hline \multicolumn{3}{|c|}{ Vaporfi Vox Volt OCC } \\
\hline 20 & 0.0523 & 0.0227 \\
\hline 30 & 0.0782 & 0.0386 \\
\hline 40 & 0.0746 & 0.0592 \\
\hline 50 & 0.0880 & 0.0399 \\
\hline
\end{tabular}

Calculating signal to noise ratio of ${ }^{1} \mathrm{H}-\mathrm{NMR}$ measurements. The signal to noise ratio for the target peak of the ${ }^{1} \mathrm{H}-\mathrm{NMR}$ spectra was 56.00 . Calculations were made using MNova's SNR calculation tool.

Statistical Significance. The average DHA of EC1 and EC2 for 10W and 15W, respectively, from Table S1 are statistically significant with a $p<0.05$. The average DHA of 
EC1 and EC2 for 10W and 15W, respectively, from Table S2 are statistically significant with a $p<0.01$; however, $5 \mathrm{~W}$ and $6 \mathrm{~W}$ are not statistically significant with a $p>0.05$.

The average mass consumed of PG/GL of EC1 and EC2 for $10 \mathrm{~W}$ and $15 \mathrm{~W}$, respectively, from Figure 4 are not statistically significant with a $p>0.05$; however, $5 \mathrm{~W}$ and $6 \mathrm{~W}$ are statistically significant with a $p<0.05$.

Wick temperature recording. Table S3 reports the maximum temperature of the wet layer of the saturated wick during a 10 second puff period. Figure S1 graphically represents the maximum temperature of the wet layer.

Table S3. Maximum temperature recorded of the wicking wet layer.

\begin{tabular}{|c|c|c|}
\hline \multicolumn{3}{|c|}{ iTaste VV4 Kanger EVOD } \\
\hline $\begin{array}{c}\text { Power } \\
(\text { W })\end{array}$ & $\begin{array}{c}\text { Average } \\
\text { Temp }\left({ }^{\circ} \mathrm{C}\right)\end{array}$ & $\begin{array}{c}\text { Standard } \\
\text { Deviation }\end{array}$ \\
\hline 6 & 70.2 & 2.34 \\
\hline 10 & 75.6 & 0.87 \\
\hline 15 & 108.5 & 4.73 \\
\hline Vaporfi Vox Kanger Protank 2 \\
\hline 5 & 66.9 & 7.49 \\
\hline 10 & 74.9 & 2.02 \\
\hline 15 & 105.2 & 3.42 \\
\hline \multicolumn{3}{|c|}{ Vaporfi Vox Volt OCC } \\
\hline 20 & 71.4 & 4.89 \\
\hline 30 & 76.0 & 5.07 \\
\hline 40 & 80.4 & 4.59 \\
\hline 50 & 89.7 & 10.55 \\
\hline
\end{tabular}




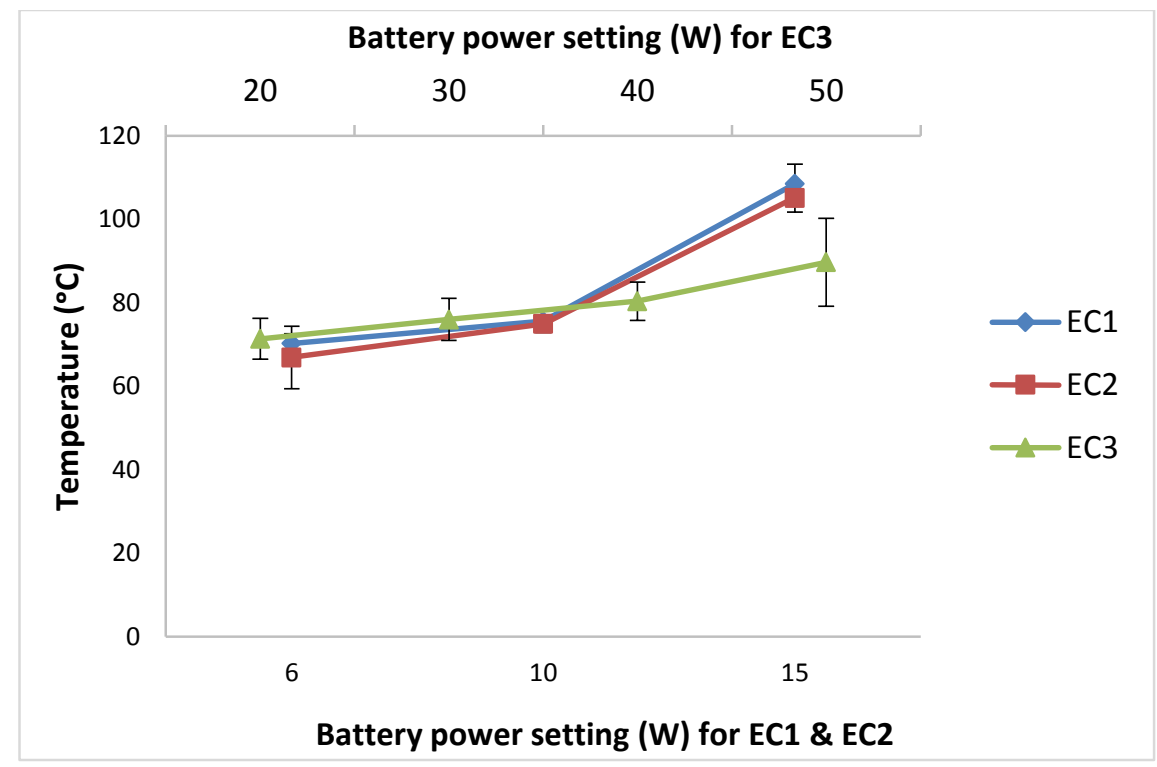

Figure S1. Maximum temperature recordings of the wet layer of the saturated wick during puff activation. The error bars represent the standard deviation.( $n=3$ for EC1 \&EC2, n=5 for EC3)

\section{REFERENCES}

1. Giovenco, D. P.; Hammond, D.; Corey, C. G.; Ambrose, B. K.; Delnevo, C. D., E-Cigarette Market Trends in Traditional U.S. Retail Channels, 2012-2013. Nicotine and Tobacco Research 2015, 17 (10), 1279-83.

2. Murthy, V. H., E-Cigarette Use among Youth and Young Adults: A Major Public Health Concern. JAMA Pediatr 2017, 171 (3), 209-210.

3. Wang, T. W.; Marynak, K. L.; Agaku, I. T.; King, B. A., Secondhand Exposure to Electronic Cigarette Aerosol among Us Youths. JAMA Pediatrics 2017, 171 (5), 490-492.

4. Jensen, R. P.; Strongin, R. M.; Peyton, D. H., Solvent Chemistry in the Electronic Cigarette Reaction Vessel. Scientific Reports 2017, 7, 42549.

5. Us Food and Drug Administration, Tanning Products. https://www.fda.gov/radiation-emittingproducts/tanning/tanning-products (accessed 10/10/19).

6. Petersen, A. B.; Wulf, H. C.; Gniadecki, R.; Gajkowska, B., Dihydroxyacetone, the Active Browning Ingredient in Sunless Tanning Lotions, Induces DNA Damage, Cell-Cycle Block and Apoptosis in Cultured Hacat Keratinocytes. Mutation Research 2004, 560 (2), 173-86.

7. Fenton, H. J. H.; Jackson, H. J., The Oxidation of Polyhydric Alcohols in Presence of Iron. Journal of the Chemical Society, Transactions 1899, 75 (0), 1-11.

8. Hall, A.; Knowles, J. R., The Uncatalyzed Rates of Enolization of Dihydroxyacetone Phoshate and of Glyceraldehyde 3-Phosphate in Neutral Aqueous Solution. The Quantitative Assessment of the Effectiveness of an Enzyme Catalyst. Biochemistry 1975, 14 (19), 4348-53.

9. Salamanca, J. C.; Munhenzva, I.; Escobedo, J. O.; Jensen, R. P.; Shaw, A.; Campbell, R.; Luo, W.; Peyton, D. H.; Strongin, R. M., Formaldehyde Hemiacetal Sampling, Recovery, and Quantification from Electronic Cigarette Aerosols. Scientific Reports 2017, 7 (1), 11044.

10. Cobas, C.; Seoane, F.; Sykora, S., Global Spectral Deconvolution (Gsd) of 1d-Nmr Spectra. 2008.

11. Talih, S.; Salman, R.; Karaoghlanian, N.; El-Hellani, A.; Saliba, N.; Eissenberg, T.; Shihadeh, A., "Juice Monsters": Sub-Ohm Vaping and Toxic Volatile Aldehyde Emissions. Chemical Research in Toxicology 2017, 30 (10), 1791-1793. 
12. Geiss, O.; Bianchi, I.; Barrero-Moreno, J., Correlation of Volatile Carbonyl Yields Emitted by E-Cigarettes with the Temperature of the Heating Coil and the Perceived Sensorial Quality of the Generated Vapours. International Journal of Hygiene and Environmental Health 2016, 219 (3), 268-77.

13. Flora, J. W.; Meruva, N.; Huang, C. B.; Wilkinson, C. T.; Ballentine, R.; Smith, D. C.; Werley, M. S.; McKinney, W. J., Characterization of Potential Impurities and Degradation Products in Electronic Cigarette Formulations and Aerosols. Regulatory Toxicology and Pharmacology 2016, 74, 1-11.

14. Wang, P.; Chen, W.; Liao, J.; Matsuo, T.; Ito, K.; Fowles, J.; Shusterman, D.; Mendell, M.; Kumagai, K., A Device-Independent Evaluation of Carbonyl Emissions from Heated Electronic Cigarette Solvents. PLoS ONE 2017, 12 (1), e0169811.

15. Gillman, I.; Kistler, K.; Stewart, E.; Paolantonio, A., Effect of Variable Power Levels on the Yield of Total Aerosol Mass and Formation of Aldehydes in E-Cigarette Aerosols. Regulatory Toxicology and Pharmacology 2016, 75, 58-65.

16. Beyhaghi, S.; Geoffroy, S.; Prat, M.; Pillai, K. M., Wicking and Evaporation of Liquids in Porous Wicks: A Simple Analytical Approach to Optimization of Wick Design. AlChE Journal 2014, 60 (5), 1930-1940.

17. Luikov, A. V., Heat and Mass Transfer in Capillary-Porous Bodies. In Advances in Heat Transfer, Irvine, T. F.; Hartnett, J. P., Eds. Elsevier: 1964; Vol. 1, pp 123-184.

18. Pankow, J. F., Calculating Compound Dependent Gas-Droplet Distributions in Aerosols of Propylene Glycol and Glycerol from Electronic Cigarettes. Journal of Aerosol Science 2017, 107, 9-13.

19. Sorooshian, A. Aerosol Composition and Hygroscopicity Studies: Instrument Development/Characterization, Ambient and Laboratory Measurements, and Modeling. California Institute of Technology, 2008.

20. Orsini, D.; Ma, Y.; Sullivan, A.; Sierau, B.; Baumann, K.; Weber, R., Refinements to the Particle-intoLiquid Sampler (Pils) for Ground and Airborne Measurements of Water Soluble Aerosol Composition. Atmospheric Environment 2003, 37, 1243-1259. 
Chapter 3: A Simple Predictive Model for Estimating Relative E-Cigarette Toxic Carbonyl Levels

\section{ABSTRACT}

E-cigarette devices are wide ranging that can lead to significantly differing levels of toxic carbonyls in their respective aerosol. Power can be a useful method in predicting relative toxic concentrations within the same device, but does not correlate well to inter-device toxin levels. Herein we have developed a simple mathematical model utilizing measurements of e-cigarette's coil and wick in order to predict relative levels of e-liquid solvent degradation. Model 1, coil length/(wick surface area*wraps), performed in the moderate to substantial range as a predictive tool $\left(R^{2}=0.69\right)$. Twelve devices, spanning a range of coil and wick styles, were analyzed. Model 1 was evaluated against thirteen total models and displayed the best predictability. Relationships including power settings displayed weak predictability, validating that power levels cannot be reliably compared between devices due to differing wicking and coil components and heat transfer efficiencies.

\section{INTRODUCTION}

The ongoing development and popularity of electronic cigarettes have challenged scientists and regulators. Issues faced by researchers include the rapidly evolving devices and e-liquid formulations, as well as a lack of standardized testing methods. These factors have exacerbated the significant interlaboratory variability in reported e-cigarette aerosol toxin levels. ${ }^{1,2,3}$ For example, Beauval et al compared 
carbonyl emissions from twenty different e-cigarette studies and found reported ranges from $2-342220 \mathrm{ng} /$ puff for formaldehyde and $0.3-135468 \mathrm{ng} /$ puff for acetaldehyde. ${ }^{4}$ Factors such as puff volume, ${ }^{4}$ e-liquid consumed ${ }^{5}$ and power output ${ }^{6}$ are known to correlate to toxin levels intra-device; however, methods for understanding inter-device levels are still needed.

E-cigarette products are wide-ranging, affording device-specific levels of toxic emissions. ${ }^{7,8-9}$ For example, Saliba et al. reported that catalysis of the degradation of eliquid solvents can occur in a manner dependent on the type of coil material, resulting in enhanced toxin levels. ${ }^{10}$ Other specific coil properties are still under investigation. ${ }^{11-13}$ One study showed that total carbonyl yields are proportional to device power (Watts) divided by coil surface area.${ }^{14}$ According to the researchers, additional study is needed beyond the two tank models examined to date. In a related investigation, an inverse relationship was identified between coil volume and nicotine aerosol yield. ${ }^{15}$ Coil volume was defined as the cylinder formed by the wick surrounded by the coil; which, by definition, limits utility to only horizontal coils (Figure 1).

E-cigarette atomizers contain a heating coil and a porous wick with various materials, designs and styles. The traditional coil contains a helical wire made of Kanthal, nichrome or stainless steel that is paired with a wick made of cotton or silica. The coil and wick can be oriented vertically or horizontally (Figure 1). The styles of coil include single, parallel and dual (Figure 2). 


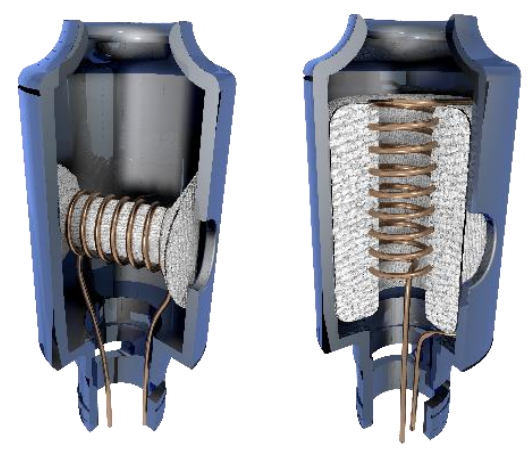

Figure 1. Depiction of horizontal (left) and vertical (right) coil orientations. The vertical coil has a surrounding wick.

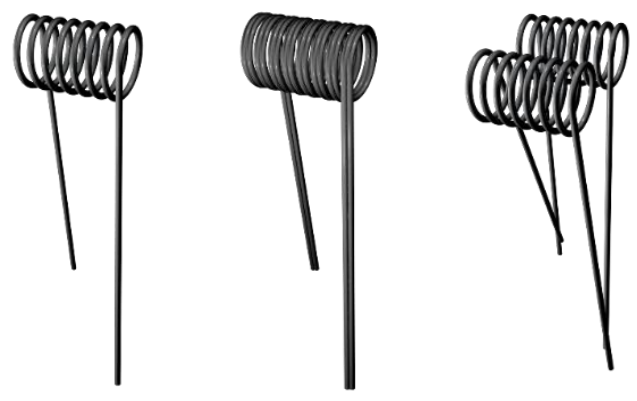

Figure 2. Illustration of single (left), parallel (middle) and dual coils. The parallel and dual coil contains two identical wires; however, the dual coils are wrapped individually with respective wicks. Each style can be oriented vertically or horizontally.

Herein, we focus on coil design and wicking in modulating toxin production. A new mathematical model for predicting relative toxin levels based on reasonably simple coil and wick measurements is derived. It can be used as a means for regulators and manufacturers to predict relative emissions and health risks associated with specific ecigarette design features. 


\section{RESULTS AND DISCUSSION}

Developing a general mathematical model. Propylene glycol and glycerol (PG/GL) degrade through excess heat; therefore, an e-cigarette coil that has a consistent supply of e-liquid and uniform heating will produce less toxins. It has been shown, for instance, that there is an inverse relationship between the efficiency of e-liquid consumption and toxic carbonyl aerosol levels. ${ }^{16}$ In the current study, we expand on our previous report on e-cigarette wicking properties, ${ }^{17}$ wherein we had shown that the stability of the wick temperature during aerosolization served as a predictor of the degree of PG/GL degradation.

Wicking controls the supply of e-liquid to the coil and enables heat transfer from the coil to the e-liquid. The wick's outer surface area influences the amount of e-liquid that can be absorbed at any given point in time. A wick with a relatively large surface area will allow a larger volume of e-liquid to absorb energy from the heating coil, therefore typically reducing excess heat. ${ }^{18}$

Heat transfer is known to be a function of surface area of a metal. ${ }^{19}$ The larger the surface area, the more heat can be applied to a system. However, within the ecigarette atomizer, some of the coil's energy is being absorbed by the e-liquid soaked wick, while some of the heat is transferred to the air passing over the coil. Therefore, coil surface area would lead to an inaccurate estimation of heat energy transferred to the e-liquid, whereas coil length is a more representative indicator. 
The number of times the coil is wrapped or turned defines the contact of energy transfer between the coil and the wick. A higher number of coil wraps will enable more even heating throughout the wick, ${ }^{20}$ thereby reducing "hot spots" and decreasing the degradation of e-liquid components. However, in horizontal style coils, wherein the coils are wrapped around the wick material, an increase in turns will lead to a decrease in the wick outer surface area, thereby altering wicking efficiency. In order to account for the variable effects of wick surface area (SA), coil wraps and coil length on wicking efficiency, we developed a model (1) to predict relative toxin emission levels in varying e-cigarette brands and devices.

$$
\propto \frac{\text { coil length }(\mathrm{mm})}{\text { wick surface area }\left(\mathrm{mm}^{2}\right) \times(n) \text { wraps }}
$$

(n) wraps = the number of coil turns

\section{Using model 1 to analyze relative levels of carbonyls produced by nine different}

e-cigarettes. To initially test model 1, nine different devices (EC 1-9), covering all common orientations and styles (see Figure 1, 2 and Table S1) were used to aerosolize 1:1 PG/GL (\% v/v) in their respective commercial e-cigarettes without modification. The model 1 parameters were plotted along with the measured concentrations of six target carbonyls produced via e-liquid solvent degradation: formaldehyde, acetaldehyde, acetone, propanal, butyraldehyde and benzaldehyde. Their levels were monitored using 
the standard EPA method with an impinger of 2,4-dinitrophenylhydrazine (DNPH) and HPLC-UV. ${ }^{21}$ An exponential regression analysis was obtained between model 1 and the experimental carbonyl concentration levels measured (Figure 3). The data was analyzed as an exponential relationship due to the exponential behavior for enthalpy of vaporization, as is consistent with the Clausius-Clapeyron equation. ${ }^{22}$

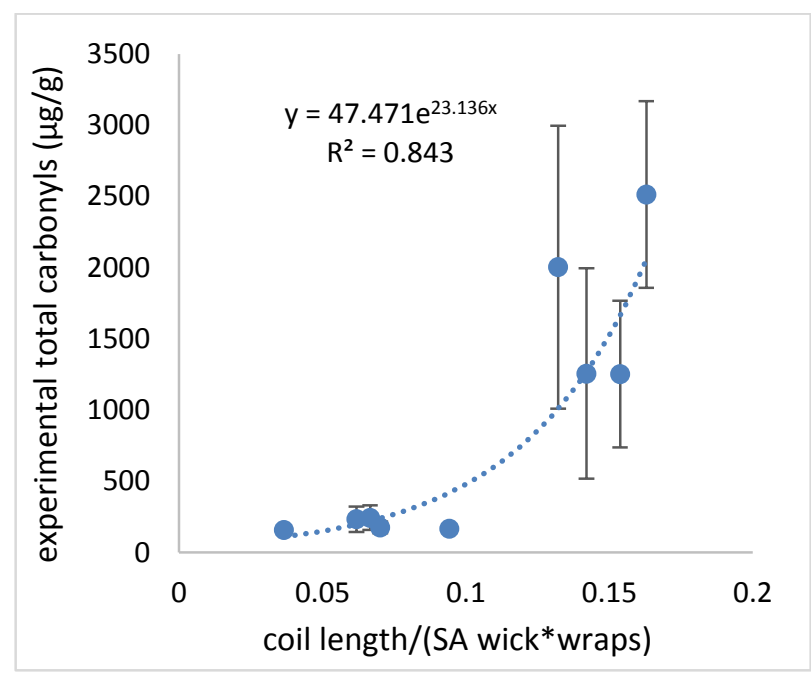

Figure 3. Total carbonyl emissions as a function of coil length per the product of outer surface area of wick and coil wraps (1). Dashed line represents best fit regression $\left(R^{2}=0.843\right)$. Each carbonyl was analyzed by HPLC (see methods section). Error bars represent one standard error. The larger error bars associated with the e-cigarettes that produce high levels of toxins are expected based on previous literature. ${ }^{4,23}$ Higher concentrations of carbonyls suggest inefficient wicking that produce a higher degree of error exacerbated by intra-device inconsistencies. EC1-9 are various brands of e-cigarettes with differing wicks, coils and coil styles (see Supporting Information).

Testing the predictive nature of model 1 using twelve different e-cigarettes. To support the hypothesis that model 1 can be used to predict relative toxin levels of ecigarette aerosols three additional e-cigarettes (EC10-12) were used to aerosolize 1:1 PG/GL. The predicted carbonyl concentration levels of all twelve e-cigarettes were calculated based on the equation of the exponential regression from the initial nine e- 
cigarettes (Figure 3). The comparison of the experimental and predicted carbonyl concentration levels gave a moderate to substantial predictive accuracy ${ }^{24}\left(R^{2}=0.6945\right)$ (Figure 4); the classification of substantial, moderate and weak correlations based on $\mathrm{R}^{2}$ thresholds is based on Hair et al. ${ }^{24}$

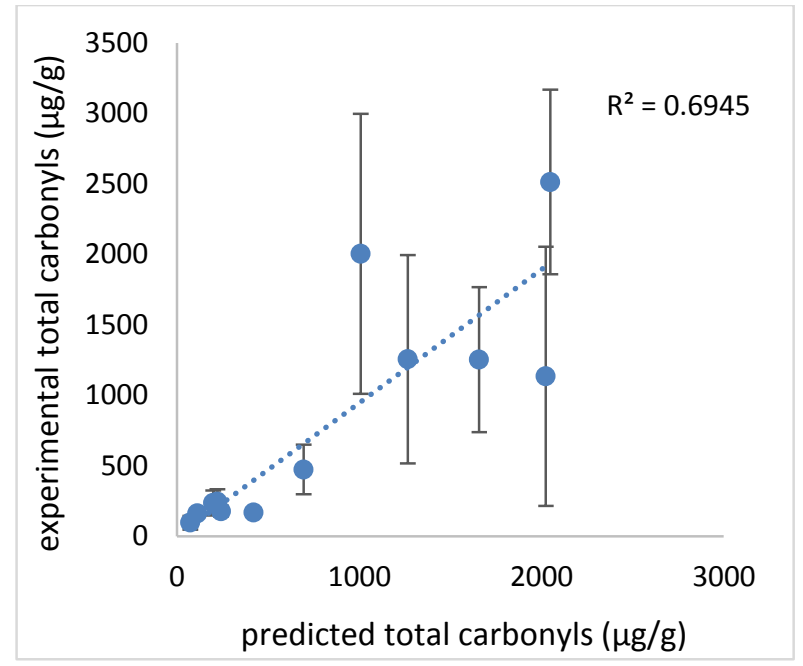

Figure 4. Experimental versus exponential fitted values of the regression analysis of EC1-9 with the experimental values of EC1-12. This demonstrates model 1 performs in the moderate to substantial range as a predictive tool $\left(R^{2}=0.6945\right) .{ }^{24}$ Dashed line represents best fit regression. Error bars represent one standard error. EC1-12 are various brands of e-cigarettes with differing wick, coil material and coil style (see Supporting Information).

Testing alternative models' predictability. We also evaluated alternative models, such as those including power levels, to compare their predictive measures of aerosol components. ${ }^{14-15}$ It is well-known that an increase in power levels will increase aerosol toxin levels within the same device. ${ }^{25}$ However, the same power levels cannot be reliably compared between devices due to differing wicking and coil components and heat transfer efficiencies. In order to address this issue, we used the high value of the manufacturers' recommended range of power settings for each device studied in this work. Alternately, the method of analyzing total carbonyl levels normalized by mass e- 
liquid consumed could inherently account for power ${ }^{26,27}$ These results indicate that models that rely on power setting values display weak predictability ${ }^{24}$ (Figure 5) when comparing multiple brands and devices. Twelve alternative models were investigated, as shown in Figure 5 as well as in the Supporting Information.
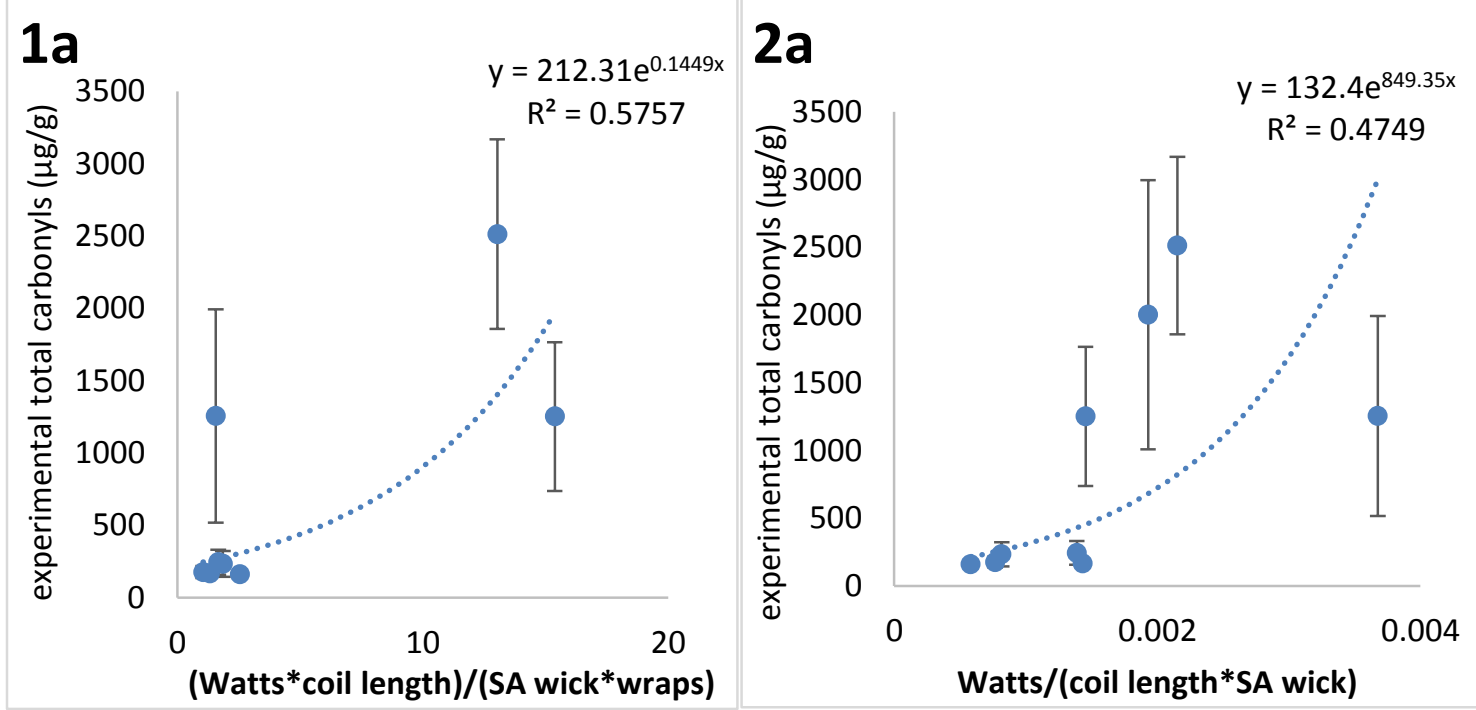

\section{$1 b$}
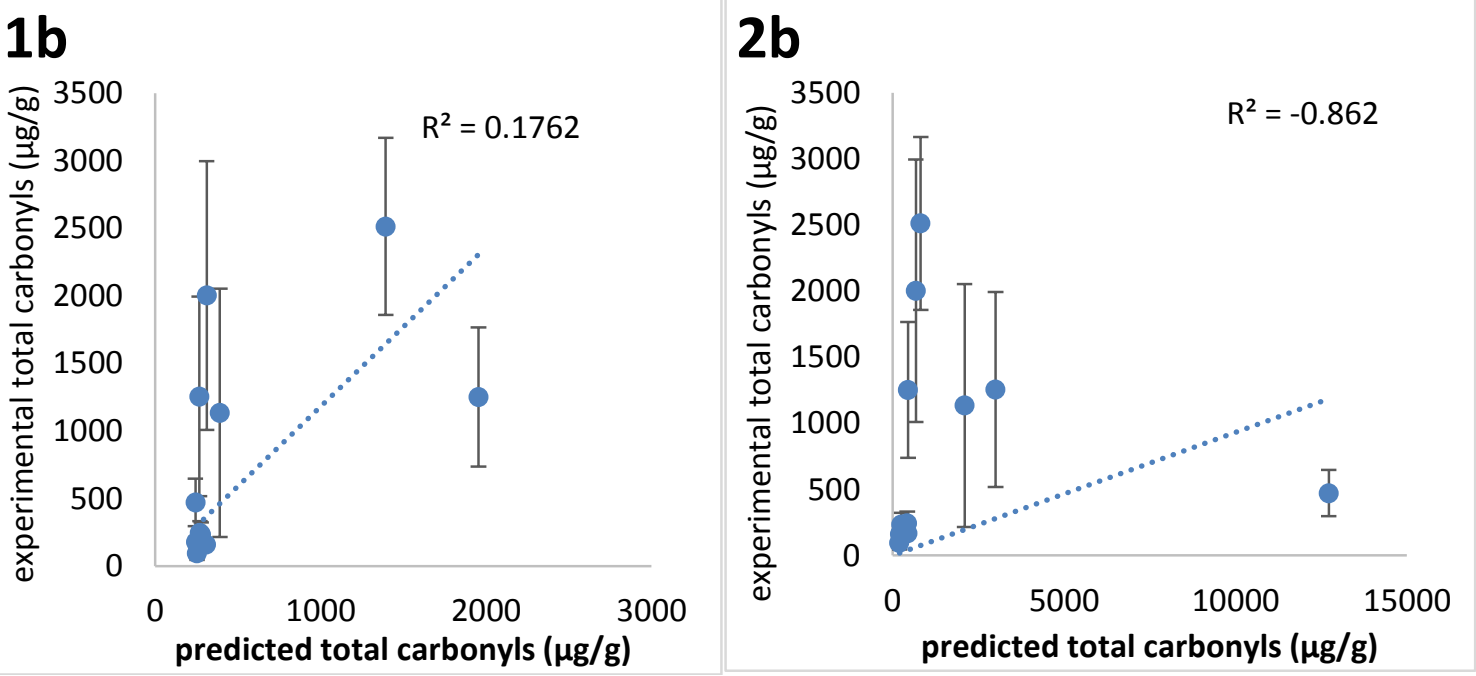

Figure 5. Analyzing alternative models as predictors of measured toxins. Graph 1a shows the regression analysis of EC1-9 using (Watts*coil length)/(SA wick*wraps). Graph 1b displays a weak predictability $\left(R^{2}=0.1762\right)$ of $E C 1-12$ using the equation of the regression analysis from $1 \mathbf{a}$. Graph 2 a shows the regression analysis of EC1-9 using Watts/(coil length*SA wick). Graph $\mathbf{2 b}$ displays a weak predictability $\left(R^{2}=-0.862\right)$ of EC1-12 using the equation of the regression analysis from $2 a$. 


\section{CONCLUSION}

A straightforward model based on e-cigarette coil and wick measurements is described to enable the efficient prediction of the relative degree of e-cigarette solvent degradation between varying brands. Testing twelve different e-cigarettes, encompassing a variety of coil and cotton types, atomizer measurements (model 1) correlated well with experimental concentrations $\left(R^{2}=0.843\right)$ of six target carbonyls. Comparison of the predicted values of the regression analysis of EC1-9 with the experimental values of EC1-12 that demonstrates model 1 performs in the moderate to substantial range as a predictive tool $\left(R^{2}=0.6945\right)$. Model 1 exhibited the best relationship out of the 13 models tested. Interestingly, models that contained power variables produced a weak predictability of relative total carbonyl concentrations.

One limitation of this study is the testing of only six gas-phase carbonyls. There may be significant quantities of other degredants present in gas phase as well as particle phase, ${ }^{5}$ however, it is unlikely to change the basic observations of this study. There are also other parameters that can influence e-liquid degradation such as vaping topography, catalysis and specific additives. ${ }^{28}$ However, model 1 's simplicity renders it potentially useful in predicting relative levels of carbonyl toxins across widely varying device generations and styles.

\section{METHODS}

Electronic cigarette devices. Twelve unique coil atomizers (EC1-12) were used for aerosolization (see SI). Each device was powered by a SMOK ${ }^{\circledR}$ Alien $220 \mathrm{~W}$ variable 
voltage/variable wattage/temperature control (VV/VW/TC) battery. Due to the wide range of resistances it would not be recommended to test each atomizer at the same power output; therefore, each atomizer was tested at the highest wattage of the manufacturer specified range.

E-liquid preparation and avoidance of dry coils and burnt e-liquid. Each device was filled with e-liquid to the highest level according to manufacturers' recommendation. A mixture of $\mathrm{PG} / \mathrm{GL}$ ( $50 \%$ by volume, $\mathrm{v} / \mathrm{v}$ ) was prepared in house from ACS-grade PG and GL and used for all sample testing. E-liquid consumed was calculated by weighing the e-cigarette tank before and after each session.

New coils were used for each session. Before sample collection, each coil was primed with five "warm-up" puffs starting at a lower wattage and increasing evenly until the target wattage was reached by the fifth puff. If the e-liquid or atomizer exhibited an unusual smell after the session, indicating burnt e-liquid, the sample was discarded. If the e-cigarette did not produce visible aerosol, indicating improper e-liquid supply to the coil, the sample was also discarded.

Puffing regime. A CH Technologies single cigarette smoking machine (SCSMSTEP) was used. The smoking machine was set to the CORESTA program with a square shape puff profile, a $3 \mathrm{~s}$ puff period, $30 \mathrm{~s}$ puff interval and a $55 \mathrm{~mL}$ puff volume. This program was used for all samples collected. Each e-cigarette was tested at minimum in triplicate. 
Aerosol collection for HPLC analysis. The aerosol produced was passed through an impinger containing $20.00 \mathrm{~mL}$ DNPH solution. 40 puffs were collected. After each session, the DNPH solution was collected into an amber vial and analyzed within 4 hours.

DNPH solution. DNPH solution was prepared in accordance with the CORESTA standardized method from DNPH stock solutions. DNPH was purified via recrystallization. ${ }^{29}$ Approximately $3 \mathrm{~g}$ DNPH hydrate was weighed and added to $62.0 \mathrm{~mL}$ EtOH and warmed with magnetic stirring agitation. $80.0 \mathrm{~mL}$ EtOAc was added slowly with heat and stirring until all of the DNPH was dissolved. The warm solution was vacuum filtered and transferred to an Erlenmeyer flask and cooled overnight. The DNPH crystals were isolated using vacuum filtration. The crystals were placed in a desiccator to protect from moisture. Recrystallized DNPH (0.805 g) was added to $175 \mathrm{~mL}$ acetonitrile (MeCN) and $75 \mathrm{~mL}$ of $\mathrm{H}_{2} \mathrm{O}$ containing $3.5 \mathrm{~mL}$ phosphoric acid (85\%). Fresh $250 \mathrm{~mL}$ batches of DNPH stock solution were prepared weekly and stored in amber flasks at room temperature.

Analysis by HPLC-UV. DNPH samples were analyzed and quantified using a Waters ${ }^{\circledR} 1525$ Binary HPLC Pump and a Waters 2996 Photodiode Array Detector. Analysis conditions: two SUPELCOSIL C-18 $(25 \mathrm{~cm} \times 4.6 \mathrm{~mm}, 5 \mu \mathrm{m}$ particle size $)$ columns connected in series inside a column heater at $40^{\circ} \mathrm{C}$. The mobile phase comprised of $\mathrm{MeCN} / \mathrm{H}_{2} \mathrm{O}$ with a gradient system as follows: 0 min. 60/40; $7 \mathrm{~min} .60 / 40 ; 25 \mathrm{~min}$. 
100/0, at a combined flow rate of $1 \mathrm{~mL} / \mathrm{min}$, with $360 \mathrm{~nm}$ detection wavelength. The sample injection volume was $20 \mu \mathrm{L}$.

Rebuildable coil. A Zeus dual RTA by Geekvape ${ }^{\circledR}$ was used with Kanthal A-1 wire (30 gauge) and Wick N'Vape cotton bacon (v2). A dual coil build compromised of two wires of $98.04 \pm 0.05 \mathrm{~mm}$ length wrapped 8 times independently. Two cotton wicks weighing $24.82 \pm 5.09 \mathrm{mg}$ each were fit through the dual coils, one wick per coil. A new coil was built for each run, and ten puffs were performed and discarded at the target power output of $65 \mathrm{~W}$ before the collection of aerosol to be analyzed by HPLC-UV.

Statistical rigor. Each e-cigarette (EC1-12) was tested at minimum in triplicate, using a new coil for each session. Post analysis a Grubbs outlier test was performed and subsequent outliers were identified and removed. These outliers could account for burnt coils, improper ohmage readings from the power battery and irregularities in the coil build. To verify model 1 is a good predictor, other coil and wick calculations were analyzed in the same fashion. Of the thirteen tested, model 1 performed the best when comparing the experimental values to the predicted values. A selected number (10 of 13) of alternative models are included in the Supporting Information. 


\section{SUPPORTING INFORMATION}

\section{Characteristic of each e-cigarette tested in the study.}

Table S1. E-cigarette identification and coil style of twelve different coils

\begin{tabular}{|c|c|c|c|c|c|c|c|}
\hline $\begin{array}{l}\text { E-cigarette brand } \\
\text { name }\end{array}$ & $\begin{array}{c}\text { Reference } \\
\text { number }\end{array}$ & $\begin{array}{c}\text { Coil } \\
\text { orientation }\end{array}$ & Coil style & $\begin{array}{c}\text { Resistance } \\
(\Omega)\end{array}$ & $\begin{array}{c}\text { Manufacturer } \\
\text { recommended } \\
\text { setting }(\mathrm{W})\end{array}$ & $\begin{array}{c}\text { Power } \\
\text { level } \\
\text { tested }(\mathrm{W})\end{array}$ & $\begin{array}{l}\text { Coil wire } \\
\text { type }\end{array}$ \\
\hline SMOK Baby Q2 & EC1 & vertical & parallel & 0.4 & $40-80$ & 80 & Kanthal \\
\hline SMOK Baby X4 & EC2 & vertical & dual & 0.15 & $30-70$ & 70 & Kanthal \\
\hline Eleaf iJust 2 Mini & EC3 & vertical & parallel & 0.5 & $30-100$ & 100 & Kanthal \\
\hline Joyetech Cubis & EC4 & vertical & single & 0.5 & $15-30$ & 30 & $\begin{array}{c}\text { stainless } \\
\text { steel }\end{array}$ \\
\hline $\begin{array}{l}\text { Aspire Nautilus } \\
\text { Mini }\end{array}$ & EC5 & vertical & single & 1.8 & $10-14$ & 14 & Kanthal \\
\hline Kanger Protank 2 & EC6 & horizontal & single & 2.2 & $\mathrm{~N} / \mathrm{R}$ & 11 & nichrome \\
\hline $\begin{array}{l}\text { Kanger Subtank } \\
\text { Mini }\end{array}$ & EC7 & vertical & single & 1.2 & $7-15$ & 15 & nichrome \\
\hline $\begin{array}{l}\text { Halo Triton } 2 \\
(0.75 \Omega)\end{array}$ & EC8 & vertical & single & 0.75 & $8-25$ & 25 & Kanthal \\
\hline $\begin{array}{l}\text { Halo Triton } 2 \\
(1.5 \Omega)\end{array}$ & EC9 & horizontal & dual & 1.5 & $8-20$ & 20 & Kanthal \\
\hline $\begin{array}{l}\text { Geekvape Zues } \\
\text { Dual RTA }\end{array}$ & EC10 & horizontal & dual & 1.38 & $\mathrm{~N} / \mathrm{A}$ & 65 & Kanthal \\
\hline JUUL & EC11 & horizontal & single & 2.0 & $\mathrm{~N} / \mathrm{A}$ & 8 & nichrome \\
\hline $\begin{array}{l}\text { Kanger Subtank } \\
\text { Mini (26W) }\end{array}$ & EC12 & vertical & single & 1.2 & $10-26$ & 26 & nichrome \\
\hline
\end{tabular}

N/R: not reported. For e-cigarettes whose power rangers were not reported by the manufacturer, user's self-reported ranges from online sources were used.

N/A: not applicable. 
Table S2. Coil and wick measurements of twelve different e-cigarettes, each measured at minimum in triplicate. Not all measurements were used in the discussion of this study.

\begin{tabular}{|c|c|c|c|c|c|c|c|c|c|}
\hline E-cigarette & $\begin{array}{c}\text { Reference } \\
\text { number }\end{array}$ & $\begin{array}{l}\text { Coil } \\
\text { length } \\
(\mathrm{mm})\end{array}$ & $\begin{array}{c}\text { Coil } \\
\text { diameter } \\
(\mathrm{mm})\end{array}$ & $\begin{array}{l}\text { Cotton } \\
\text { length } \\
(\mathrm{mm})\end{array}$ & $\begin{array}{l}\text { Cotton } \\
\text { diameter } \\
(\mathrm{mm})\end{array}$ & $\begin{array}{c}\text { Coil length } \\
\text { (coiled, } \\
\mathrm{mm} \text { ) }\end{array}$ & $\begin{array}{c}\text { Coil } \\
\text { diameter } \\
\text { (coiled, } \mathrm{mm} \text { ) }\end{array}$ & $\begin{array}{c}\text { Number } \\
\text { of wraps } \\
\text { (n) }\end{array}$ & $\begin{array}{c}\text { Surface area } \\
\text { of cotton } \\
\left(\mathrm{mm}^{2}\right)\end{array}$ \\
\hline \multirow{3}{*}{$\begin{array}{l}\text { SMOK Baby } \\
\text { Q2 }\end{array}$} & \multirow{3}{*}{ EC1 } & 154.04 & 0.46 & 7.44 & 9.8 & 8.14 & 6.95 & 4 & 229.06 \\
\hline & & 155.19 & 0.47 & 8.27 & 9.26 & 6.9 & 6.94 & 4 & 240.58 \\
\hline & & 157.71 & 0.45 & 7.91 & 9.96 & 7.29 & 6.93 & 4 & 247.51 \\
\hline \multirow{3}{*}{$\begin{array}{l}\text { SMOK Baby } \\
\text { X4 }\end{array}$} & \multirow{3}{*}{ EC2 } & 223.94 & 0.36 & 15.52 & 5.46 & 5.89 & 4.14 & 12 & 532.4 \\
\hline & & 231.28 & 0.37 & 15 & 5.41 & 6.26 & 3.81 & 12 & 509.9 \\
\hline & & 230.82 & 0.37 & 14.54 & 5.66 & 6.39 & 3.84 & 12 & 517.1 \\
\hline \multirow{4}{*}{$\begin{array}{l}\text { Eleaf iJust } 2 \\
\text { Mini }\end{array}$} & \multirow{4}{*}{ EC3 } & 294.16 & 0.41 & 9.44 & 8.1 & 9.55 & 5.18 & 8 & 240.2 \\
\hline & & 289.38 & 0.30 & 9.59 & 7.74 & 9.84 & 5.17 & 8 & 233.2 \\
\hline & & 294.34 & 0.37 & 9.57 & 7.04 & 9.62 & 5.12 & 8 & 211.7 \\
\hline & & 284.34 & 0.34 & 9.53 & 8.93 & 9.97 & 5.05 & 8 & 267.4 \\
\hline \multirow{3}{*}{$\begin{array}{l}\text { Joyetech } \\
\text { Cubis }\end{array}$} & \multirow{3}{*}{ EC4 } & 153.14 & 0.30 & 10.43 & 7.38 & 9.16 & 2.69 & 10 & 241.8 \\
\hline & & 148.00 & 0.30 & 10.28 & 7.13 & 9.02 & 2.85 & 10 & 230.3 \\
\hline & & 151.37 & 0.30 & 10.78 & 7.7 & 9.2 & 2.63 & 10 & 260.8 \\
\hline \multirow{3}{*}{$\begin{array}{l}\text { Aspire } \\
\text { Nautilus } \\
\text { Mini }\end{array}$} & \multirow{3}{*}{ EC5 } & 93.47 & 0.22 & 6.54 & 5.68 & 5.23 & 2.52 & 9 & 116.7 \\
\hline & & 92.24 & 0.12 & 6.27 & 5.1 & 6.09 & 2.5 & 9 & 100.5 \\
\hline & & 92.33 & 0.18 & 6.01 & 5.33 & 5.95 & 2.47 & 10 & 100.6 \\
\hline \multirow{3}{*}{$\mid \begin{array}{l}\text { Kanger } \\
\text { Protank } 2\end{array}$} & \multirow{3}{*}{ EC6 } & 47.11 & 0.13 & 9.89 & 1.56 & 3.4 & 2.01 & 5 & 66.2 \\
\hline & & 46.61 & 0.14 & 10.34 & 1.54 & 3.42 & 1.9 & 5 & 64.6 \\
\hline & & 44.66 & 0.14 & 10.24 & 1.54 & 3.01 & 1.98 & 5 & 64.0 \\
\hline \multirow{4}{*}{\begin{tabular}{|l} 
Kanger \\
Subtank \\
Mini (15W)
\end{tabular}} & \multirow{4}{*}{ EC7 } & 113.76 & 0.22 & 6.95 & 7.85 & 5.47 & 3.2 & 9 & 171.4 \\
\hline & & 107.33 & 0.20 & 8.11 & 7.87 & 6.94 & 3.13 & 9 & 200.5 \\
\hline & & 111.37 & 0.20 & 7.2 & 7.28 & 7.37 & 3.15 & 9 & 164.7 \\
\hline & & 111.48 & 0.21 & 7.38 & 7.39 & 6.57 & 3.17 & 9 & 171.3 \\
\hline \multirow{4}{*}{$\begin{array}{l}\text { Halo Triton } \\
2(0.75 \Omega)\end{array}$} & \multirow{4}{*}{ EC8 } & 97.75 & 0.29 & 7.75 & 7.25 & 7.18 & 3.38 & 8 & 176.5 \\
\hline & & 97.91 & 0.30 & 8.04 & 7.65 & 7.54 & 3.43 & 8 & 193.2 \\
\hline & & 98.32 & 0.29 & 7.76 & 7.35 & 6.25 & 3.4 & 8 & 179.2 \\
\hline & & 97.88 & 0.28 & 7.7 & 7.76 & 7.34 & 3.41 & 8 & 187.7 \\
\hline \multirow{3}{*}{$\begin{array}{l}\text { Halo Triton } \\
2(1.5 \Omega)\end{array}$} & \multirow{3}{*}{ EC9 } & 152.22 & 0.14 & 6.14 & 1.49 & 3.76 & 2.36 & 16 & 65.39 \\
\hline & & 141.64 & 0.13 & 6.54 & 1.69 & 3.69 & 2.29 & 16 & 77.05 \\
\hline & & 149.68 & 0.15 & 6.43 & 1.54 & 3.24 & 2.38 & 16 & 68.68 \\
\hline \multirow{4}{*}{$\begin{array}{l}\text { Geekvape } \\
\text { Zeus RTA } \\
\text { dual }\end{array}$} & \multirow{4}{*}{ EC10 } & 196.00 & 0.25 & 29.1 & 4.01 & 8.15 & 3.32 & 16 & 733.2 \\
\hline & & 196.00 & 0.25 & 29.93 & 3.43 & 8.46 & 3.16 & 16 & 645.0 \\
\hline & & \begin{tabular}{|l|}
196.14 \\
\end{tabular} & 0.25 & 27.86 & 3.44 & 7.76 & 3.25 & 16 & 602.17 \\
\hline & & 196.20 & 0.25 & 31.38 & 3.52 & 6.58 & 3.15 & 16 & 694.0 \\
\hline \multirow{4}{*}{ JUUL } & \multirow{4}{*}{ EC11 } & 29.28 & 0.13 & 11.86 & 1.13 & 3.69 & 1.57 & 5 & 42.10 \\
\hline & & 27.39 & 0.13 & 11.78 & 1.6 & 3.15 & 1.6 & 5 & 59.21 \\
\hline & & 30.88 & 0.12 & 11.11 & 1.3 & $\mathrm{~N} / \mathrm{A}$ & 1.67 & 5 & 45.37 \\
\hline & & 29.71 & 0.13 & 11.27 & 1.74 & 3.25 & 1.59 & 5 & 61.61 \\
\hline \multirow{4}{*}{$\begin{array}{l}\text { Kanger } \\
\text { Subtank } \\
\text { Mini (26W) }\end{array}$} & & 109.97 & 0.18 & 4.92 & 4.66 & $\mathrm{~N} / \mathrm{A}$ & 3.01 & 10 & 67.99 \\
\hline & $\mathrm{FC} 12$ & 114.02 & 0.20 & 5.37 & 4.59 & 6.91 & 3.2 & 9 & 77.43 \\
\hline & ECIL & 109.30 & 0.18 & 5.17 & 4.2 & 5.22 & 3.24 & 10 & 68.22 \\
\hline & & 110.98 & 0.17 & 5.16 & 4.64 & 6.56 & 3.16 & 9 & 75.21 \\
\hline
\end{tabular}




\section{Calibration curves for HPLC analysis.}

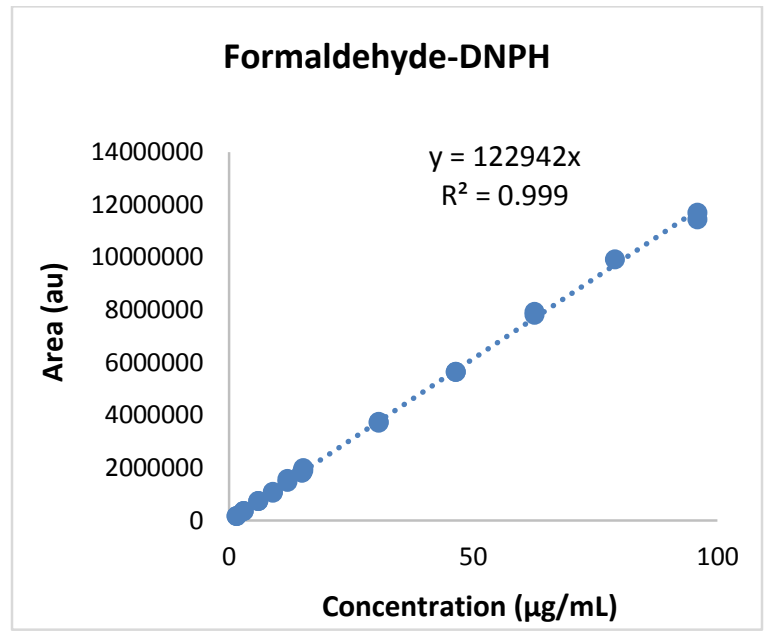

Figure S1. Formaldehyde-DNPH calibration curve for HPLC analysis. LOD was $0.105 \mathrm{mM}$.

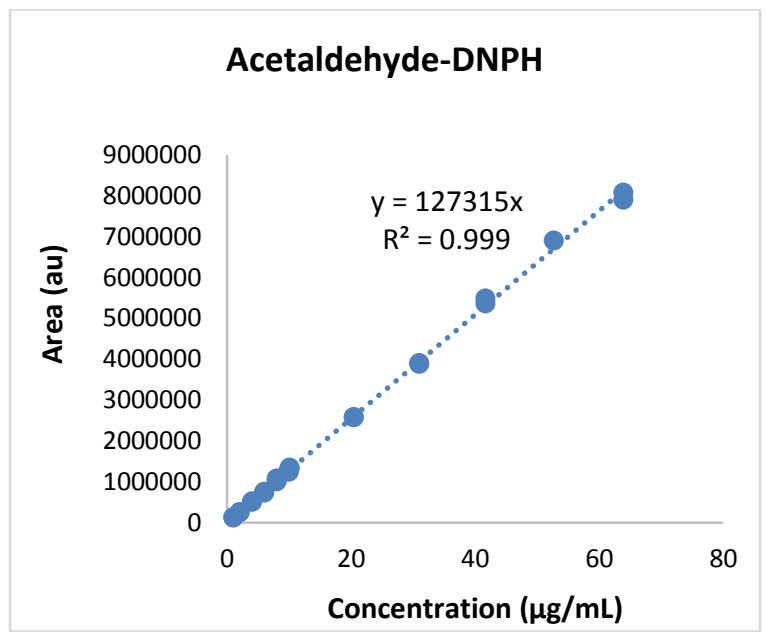

Figure S2. Acetaldehyde-DNPH calibration curve for HPLC analysis. LOD was $0.0488 \mathrm{mM}$. 


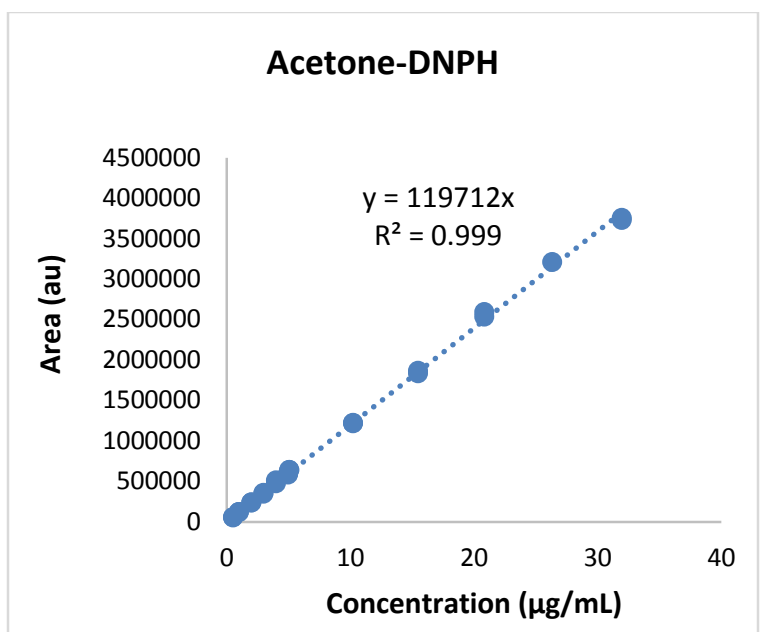

Figure S3. Acetone-DNPH calibration curve for HPLC analysis. LOD was $0.0184 \mathrm{mM}$.

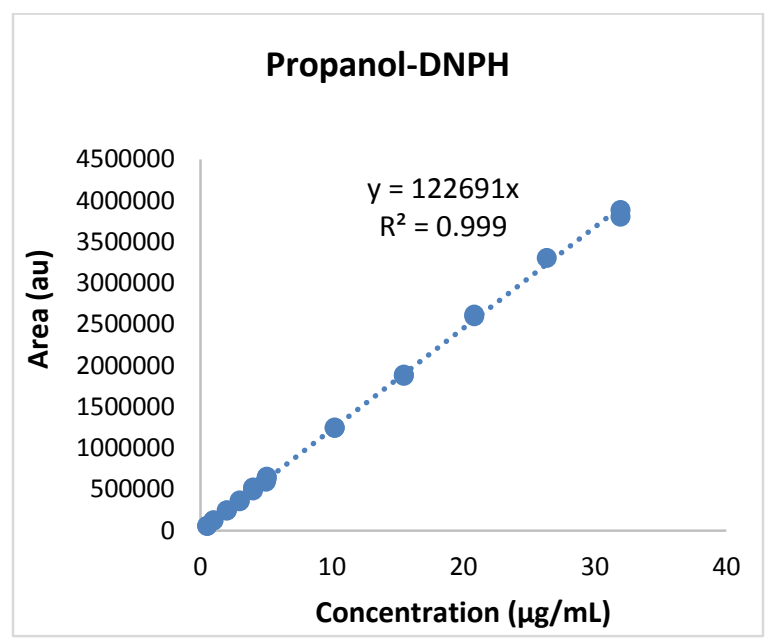

Figure S4. Propanol-DNPH calibration curve for HPLC analysis. LOD was $0.0171 \mathrm{mM}$.

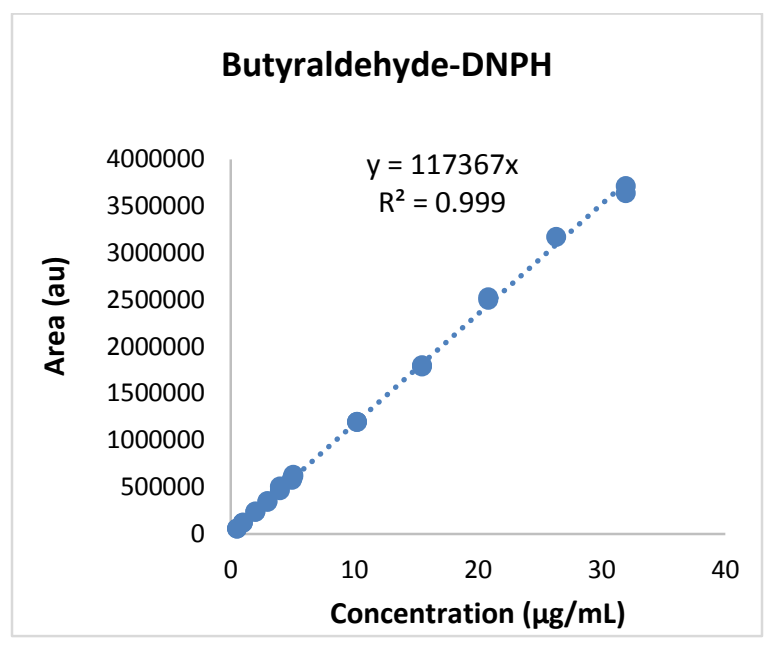

Figure S5. Butyraldehyde-DNPH calibration curve for HPLC analysis. LOD was $0.0154 \mathrm{mM}$ 


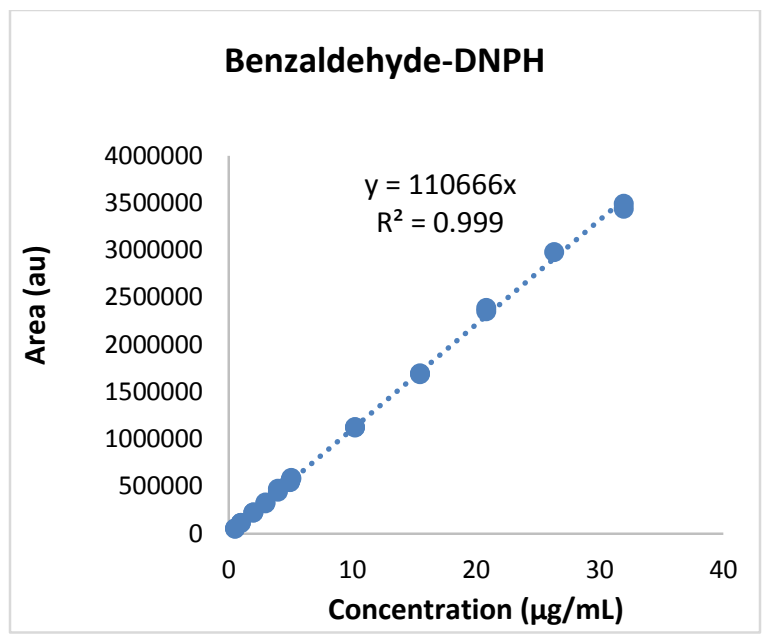

Figure S6. Benzaldehyde-DNPH calibration curve for HPLC analysis. LOD was $0.0101 \mathrm{mM}$

E-cigarette aerosol aldehyde concentration quantification and analysis.

Aldehyde concentration was reported as total analytes $(\mu \mathrm{g})$ per e-liquid

consumed (g). By normalizing the analyte concentration by e-liquid consumed we

eliminate the variability between individual puffs as well as individual user puffing

patterns. In addition, this normalizes for power, since an increase in power output is

proportional to an increase in e-liquid consumed, assuming proper wicking. This method

eliminates the need for power in a predictive model, further verified by Figure S7-S16. 
Table S3. Average concentrations of 6 target carbonyls generated from twelve e-cigarettes tested. The error represents one standard error of three or more independent collections.

\begin{tabular}{|l|c|c|c|}
\hline E-cigarette & Reference number & Total aldehydes $(\mu \mathrm{g} / \mathrm{g})$ & Standard error \\
\hline SMOK Baby Q2 & EC1 & 2513.3 & 655.05 \\
\hline SMOK Baby X4 & EC2 & 160.3 & 5.26 \\
\hline Eleaf iJust 2 Mini & EC3 & 1234.5 & 520.23 \\
\hline Joyetech Cubis & EC4 & 234.3 & 88.76 \\
\hline Aspire Nautilus Mini & EC5 & 167.2 & 6.20 \\
\hline Kanger Protank 2 & EC6 & 1256.1 & 738.63 \\
\hline Kanger Subtank Mini (15W) & EC7 & 177.3 & 40.74 \\
\hline Halo Triton 2 (0.75 $\Omega)$ & EC8 & 245.2 & 86.83 \\
\hline Halo Triton 2 (1.5 $\Omega)$ & EC9 & 2002.4 & 993.40 \\
\hline Geekvape Zeus RTA dual & EC10 & 95.4 & 48.97 \\
\hline JUUL & EC11 & 472.2 & 175.69 \\
\hline Kanger Subtank Mini (26W) & EC12 & 1133.6 & 918.49 \\
\hline
\end{tabular}

Table S4. Average mass e-liquid consumed during each independent collection from twelve coils tested. Values represented as grams e-liquid per single puff.

\begin{tabular}{|l|c|ccc|}
\hline E-cigarette & Reference number & \multicolumn{3}{|c|}{ Average e-liquid consumed (g/puff) } \\
\hline SMOK Baby Q2 & EC1 & 0.03403 & \pm & 0.00204 \\
\hline SMOK Baby X4 & EC2 & 0.03022 & \pm & 0.00050 \\
\hline Eleaf iJust 2 Mini & EC3 & 0.04166 & \pm & 0.00505 \\
\hline Joyetech Cubis & EC4 & 0.01658 & \pm & 0.00081 \\
\hline Aspire Nautilus Mini & EC5 & 0.01241 & \pm & 0.00047 \\
\hline Kanger Protank 2 & EC6 & 0.00876 & \pm & 0.00131 \\
\hline Kanger Subtank Mini (15W) & EC7 & 0.01146 & \pm & 0.00124 \\
\hline Halo Triton 2 (0.75 $\Omega)$ & EC8 & 0.02237 & \pm & 0.00203 \\
\hline Halo Triton 2 (1.5 $\Omega$ ) & EC9 & 0.01772 & \pm & 0.00376 \\
\hline Geekvape Zeus RTA dual & EC10 & 0.01078 & \pm & 0.00257 \\
\hline JUUL & EC11 & 0.00135 & \pm & 0.00152 \\
\hline Kanger Subtank Mini (26W) & EC12 & 0.02636 & \pm & 0.00273 \\
\hline
\end{tabular}

\section{Comparison of alternative e-cigarette models.}

Alternative models were tested and compared to model 1. Each model was

plotted against experimental total carbonyl yields from EC1-9 and analyzed by 
exponential regression. Using the equation of the regression line predicted values of total carbonyl yields were calculated for EC1-12 and plotted against experimental yields.
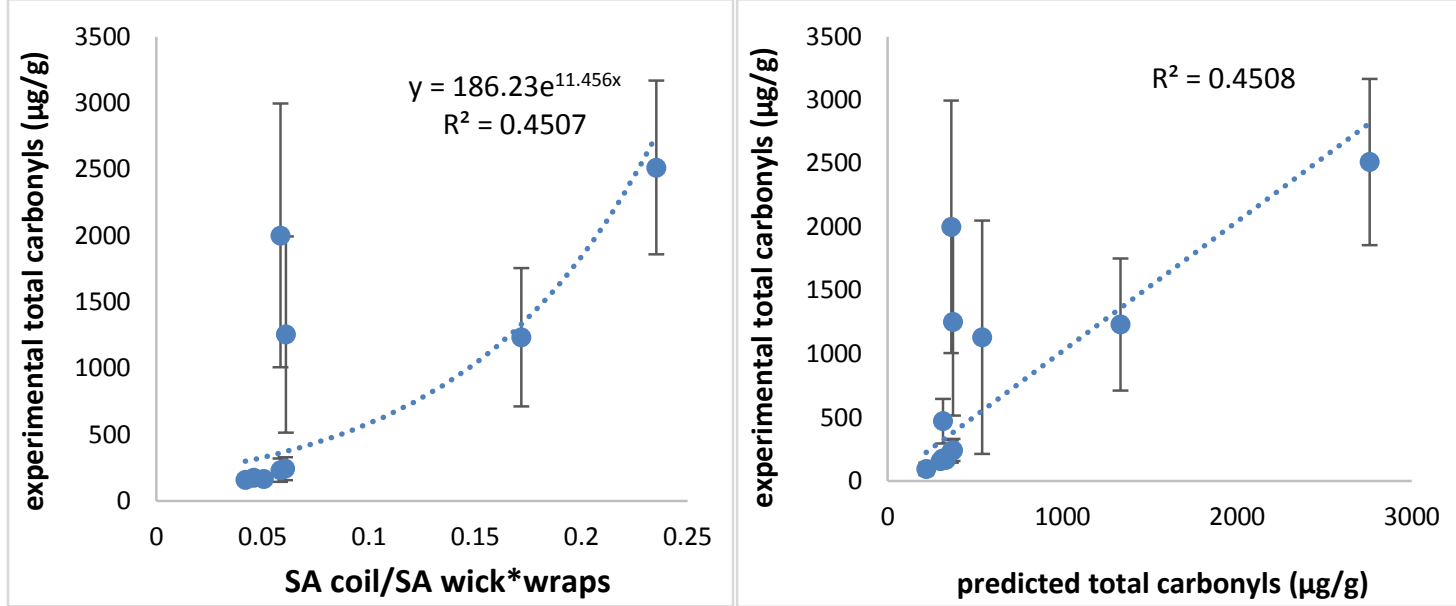

Figure S7. Regression analysis of alternative model (SA coil/SA wick*wraps) (left) and subsequent predictability (right).
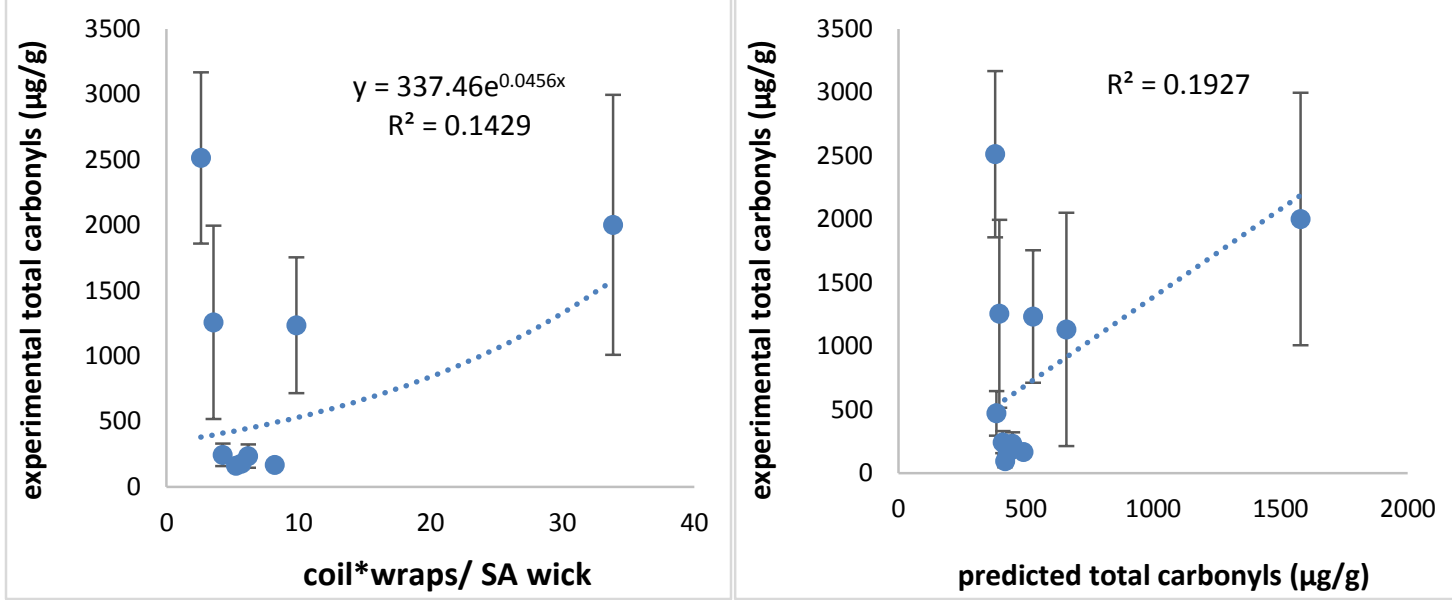

Figure S8. Regression analysis of alternative model (coil*wraps/SA wick) (left) and subsequent predictability (right). 

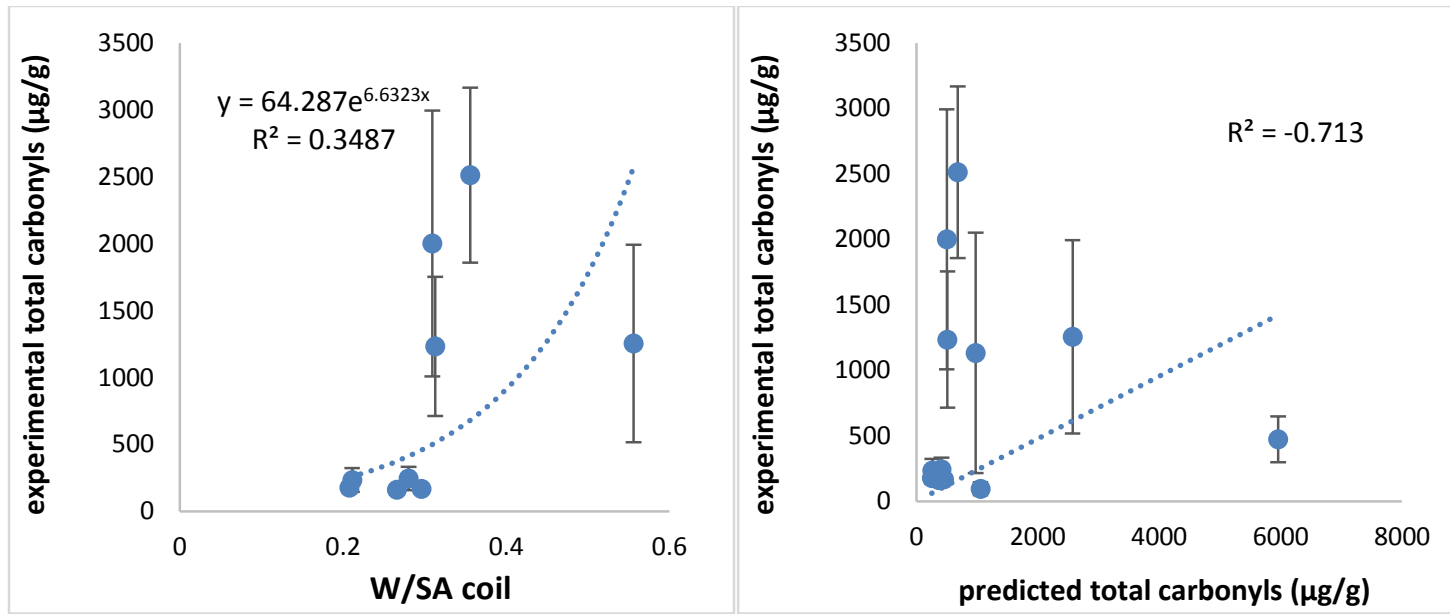

Figure S9. Regression analysis of alternative model (Watts/SA coil) (left) and subsequent predictability (right).

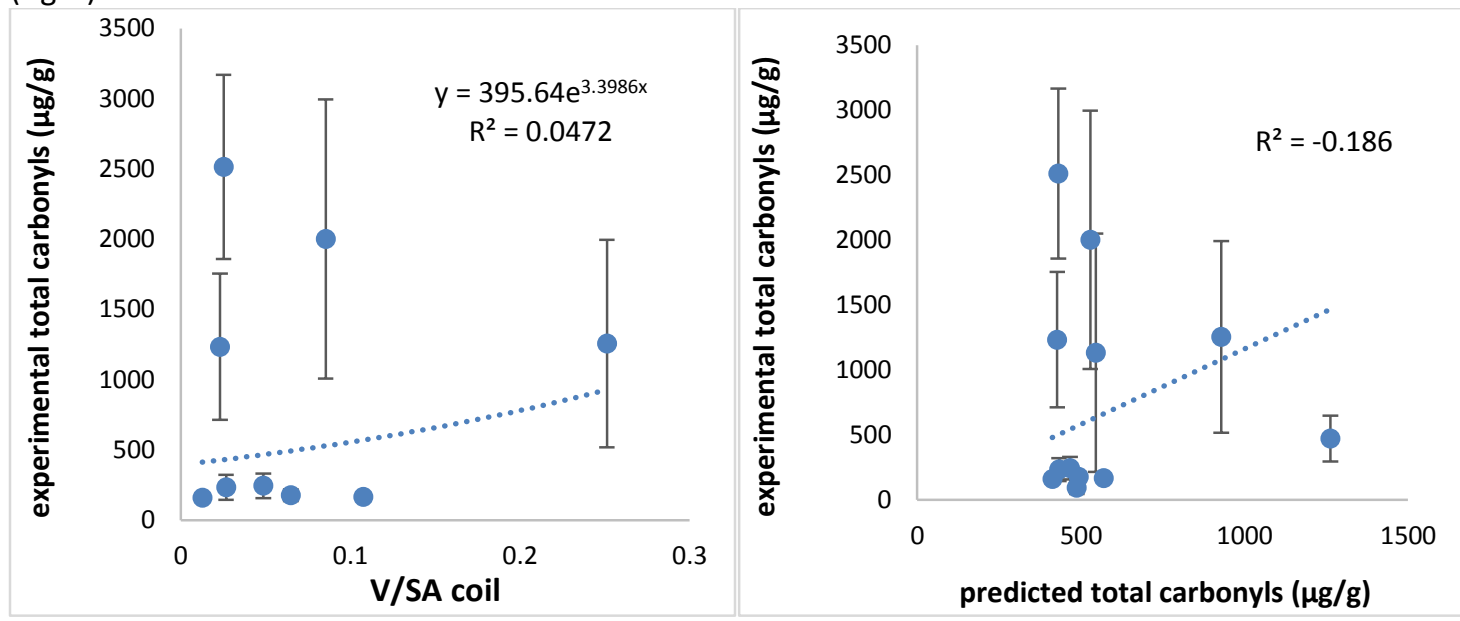

Figure S10. Regression analysis of alternative model (Volts/SA coil) (left) and subsequent predictability (right).
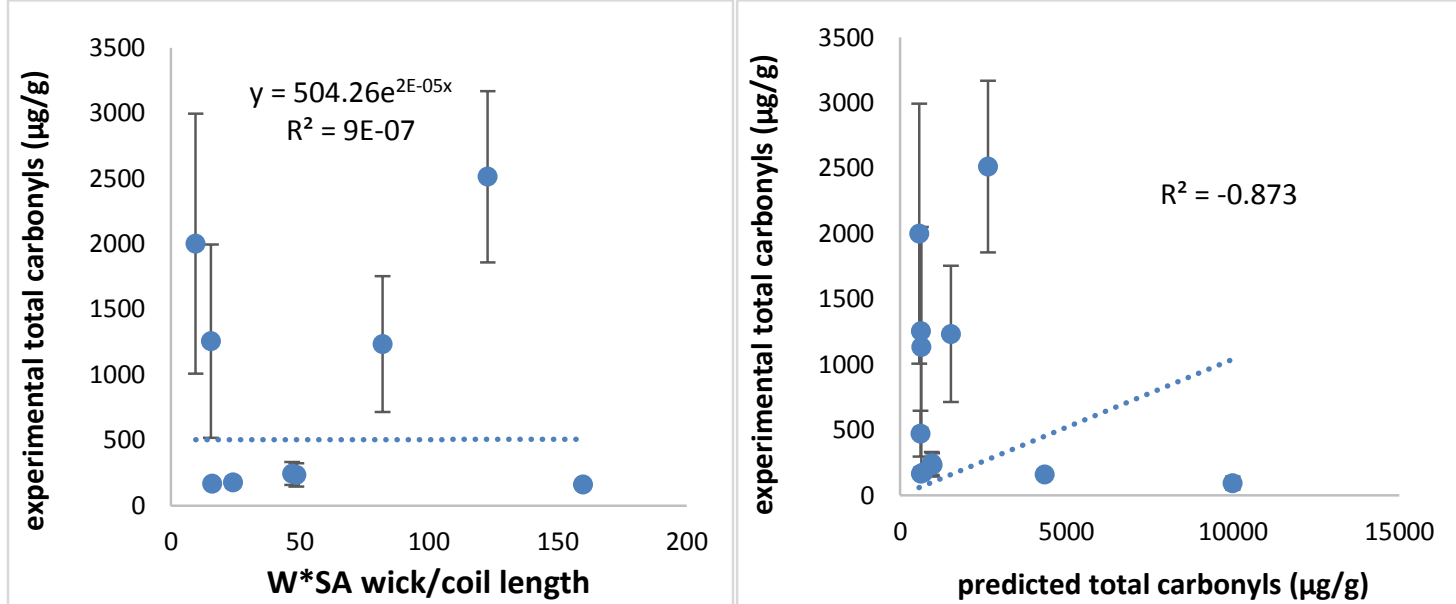

Figure S11. Regression analysis of alternative model (Watts*SA wick/coil length) (left) and subsequent predictability (right). 

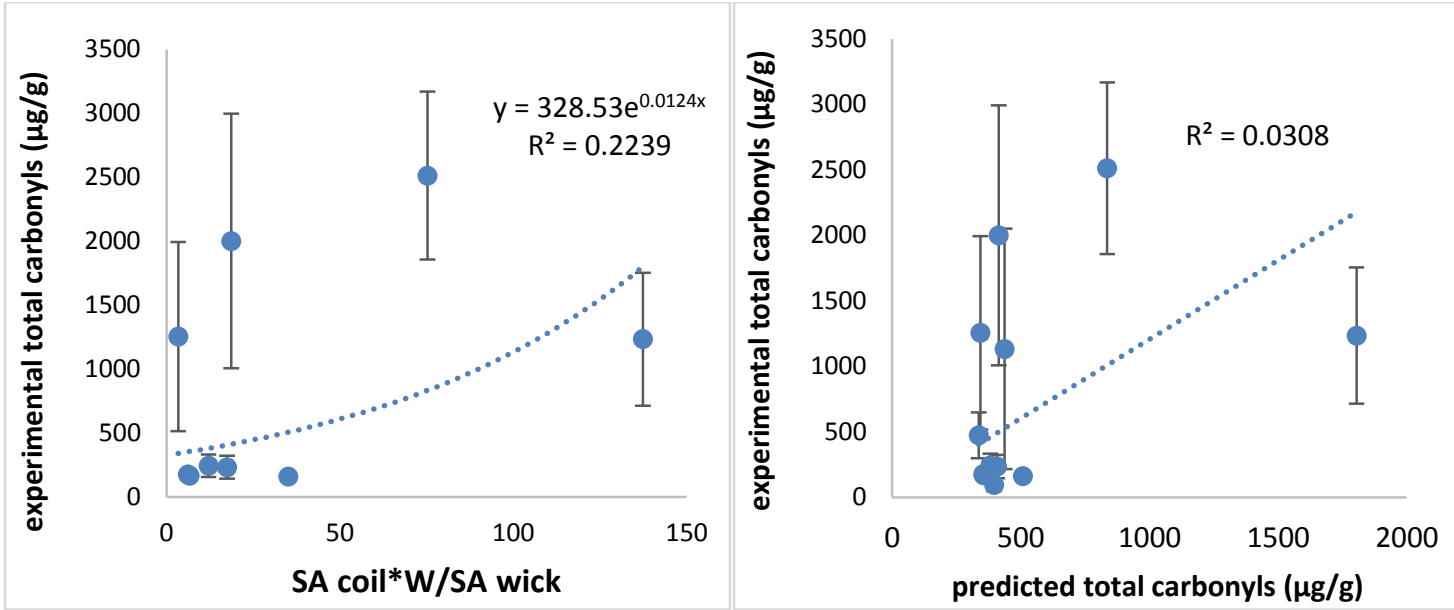

Figure S12. Regression analysis of alternative model (SA coil*Watts/SA wick) (left) and subsequent predictability (right).

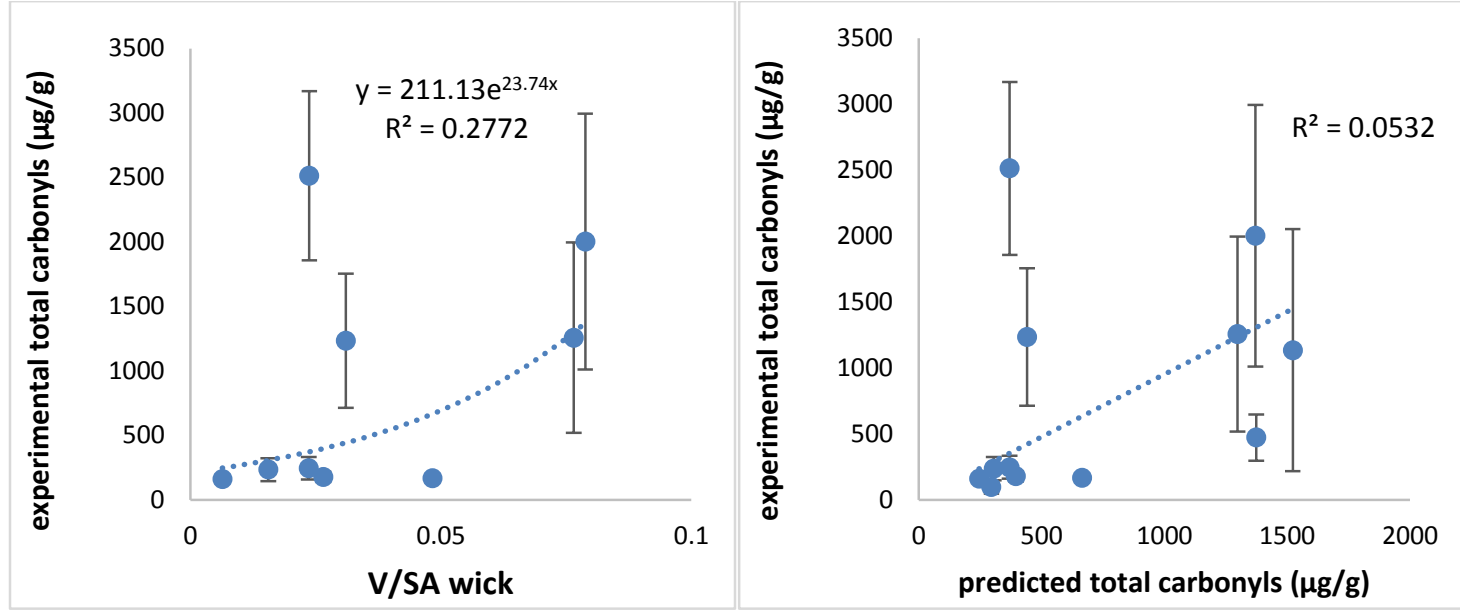

Figure S13. Regression analysis of alternative model (Volts/SA wick) (left) and subsequent predictability (right).
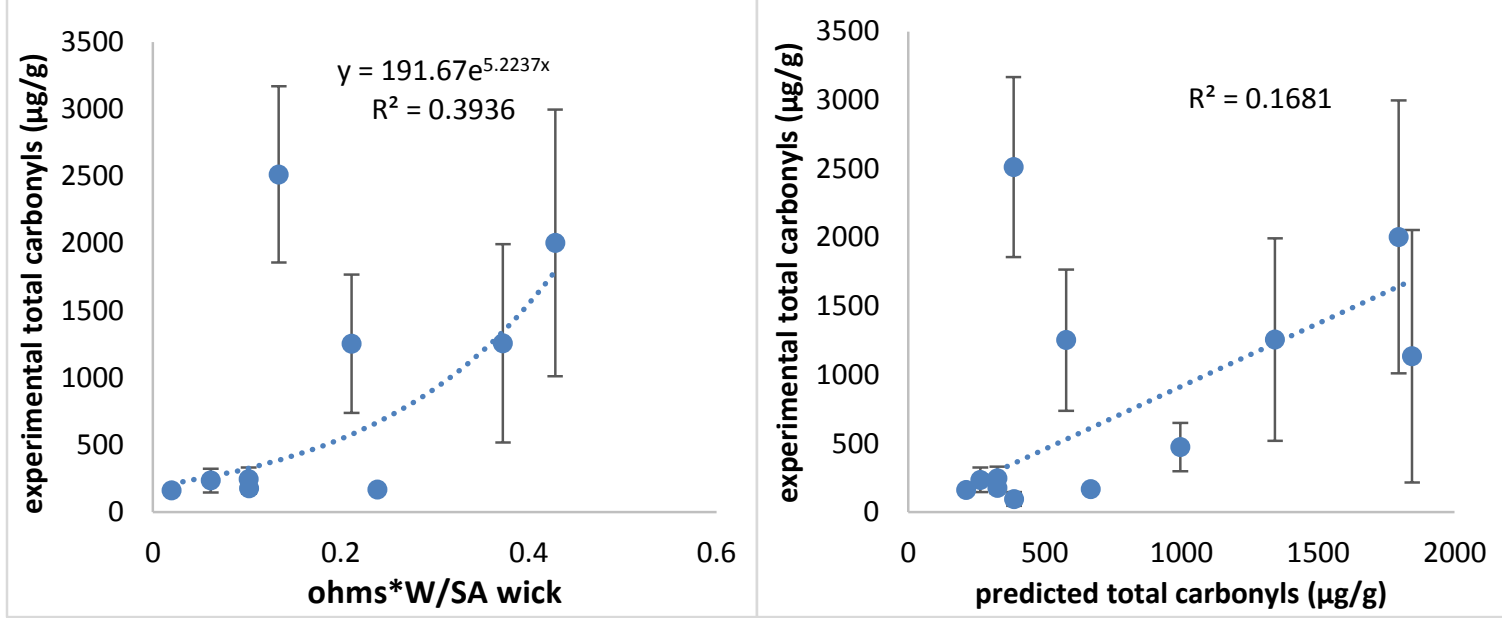

Figure S14. Regression analysis of alternative model (ohms*Watts/SA wick) (left) and subsequent predictability (right). 

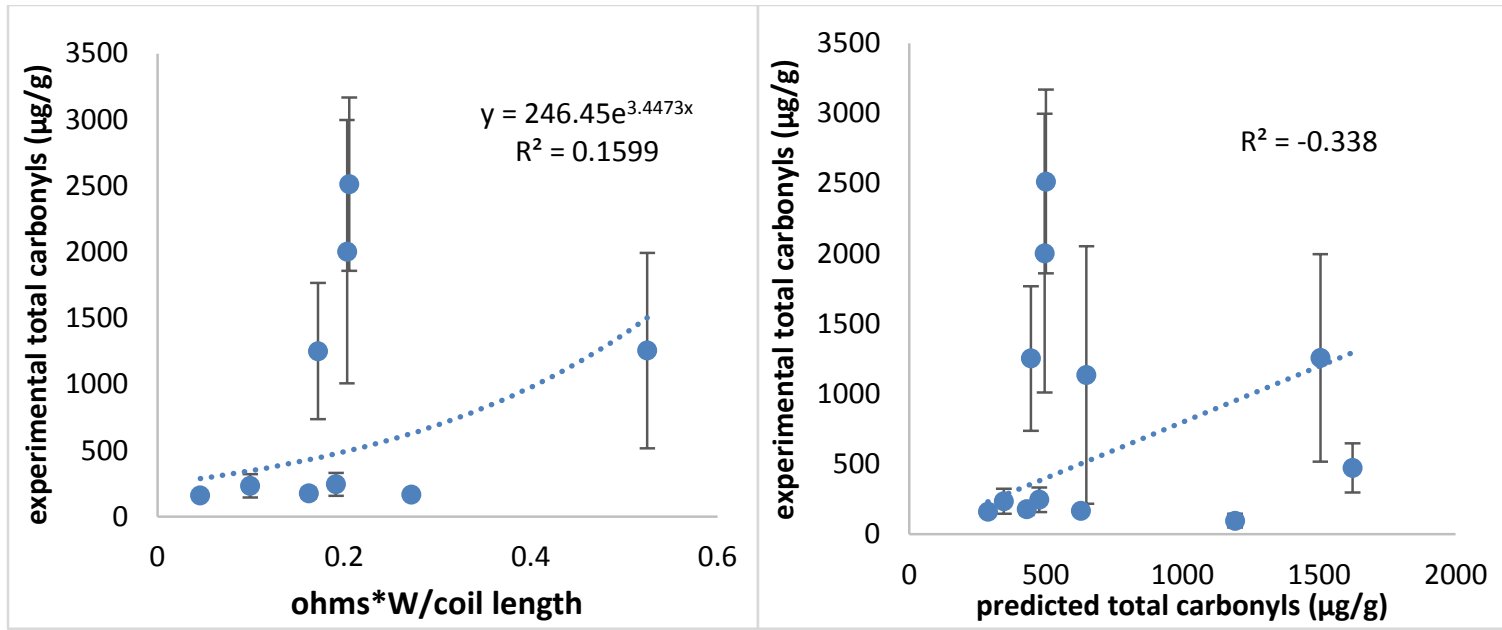

Figure S15. Regression analysis of alternative model (ohms*Watts/coil length) (left) and subsequent predictability (right).

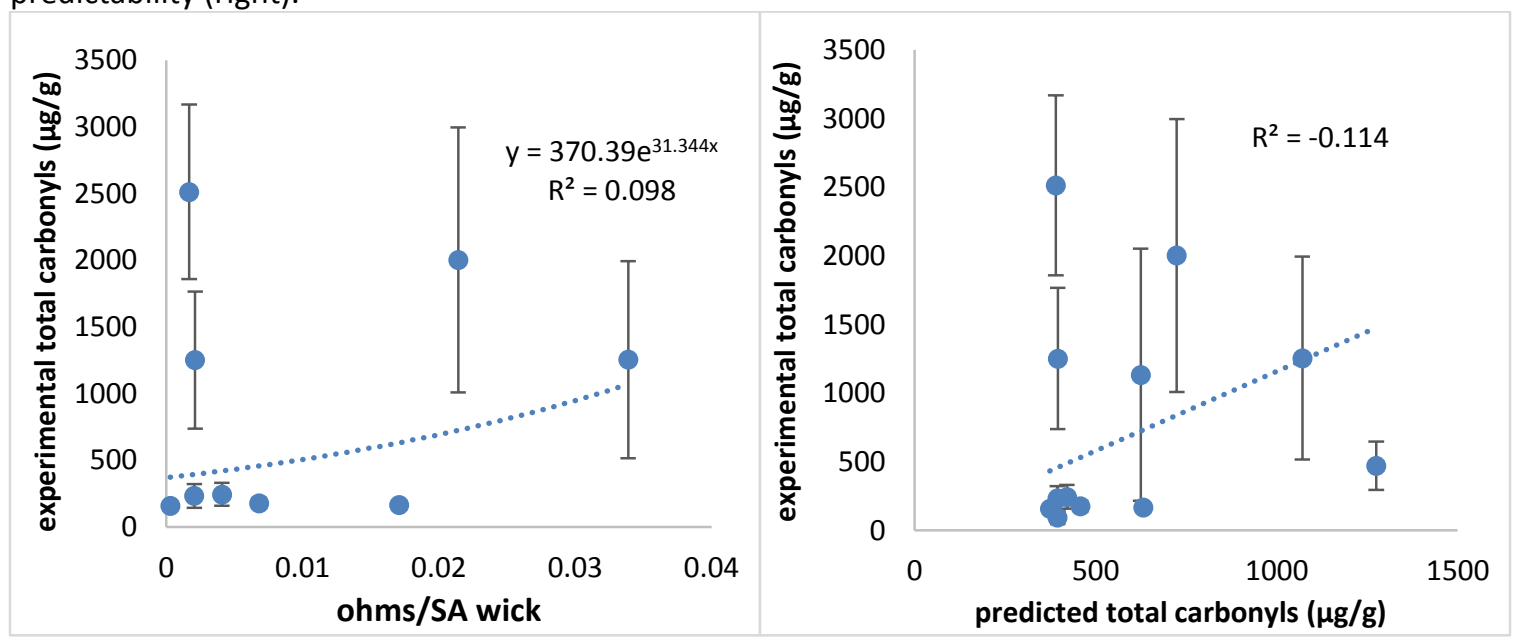

Figure S16. Regression analysis of alternative model (ohms/SA wick) (left) and subsequent predictability (right).

\section{REFERENCES}

1. Hess, C. A.; Olmedo, P.; Navas-Acien, A.; Goessler, W.; Cohen, J. E.; Rule, A. M., E-Cigarettes as a Source of Toxic and Potentially Carcinogenic Metals. Environmental Research 2017, 152, 221-225.

2. Korzun, T.; Lazurko, M.; Munhenzva, I.; Barsanti, K. C.; Huang, Y.; Jensen, R. P.; Escobedo, J. O.; Luo, W.; Peyton, D. H.; Strongin, R. M., E-Cigarette Airflow Rate Modulates Toxicant Profiles and Can Lead to Concerning Levels of Solvent Consumption. ACS Omega 2018, 3 (1), 30-36.

3. Martínez-Sánchez, J. M.; Ballbè, M.; Pérez-Ortuño, R.; Fu, M.; Sureda, X.; Pascual, J. A.; Peruga, A.; Fernández, E., Secondhand Exposure to Aerosol from Electronic Cigarettes: Pilot Study of Assessment of Tobacco-Specific Nitrosamine (Nnal) in Urine. Gaceta Sanitaria 2018.

4. Beauval, N.; Verrièle, M.; Garat, A.; Fronval, I.; Dusautoir, R.; Anthérieu, S.; Garçon, G.; Lo-Guidice, J.M.; Allorge, D.; Locoge, N., Influence of Puffing Conditions on the Carbonyl Composition of E-Cigarette Aerosols. International Journal of Hygiene and Environmental Health 2019, 222 (1), 136-146.

5. Jensen, R. P.; Strongin, R. M.; Peyton, D. H., Solvent Chemistry in the Electronic Cigarette Reaction Vessel. Scientific Reports 2017, 7, 42549. 
6. Geiss, O.; Bianchi, I.; Barrero-Moreno, J., Correlation of Volatile Carbonyl Yields Emitted by E-Cigarettes with the Temperature of the Heating Coil and the Perceived Sensorial Quality of the Generated Vapours. International Journal of Hygiene and Environmental Health and Preventive Medicine 2016, 219 (3), 268-277.

7. Zhao, T.; Shu, S.; Guo, Q.; Zhu, Y., Effects of Design Parameters and Puff Topography on Heating Coil Temperature and Mainstream Aerosols in Electronic Cigarettes. Atmospheric Environment 2016, 134, 61-69.

8. Zhao, J.; Nelson, J.; Dada, O.; Pyrgiotakis, G.; Kavouras, I. G.; Demokritou, P., Assessing Electronic Cigarette Emissions: Linking Physico-Chemical Properties to Product Brand, E-Liquid Flavoring Additives, Operational Voltage and User Puffing Patterns. Inhalation Toxicology 2018, 30 (2), 78-88.

9. Uchiyama, S.; Senoo, Y.; Hayashida, H.; Inaba, Y.; Nakagome, H.; Kunugita, N., Determination of Chemical Compounds Generated from Second-Generation E-Cigarettes Using a Sorbent Cartridge Followed by a Two-Step Elution Method. Analytical Sciences 2016, 32 (5), 549-555.

10. Saliba, N. A.; El Hellani, A.; Honein, E.; Salman, R.; Talih, S.; Zeaiter, J.; Shihadeh, A., Surface Chemistry of Electronic Cigarette Electrical Heating Coils: Effects of Metal Type on Propylene Glycol Thermal Decomposition. Journal of Analytical and Applied Pyrolysis 2018, 134, 520-525.

11. El-Hellani, A.; Salman, R.; El-Hage, R.; Talih, S.; Malek, N.; Baalbaki, R.; Karaoghlanian, N.; Nakkash, R.; Shihadeh, A.; Saliba, N. A., Nicotine and Carbonyl Emissions from Popular Electronic Cigarette Products: Correlation to Liquid Composition and Design Characteristics. Nicotine and Tobacco Research 2018, 20 (2), 215-223.

12. Breland, A.; Soule, E.; Lopez, A.; Ramôa, C.; El-Hellani, A.; Eissenberg, T., Electronic Cigarettes: What Are They and What Do They Do? Annals of the New York Academy of Sciences 2017, 1394 (1), 5-30.

13. Robinson, R. J.; Eddingsaas, N. C.; DiFrancesco, A. G.; Jayasekera, S.; Hensel, E. C., Jr., A Framework to Investigate the Impact of Topography and Product Characteristics on Electronic Cigarette Emissions. PLOS ONE 2018, 13 (11), e0206341.

14.Talih, S.; Salman, R.; Karaoghlanian, N.; El-Hellani, A.; Saliba, N.; Eissenberg, T.; Shihadeh, A., "Juice Monsters": Sub-Ohm Vaping and Toxic Volatile Aldehyde Emissions. Chemical Research in Toxicology 2017, 30 (10), 1791-1793.

15. Malek, N.; Nakkash, R.; Talih, S.; Lotfi, T.; Salman, R.; Karaoghlanian, N.; El-Hage, R.; Saliba, N.; Eissenberg, T.; Shihadeh, A., A Transdisciplinary Approach to Understanding Characteristics of Electronic Cigarettes. Tobacco Regulatory Science 2018, 4 (3), 47-72.

16. Gillman, I. G.; Kistler, K. A.; Stewart, E. W.; Paolantonio, A. R., Effect of Variable Power Levels on the Yield of Total Aerosol Mass and Formation of Aldehydes in E-Cigarette Aerosols. Regulatory Toxicology and Pharmacology 2016, 75, 58-65.

17.Vreeke, S.; Korzun, T.; Luo, W.; Jensen, R. P.; Peyton, D. H.; Strongin, R. M., Dihydroxyacetone Levels in Electronic Cigarettes: Wick Temperature and Toxin Formation. Aerosol Science and Technology 2018, 52 (4), 370-376.

18. Luikov, A. V., Heat and Mass Transfer in Capillary-Porous Bodies. In Advances in Heat Transfer, Irvine, T. F.; Hartnett, J. P., Eds. Elsevier: 1964; Vol. 1, pp 123-184.

19. Özışık, M. N., Heat Transfer: A Basic Approach. McGraw-Hill: 1985.

20.Zinn, S.; Semiatin, S. L., Elements of Induction Heating: Design, Control, and Applications. ASM International: 1988; Vol. 516, p 338-5151.

21. EPA, U. S., Method 8315a (Sw-846): Determination of Carbonyl Compounds by High Performance Liquid Chromatography (Hplc). Washington, DC, 1996.

22. Atkins, P.; de Paula, J., Atkins' Physical Chemistry. OUP Oxford: 2010.

23. Reilly, S. M.; Bitzer, Z. T.; Goel, R.; Trushin, N.; Richie, J. J. P., Free Radical, Carbonyl, and Nicotine Levels Produced by Juul Electronic Cigarettes. Nicotine and Tobacco Research 2018, nty221-nty221.

24. Hair, J.; Sarstedt, M.; Hopkins, L.; Kuppelwieser, V., Partial Least Squares Structural Equation Modeling (PIs-Sem): An Emerging Tool for Business Research. European Business Review 2014, 26, 106-121. 
25. Sleiman, M.; Logue, J. M.; Montesinos, V. N.; Russell, M. L.; Litter, M. I.; Gundel, L. A.; Destaillats, H., Emissions from Electronic Cigarettes: Key Parameters Affecting the Release of Harmful Chemicals. Environmental Science \& Technology 2016, 50 (17), 9644-9651.

26. Kim, K.-H., Mass Change Tracking Approach as Collection Guidelines for Aerosol and Vapor Samples Released During E-Cigarette Smoking. Anal. Methods 2016, 8.

27. Soulet, S.; Duquesne, M.; Toutain, J.; Pairaud, C.; Lalo, H., Influence of Coil Power Ranges on the ELiquid Consumption in Vaping Devices. International Journal of Environmental Research and Public Health 2018, 15 (9), 1853.

28. Vreeke, S.; Peyton, D. H.; Strongin, R. M., Triacetin Enhances Levels of Acrolein, Formaldehyde Hemiacetals, and Acetaldehyde in Electronic Cigarette Aerosols. ACS Omega 2018, 3 (7), 7165-7170.

29. Coresta. Coresta Recommended Method No 74. Determination of Selected Carbonyls in Mainstream Cigarette Smoke by Hplc.

https://www.coresta.org/sites/default/files/technical_documents/main/CRM_74-updateFeb2018.pdf. 
Chapter 4: Triacetin Enhances Levels of Acrolein, Formaldehyde Hemiacetals and Acetaldehyde in Electronic Cigarette Aerosols

Vreeke, S.; Peyton, D. H.; Strongin, R. M., Triacetin Enhances Levels of Acrolein, Formaldehyde Hemiacetals, and Acetaldehyde in Electronic Cigarette Aerosols. ACS Omega 2018, 3 (7), 7165-7170. The following paper has been modified.

\section{ABSTRACT}

The health effects of inhaled electronic cigarette (e-cigarette) flavoring compounds are largely unknown. Earlier reports of their chemical reactivity have been conflicting, with some claiming, for example, that the degradation of flavoring chemicals in e-cigarettes to aldehydes is statistically insignificant. It is thus important to understand how these molecules react to afford enhanced aerosol products. The purpose of the current study was to investigate the origin of formaldehyde, acrolein and acetaldehyde in e-cigarettes that contain the popular additive, triacetin (TA). By using carbon-13 labeling and a combination of ${ }^{1} \mathrm{H}$ NMR and ${ }^{13} \mathrm{C}$ NMR, we were able to identify that ester hydrolysis of TA occurs to form acetic acid (HOAc) during aerosolizaton. The released HOAc acts as a catalyst in the degradation of propylene glycol (PG) and glycerol $(G L)$, increasing the formation of formaldehyde hemiacetals, acrolein and acetaldehyde. A solution of $10 \%$ TA in 1:1 PG/GL e-liquid was aerosolized using two different ecigarettes at two wattages. Each device exhibited a significant increase in aldehyde levels, of up to $185 \%$ compared to the aerosol from a $1: 1 \mathrm{PG} / \mathrm{GL}$ e-liquid. In addition, the GL formaldehyde hemiacetal was more predominant within the presence of HOAC, indicating that GL may be relatively more prone to degradation from protonation. 


\section{INTRODUCTION}

There are approximately 3 million adolescents using electronic cigarettes (ecigarettes) in the US. ${ }^{1}$ Moreover, e-cigarette usage has been reported to be a major risk factor among youth for traditional cigarette usage. ${ }^{2}$ Flavors are well-known to be a major contributing factor to the appeal of e-cigarettes, ${ }^{3-4}$ particularly among young people. ${ }^{5-6}$ Among US current e-cigarette users, $82 \%$ of young people and $70 \%$ of older adults use flavored e-cigarette liquid (e-liquid). ${ }^{7}$ The FDA has yet to pass federal regulation on e-liquid flavoring chemicals. ${ }^{8}$ Research is needed to better understand the identity, levels, reactivity and inhalation toxicology of specific flavor compounds.

E-liquid is typically composed of a mixture of carrier solvents, nicotine, and flavoring compounds. Many flavorings are listed as "generally recognized as safe" (GRAS) by the FDA as food additives for ingestion. However, their inhalation toxicity is largely unknown. Despite this, some vaping industry websites claim that e-liquids are safe for inhalation due to their GRAS rating. ${ }^{9-10}$

In addition to the lack of inhalation toxicity data, the chemical reactivity of the flavoring compounds used in e-cigarettes has also not been extensively investigated. Previous studies have shown that the aerosolization of flavored e-liquid increases toxic aldehyde production, ${ }^{11}$ oxidative stress $s^{12-13}$ and inflammatory responses. ${ }^{14-15}$ Khlystov and Samburova compared the aldehyde production of flavored e-liquid to that of the aerosol derived from carrier e-liquid (propylene glycol and glycerol, PG/GL). They identified a direct relationship between enhanced aldehyde levels and flavor compound 
concentration. ${ }^{11}$ Others have found that different commercial e-liquid flavoring formulations produced varying aerosol product profiles. ${ }^{16-17}$ However, to date, apart from the determination of sugar-derived furans in e-cigarette aerosols, ${ }^{18}$ there have been no reports focusing on how aerosol products derive from flavoring additives. For example, it is not known if enhanced levels of aldehydes derive directly from the flavoring molecules themselves or if flavorings promote the degradation of other eliquid components such as the solvents PG/GL. Herein, we used carbon-13 labeling to unambiguously determine the origin of enhanced aldehyde levels from a relatively common e-liquid additive, triacetin (TA), the triester of glycerol (i.e., glycerin triacetate, 1,2,3-triacetoxypropane). In addition to e-cigarette products, TA is also found in traditional cigarettes and cigars. ${ }^{19}$

TA is mainly used to enhance the overall flavor of the e-cigarette aerosol. It has become popular in the 'do-it-yourself' community due to its ability to lessen the "bite". ${ }^{20}$ Manufactures are not required to report TA's presence or levels in e-liquids, so its abundance in e-liquids is largely unknown. However, we found three manufacturer websites that do report TA (Table 1, see also Table S3 in Supporting Information). Importantly, some companies have also begun to use it as a replacement solvent for PG. ${ }^{21}$

Table 1. Triacetin reported in various e-liquid flavors.

\begin{tabular}{|l|c|c|c|}
\hline Vendor & $\begin{array}{c}\text { Flavors which are } \\
\text { reported to contain TA }\end{array}$ & Total flavors available & Frequency (\%) \\
\hline The Flavor Apprentice (TFA) & 20 & 330 & 6.1 \\
\hline Flavor West & 24 & 340 & 7.1 \\
\hline Simply Flavors & 52 & 148 & 35.1 \\
\hline
\end{tabular}




\section{RESULTS AND DISCUSSION}

Determination of the aerosol product profiles. The two e-cigarette devices EC1 and EC2 were chosen to represent different coil options, namely a sub-ohm vertical coil (EC1) and a horizontal coil (EC2) ${ }^{22}$. Each was tested at two battery power settings that were chosen from self-described user preferences (Supporting Information) that were also within the manufacturers' recommended ranges. In order to determine the origin of aldehyde aerosol products from the TA-containing e-liquid, we synthesized ${ }^{13} \mathrm{C}$ labeled TA from the reaction of GL and acetic anhydride. Compound 4 (Figure 1) was derived from ${ }^{13} \mathrm{C}$-labeled $\mathrm{GL}$, and compound 5 (Figure 1) from ${ }^{13} \mathrm{C}$-labeled acetic anhydride. The use of ${ }^{13} \mathrm{C}$-labeled TA molecules allowed us to determine whether TA forms aldehydes directly via its thermal decomposition (Scheme 1), or if TA plays a different role.

TA has been reported ${ }^{23}$ to degrade under thermal conditions to form acetic acid (HOAC), formaldehyde, acrolein (2) and acetaldehyde (3), as shown in Scheme 1. The IARC (International Agency for Research on Cancer) reports formaldehyde as a known carcinogen, and acetaldehyde as a possible carcinogen. ${ }^{24}$ Acrolein is a notorious air pollutant. It has been shown to cause a decrease in respiratory rates and to cause intense eye and respiratory irritation in humans. It has been shown to lead to inflammation, obstruction of the trachea and bronchi, and hemorrhaging in animals. ${ }^{25}$ Previously, 1-3 have been identified in the aerosols of e-cigarettes from the dehydration and oxidation of the e-liquid solvents. ${ }^{26}$ 


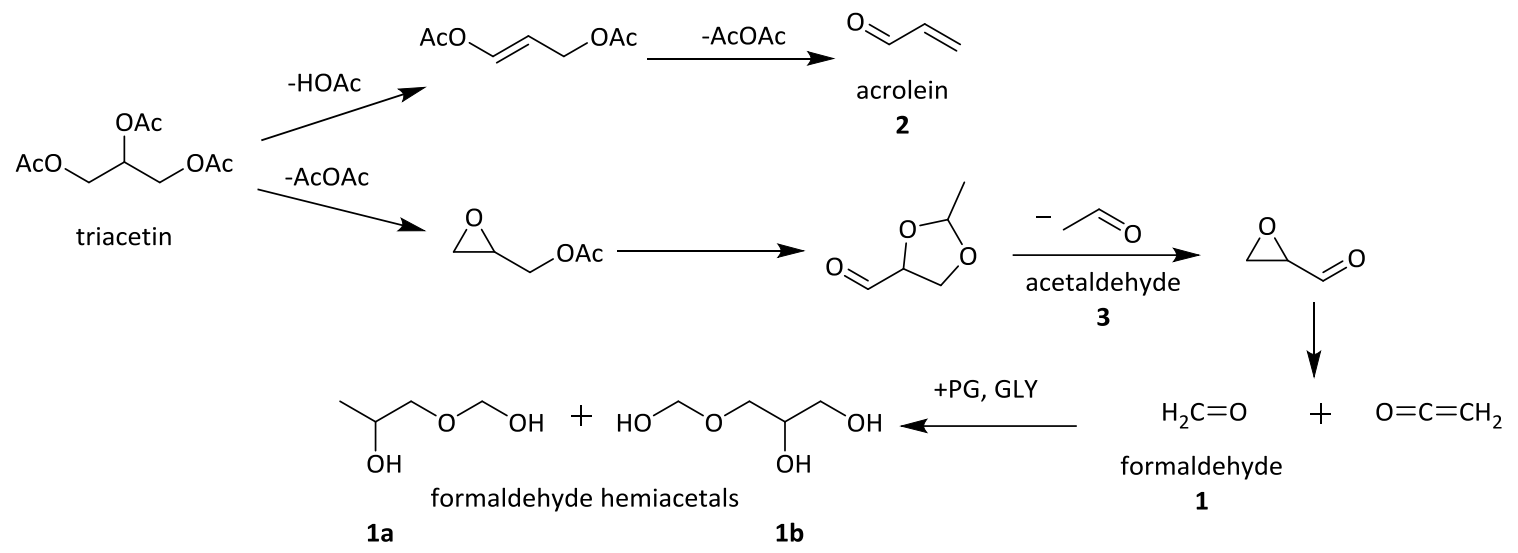

Scheme 1. Two pathways of triacetin (TA) proposed thermal degradation. TA forms acrolein, acetaldehyde, and formaldehyde. In e-cigarettes, formaldehyde further reacts with PG/GL to form formaldehyde hemiacetals. ${ }^{23,} 26$

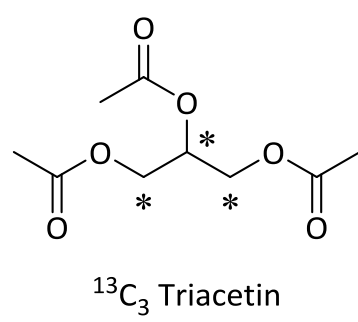

4

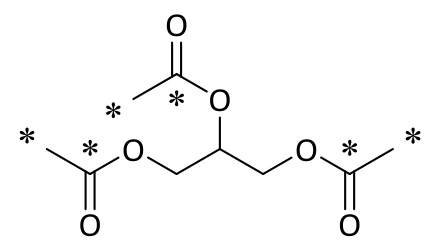

${ }^{13} \mathrm{C}_{6}$ Triacetin

5

Figure 1. Isotopically-labeled TA. TA derived from isotopically-labeled glycerol (4) and from isotopic labeled acetic anhydride (5).

Based on literature precedent, ${ }^{11,23}$ we anticipated an enhanced level of aldehyde byproducts in the aerosol derived from the flavored (i.e., TA-containing) e-liquid as compared to the aerosol from the e-liquid composed of PG/GL alone. Indeed, an overlay of the ${ }^{1} \mathrm{H}$ NMR spectra (Figure 2 ) of the aerosol derived from each type of eliquid clearly shows that the aerosol derived from the TA/PG/GL e-liquid contained higher levels of aldehydes 1a-b (as the formaldehyde hemiacetals), ${ }^{27}$ as well as $\mathbf{2}$ (acrolein) and $\mathbf{3}$ (acetaldehyde). 

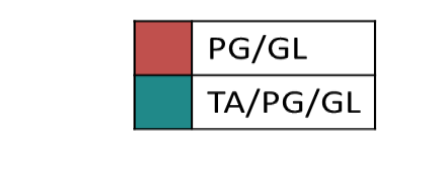
increases in $\mathbf{1} \mathbf{a}-\mathbf{b}$, as well as a detectable level of $\mathbf{2}$ in the aerosols. The relatively large error bars observed for the EC1 results are due to the fact that the relatively low levels of aldehydes produced were close to the limit of detection (LOD) of the NMR technique. Although sub-ohm devices typically produce lower concentrations of aerosol aldehyde products, they typically deliver much greater relative levels of PG and GL to the user. ${ }^{28}$ The EC2 device thus produced orders of magnitude greater levels of $\mathbf{1 a - 3}$ (at $11 \mathrm{~W}$ ) as compared to EC1 (no TA added). The inclusion of 10\% TA in the EC2 e-liquid led to product increases of $185 \%, 149 \%$ and $173 \%$, respectively. Using EC2 at $9 \mathrm{~W}$, aerosolized PG/GL alone afforded no detectable levels of 1a-3. However, the addition of $10 \%$ TA afforded 1a-b, $\mathbf{2}$ and $\mathbf{3}$ in measurable amounts of $0.09 \mathrm{mg} / \mathrm{g}, 0.004 \mathrm{mg} / \mathrm{g}$ and 0.003 $\mathrm{mg} / \mathrm{g}$, respectively. Thus, in the case of each e-cigarette, the e-liquids containing $10 \%$ TA exhibited a clear trend of enhanced relative levels of aldehydes compared to those containing only PG/GL. 

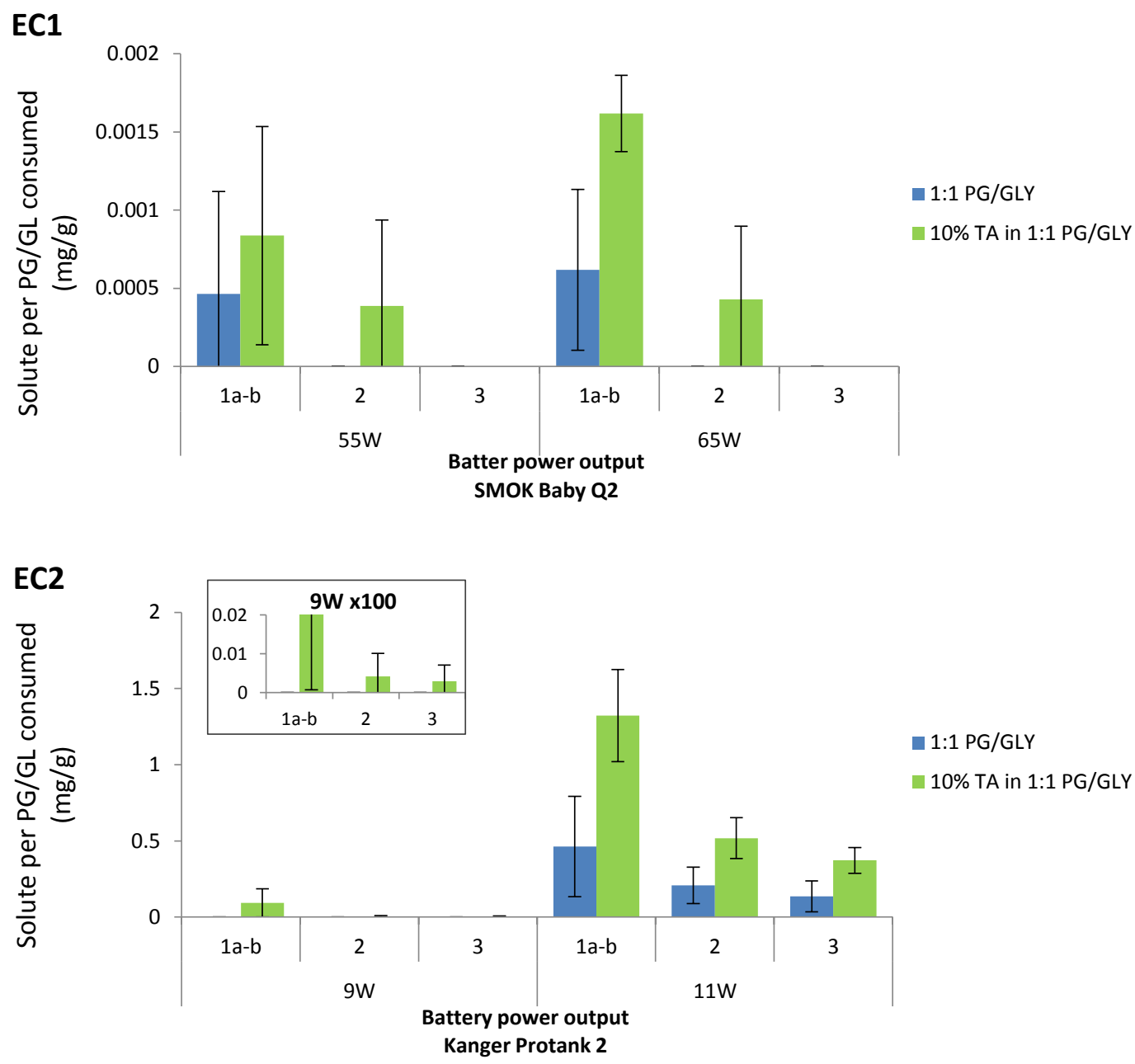

Figure 3. Concentrations of compounds $\mathbf{1 a - 3}$ in the aerosolization of PG/GL and increased levels with the addition of $10 \%$ TA. The blue bar is the amount of product (mg solute / $\mathrm{g}$ solution consumed) formed from aerosolized PG/GL e-liquid. The green bar represents the amount of products formed from aerosolized TA/PG/GL e-liquid. The inset displays the results from EC2 at $9 \mathrm{~W}$, expanded by 100 times. 1a, $\mathbf{1 b}, \mathbf{2}$ and $\mathbf{3}$ represent PG formaldehyde hemiacetal, GL formaldehyde hemiacetal, acrolein and acetaldehyde, respectively. Errors bars were calculated by one standard deviation. The enhanced concentration of 1a-3 was significant under all conditions except in the case of $\mathbf{1 a - b}$ generated by EC1 at 55W (see Supporting Information).

The origin of the enhanced product formation. In order to best inform manufactures, regulatory agencies, and users of potential health risks, it is imperative to determine the sources of increased levels of 1-3. Aerosols derived from PG/GL containing either $10 \%{ }^{13} \mathrm{C}_{3}$-TA (4) or $10 \%{ }^{13} \mathrm{C}_{6}$-TA (5) e-liquids were analyzed by ${ }^{1} \mathrm{H}$ NMR 
and ${ }^{13} \mathrm{C}$ NMR. The ${ }^{13} \mathrm{C}$ NMR of the $10 \%{ }^{13} \mathrm{C}_{6}$-TA (5, acetate-labeled) aerosol displays a prominent peak at $172 \mathrm{ppm}$ corresponding to the carbonyl peak of acetic acid. Importantly, this was the only carbon-13 labeled product observed, and it was not detectable in the $10 \%{ }^{13} \mathrm{C}_{3}$-TA-derived aerosol (4) spectrum. This indicates that ester hydrolysis of TA occurs to form HOAc during aerosolizaton. The formation of HOAc has the lowest energy barrier of the initial steps in the pyrolysis pathways of TA. ${ }^{23,} 29$<smiles>CC(=O)OCC1CC(C)C(=O)O1</smiles>

5

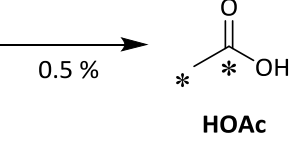

HOAC

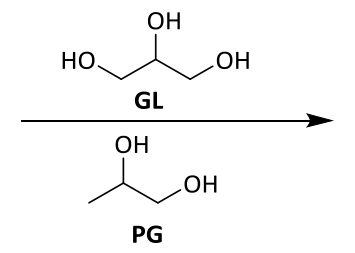

PG
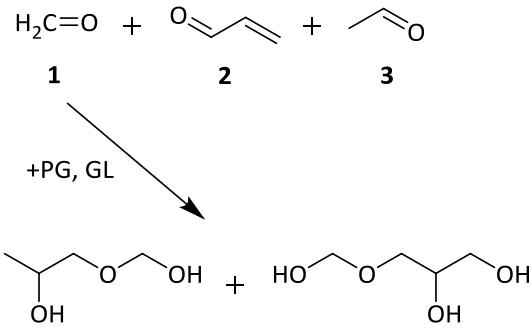

1a

1b

Scheme 2. TA in e-cigarettes leads to HOAc formation and subsequent protonation of PG/GL to catalyze the formation of products such as 1-3. This was confirmed via the use carbon-13 labeled triacetin as the predominant pathway observed under the conditions used herein.

Importantly, the degradation of PG and GL is well-known to be catalyzed by acid, and can lead to increased levels of $1-3 .^{30-31}$ Therefore, we can conclude that TA promotes aldehyde formation in e-cigarettes by producing HOAc that serves as a catalyst to enhance PG and GL reactivity (Scheme 2). This was confirmed by analyzing the aerosol derived from a control e-liquid consisting of a 1:1 PG/GL solution containing $0.5 \% \mathrm{HOAc}$, the level of HOAc produced in the experiments using the acetate-labeled TA, 5. Figure 4 reveals that the $\mathbf{1 a - 3}$ aerosol spectrum derived from the HOAc/PG/GL eliquid exhibits enhanced $\mathbf{1 a - 3}$ levels, as is consistent with the findings from the TA/PG/GL e-liquid (Figure 2). 


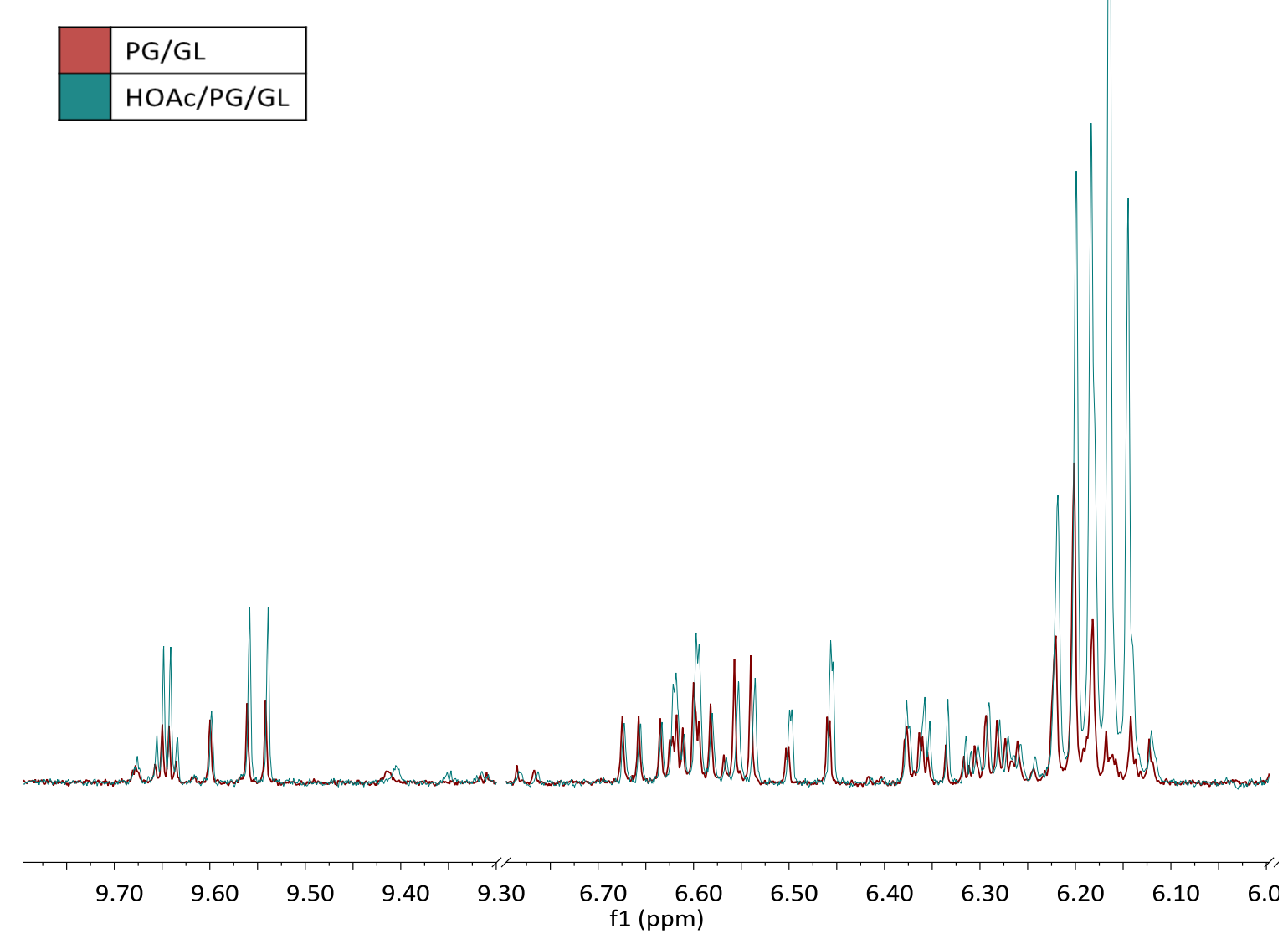

Figure 4. Overlay of ${ }^{1} \mathrm{H}$ NMR spectra of aerosolized (red) PG/GL e-liquid and (blue) 0.5\% HOAc/PG/GL eliquid. The triplet at $6.20 \mathrm{ppm}$ was identified as $\mathbf{1 a}$. The triplet at 6.17 was identified as $\mathbf{1 b}$. The doublet at $9.55 \mathrm{ppm}$, multiplet at $6.35 \mathrm{ppm}$, doublet at $6.47 \mathrm{ppm}$ and doublet at $6.625 \mathrm{ppm}$ was identified as 2 . The quartet at 9.65 ppm was identified as 3. Under the presence of HOAc there is a visible increase in 1a-3. These spectra were obtained using EC2 at $11 \mathrm{~W}$.

Finally, we found that the presence of HOAc leads to greater production of the GL-derived formaldehyde hemiacetal $\mathbf{1 b}$ as compared to the PG formaldehyde hemiacetal 1a (Figure 4). Protonation of GL has been reported to significantly lower the activation energy of its dehydration from $65-71 \mathrm{kcal} \mathrm{mol}^{-1}$ to $20-25 \mathrm{kcal} \mathrm{mol}^{-1}$. These results indicate that e-liquids containing TA and higher GL:PG ratios may be relatively more prone to the enhanced production of formaldehyde and related products. 


\section{CONCLUSION}

Herein, we have shown the addition of TA to PG/GL e-liquid affords higher levels of formaldehyde hemiacetals (1a-b), acrolein (2), and acetaldehyde (3) by releasing HOAc. This occurs via HOAc formation from TA followed by acid catalysis of PG/GL degradation. Although TA may be a direct source of aldehydes, we did not observe this under the conditions herein. One limitation of this study includes not quantifying gaseous formaldehyde due to the method of collection and analysis. However, our previous research has shown that an increase in $\mathbf{1} \mathbf{a}-\mathbf{b}$ concentration is proportional to an increase in gaseous formaldehyde (1) production. ${ }^{32}$ Further related investigations involving additional e-liquid formulations are currently under study in our labs.

\section{METHODS}

Electronic cigarette devices. Two devices were used for aerosolization. EC1: A $\mathrm{SMOK}^{\circledR}$ Alien $220 \mathrm{~W}$ variable voltage/variable wattage/temperature control (VV/VW/TC) battery was fitted with a SMOK ${ }^{\circledR}$ Baby containing a Q2 $0.4 \Omega$ single vertical coil. EC2: A SMOK Alien 220W VV/VW/TC battery was fitted with a Kanger ${ }^{\circledR}$ Protank-2 clearomizer containing a MT32 $2.2 \Omega$ single horizontal coil.

Synthesis of ${ }^{13} \mathrm{C}$-labeled TA. ${ }^{13} \mathrm{C}_{3}-\mathrm{GL}$ (Sigma-Aldrich ${ }^{\circledR}$ ) was converted to $\mathrm{C}_{6}$ ${ }^{13} \mathrm{C}_{3} \mathrm{H}_{14} \mathrm{O}_{6}\left({ }^{13} \mathrm{C}_{3}-\mathrm{TA}, 4\right)$ by acetic anhydride and pyridine $\left(25^{\circ} \mathrm{C}, 22 \mathrm{~h}\right)$. Purification was performed by column chromatography followed by solvent evaporation under reduced pressure to afford the liquid product. Purity was confirmed by ${ }^{1} \mathrm{H}$ NMR and ${ }^{13} \mathrm{C}$ NMR. GL was converted to $\mathrm{C}_{3}{ }^{-13} \mathrm{C}_{6} \mathrm{H}_{14} \mathrm{O}_{6}\left({ }^{13} \mathrm{C}_{6}-\mathrm{TA}, 5\right)$ by ${ }^{13} \mathrm{C}_{4}$ acetic anhydride (Cambridge 
Isotopes $\left.{ }^{\circledR}\right)$ and pyridine $\left(25^{\circ} \mathrm{C}, 22 \mathrm{~h}\right)$. Purification was performed by column chromatography followed by solvent evaporation under reduced pressure to afford the liquid product. Purity was confirmed by ${ }^{1} \mathrm{H} N M R$ and ${ }^{13} \mathrm{C}$ NMR.

E-liquid preparation and avoidance of dry coils and burnt e-liquid. Each device was filled with e-liquid to the highest level according to manufacturers' recommendation. $P G / G L$ solution: a 1:1 ratio (by volume, $\% \mathrm{v} / \mathrm{v}$ ) of $\mathrm{PG} / \mathrm{GL}$ was mixed in house from ACS-grade PG and GL. EC1 and EC2 were filled with a mixture of $1.0 \mathrm{~mL}$ PG and $1.0 \mathrm{~mL} \mathrm{GL}$.

10\% TA solution: a 1:1 ratio of PG/GL (\% v/v) was mixed in house with an addition of $10 \%$ (\% v/v) ACS-grade TA. $10 \%{ }^{13} C_{3}$-TA (4) solution: a $1: 1$ ratio of PG/GL (\% $\mathrm{v} / \mathrm{v}$ ) was mixed in house with an addition of $10 \%(\% \mathrm{v} / \mathrm{v})$ synthesized $4.10 \%{ }^{13} \mathrm{C}_{6}$-TA (5) solution: a $1: 1$ ratio of $P G / G L(\% \mathrm{v} / \mathrm{v})$ was mixed in house with an addition of $10 \%(\% \mathrm{v} / \mathrm{v})$ synthesized $\mathbf{5}$.

Throughout each vaping session, ample e-liquid was maintained to cover the wicking material. After each session, the e-liquid was replaced with a fresh solution. New coils were also used in each session. Each device was studied at two wattages that were within self-reported user preferences (Supporting Information) as well as within the range of the manufacturers' recommendation.

Collecting the aerosol. The e-cigarette aerosol consists of liquid particles suspended in the gas phase. ${ }^{33}$ The aerosol produced was passed through a dry cold trap submerged in a dry ice/acetone bath $\left(-76^{\circ} \mathrm{C} \pm 2{ }^{\circ} \mathrm{C}\right)$, followed by an impinger of $0.6 \mathrm{~mL}$ 
DMSO- $d_{6}$ connected to a $\mathrm{CH}$ Technologies single cigarette smoking machine (SCSMSTEP). Each vaping session consisted of 10 puffs. The SCSM-STEP was set to the CORESTA program, which has a square shape puff profile, a $3 \mathrm{~s}$ puff period and a $55 \mathrm{~mL}$ puff volume. In this study, the puff interval was set to 1 min to aid cooling of the heating coils between puffs. EC1 was tested in triplicate at $55 \mathrm{~W}$ and $65 \mathrm{~W}$. EC2 was tested in triplicate at $9 \mathrm{~W}$ and $11 \mathrm{~W}$. The aerosolization of ${ }^{13} \mathrm{C}_{3}$-TA (4) e-liquid and ${ }^{13} \mathrm{C}_{6}$-TA (5) eliquid were each performed once with EC1 at 65W and once with EC2 at 11W. After each puff, the DMSO- $d_{6}$ from the impinger was used to collect the aerosols that had condensed inside the cold trap. $0.425 \mathrm{~mL}$ of the dissolved aerosol was placed in a Wilmad ${ }^{\circledR} 400 \mathrm{MHz}$ NMR tube. An internal standard was added via a $40 \mu \mathrm{L}$ aliquot of a 10.01 mM 2,3,5,6-tetrachloro-4-nitrobenzene solution in DMSO- $d_{6}$.

Analysis by NMR. NMR spectra were obtained with a Bruker ${ }^{\circledR} 400 \mathrm{MHz}$ AVANCE II+ spectrometer. ${ }^{1} \mathrm{H}$ NMR: $30^{\circ}$ pulse angle, $10 \mathrm{~s}$ relaxation delay and 256 acquisitions. ${ }^{13} \mathrm{C} N M R: 30^{\circ}$ pulse angle, $2 \mathrm{~s}$ relaxation delay and 2048 acquisitions. ${ }^{13} \mathrm{C}$ NMR spectra were obtained for the sample of (i) $10 \%{ }^{13} \mathrm{C}_{3}$-TA (4) solution, (ii) $10 \%{ }^{13} \mathrm{C}_{6}$-TA (5) solution and (iii) $10 \%$ TA solution for EC1 at $65 \mathrm{~W}$ and for EC2 at $11 \mathrm{~W}$. Data was processed and analyzed using the software, MNova ${ }^{\circledR}$.

\section{SUPPORTING INFORMATION}

\section{Synthesis and characterization of ${ }^{13} \mathrm{C}$-labeled triacetin.}

General procedure from glycerol. Glycerol (5 mmol, 1 equiv.) and acetic anhydride ( $20 \mathrm{mmol}, 4$ equiv.) were added to a $50 \mathrm{~mL}$ round bottom flask with a magnetic stir bar. Pyridine (20 mmol, 4 equiv.) was added and sealed with a closed cap. 
The solution was stirred for 24 hours. The mixture was added to a separatory funnel, and the ethyl acetate (EtOAc)/water layers separated. The water layer was extracted with EtOAc $(3 \times 50 \mathrm{~mL})$. The combined EtOAc layers were dried over $\mathrm{Na}_{2} \mathrm{SO}_{4}$, filtered, and the solvent removed on the rotary evaporator. The crude residue was purified by flash column chromatography on silica gel with EtOAc/hexane 4/6 mixture as the eluent. 
${ }^{13} \mathrm{C}_{3}-\mathrm{C}_{6} \mathrm{H}_{14} \mathrm{O}_{6}(4)$

Prepared according to the general procedure on $1.6 \mathrm{mmol}$ scale and obtained an isolated yield of $95 \%(0.3326 \mathrm{~g})$ as a clear liquid. Spectral data is consistent with that of commercially obtained triacetin.

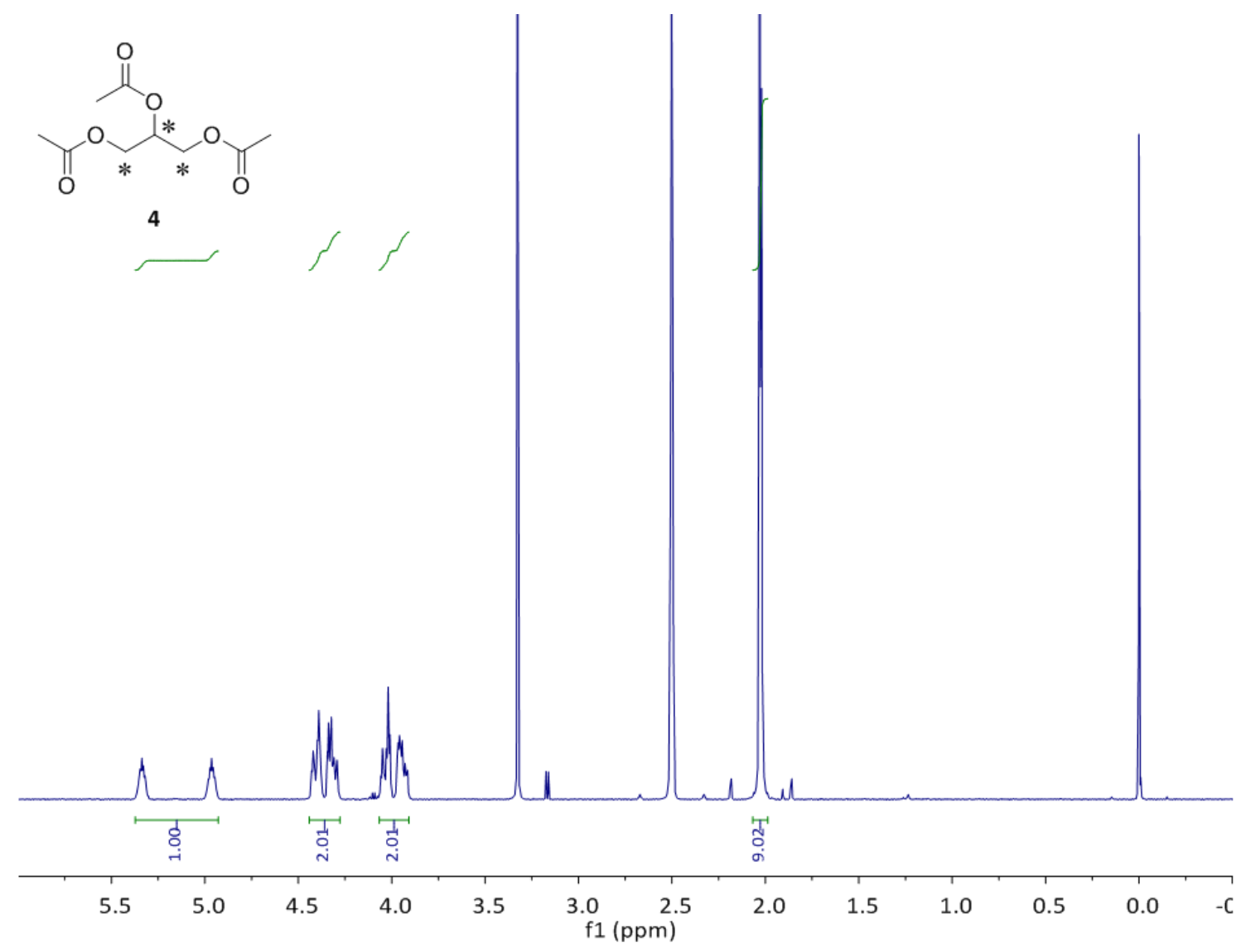

Figure S1. ${ }^{1} \mathrm{H}$ NMR spectra of compound $4\left({ }^{13} \mathrm{C}_{3}-\mathrm{TA}\right)$. The asterisks represent the ${ }^{13} \mathrm{C}$-labeling. 


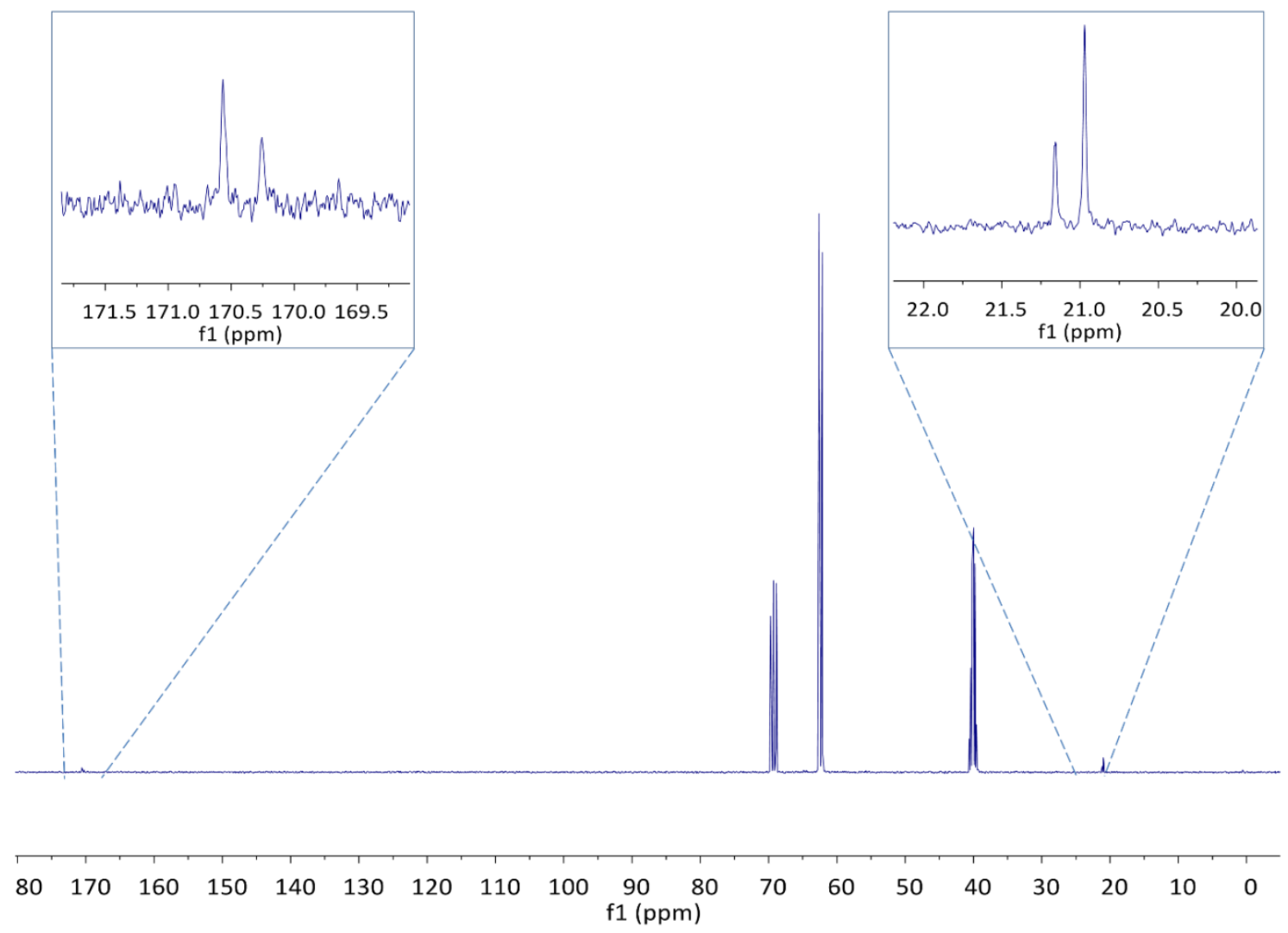

Figure S2. ${ }^{13} \mathrm{C}$ NMR spectra of compound $4\left({ }^{13} \mathrm{C}_{3}-\mathrm{TA}\right)$. The insets display the carbon peaks which are at much lower relative intensities due to the ${ }^{13} \mathrm{C}$-labeling. 
${ }^{13} \mathrm{C}_{6}-\mathrm{C}_{3} \mathrm{H}_{14} \mathrm{O}_{6}(5)$

Prepared according to the general procedure on $1.1 \mathrm{mmol}$ scale and obtained an isolated yield of $95 \%(0.2333 \mathrm{~g})$ as a clear liquid. Spectral data is consistent with that of commercially obtained triacetin.
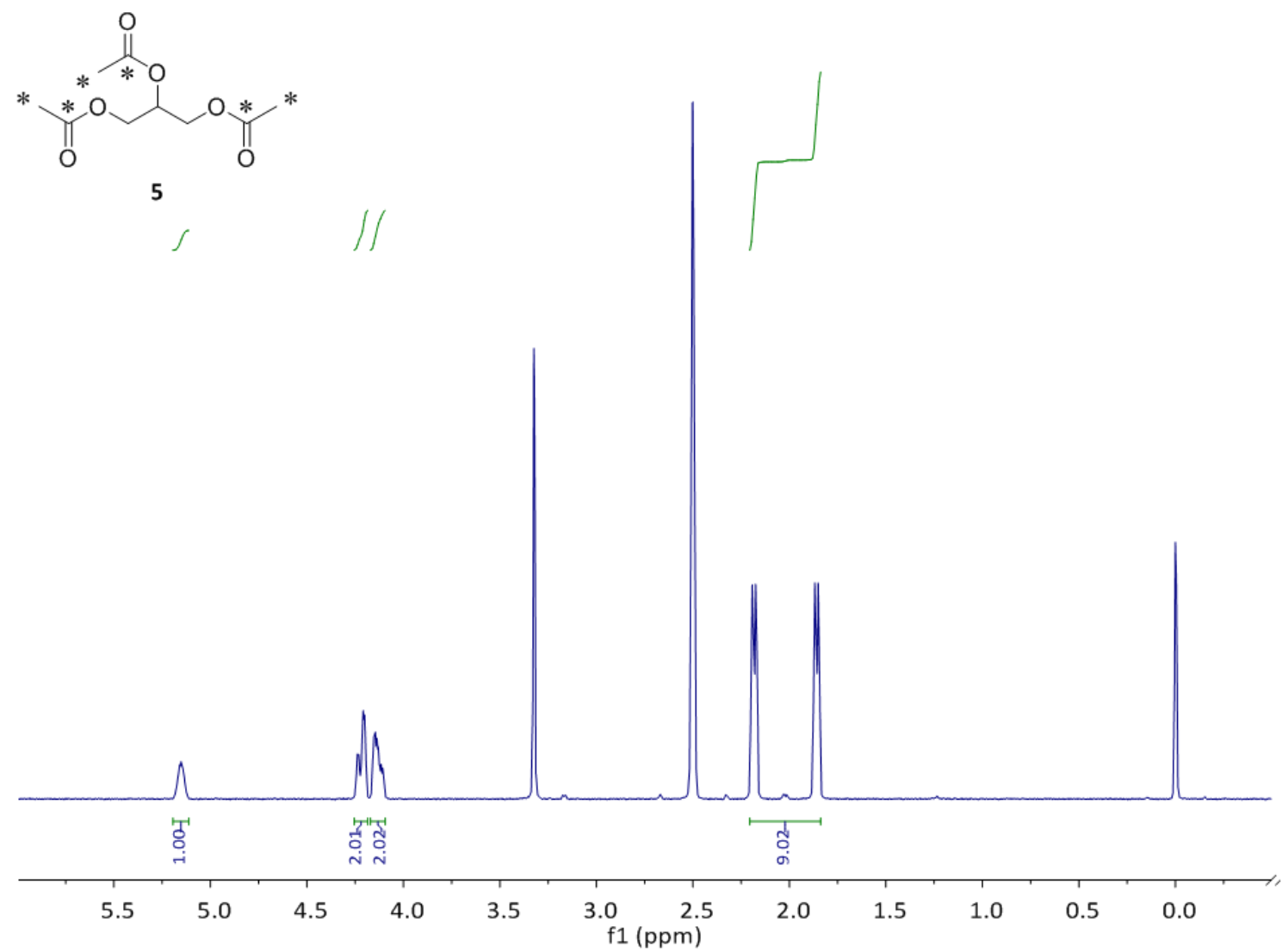

Figure S3. ${ }^{1} \mathrm{H}$ NMR spectra of compound $\mathbf{5}\left({ }^{13} \mathrm{C}_{6}-\mathrm{TA}\right)$. The asterisks represent the ${ }^{13} \mathrm{C}$-labeling. 


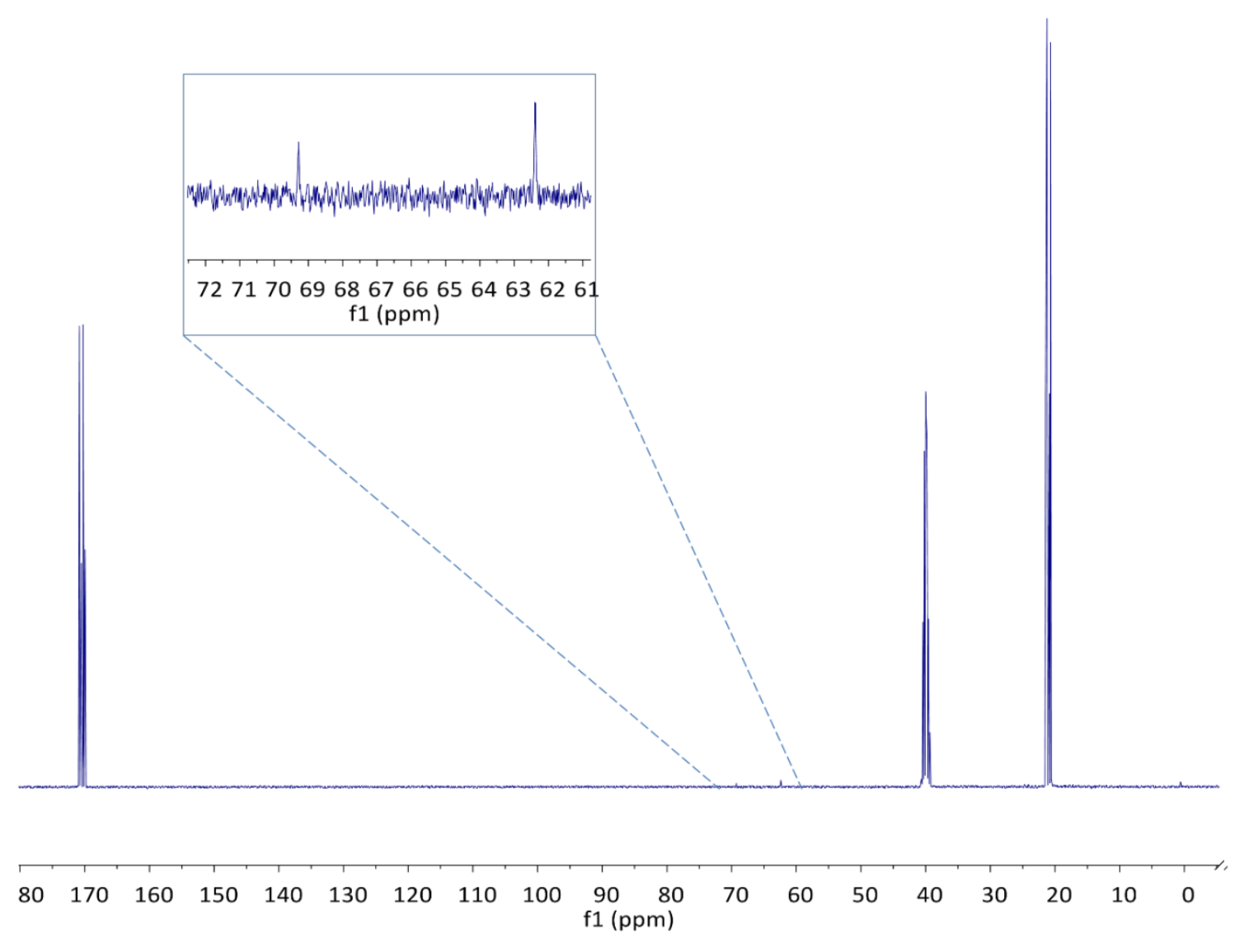

Figure S4. ${ }^{13} \mathrm{C}$ NMR spectra of compound $5\left({ }^{13} \mathrm{C}_{6}-\mathrm{TA}\right)$. The inset displays the carbon peaks which are at much lower relative intensities due to the ${ }^{13} \mathrm{C}$-labeling.

Quantification of 1a-3. Table S1 reports the quantification of formaldehyde hemiacetals (1a-b), acrolein (2), and acetaldehyde (3) by ${ }^{1} \mathrm{H}$ NMR using relative integrations against an internal standard. Values are presented as an average $\mathrm{mg} / \mathrm{g}$ eliquid consumed for each wattage tested. 1a-b were integrated together due to their overlapping peaks. A $p$-value of $<0.05$ represents statistical significance. LOD was calculated to be $0.025 \mathrm{mM}$ using the International Union of Pure and Applied Chemistry 
method. ${ }^{34}$ Table S2 reports the mass of e-liquid consumed for each sample, which were used to calculate the average $\mathrm{mg} / \mathrm{g}$.

Table S1. Quantification of compounds $\mathbf{1} \mathbf{a}-\mathbf{b}, \mathbf{2}$ and $\mathbf{3}$ by ${ }^{1} \mathrm{H}$ NMR.

\begin{tabular}{|c|c|c|c|c|c|c|}
\hline \multicolumn{7}{|c|}{ EC1: SMOK ${ }^{\circledR}$ Baby Q2 } \\
\hline $\begin{array}{l}\text { Power } \\
\text { setting }\end{array}$ & $\begin{array}{c}\text { Target } \\
\text { compound }\end{array}$ & $\begin{array}{l}\text { Concentration of } \\
\text { solute in aerosol of } \\
\text { PG/GL e-liquid } \\
\text { (mg/g) }\end{array}$ & $\begin{array}{l}\text { Standard } \\
\text { deviation }\end{array}$ & $\begin{array}{l}\text { Concentration of } \\
\text { solute in aerosol of } \\
\text { 10\% TA e-liquid } \\
\text { (mg/g) }\end{array}$ & $\begin{array}{l}\text { Standard } \\
\text { deviation }\end{array}$ & $p$-value \\
\hline \multirow[t]{3}{*}{$55 W$} & $1 a$ and $b$ & 0.00046 & 0.000656 & 0.00084 & 0.00070 & 0.611 \\
\hline & 2 & $<$ LOD & - & 0.00039 & 0.00055 & - \\
\hline & 3 & $<L O D$ & - & $<\mathrm{LOD}$ & - & - \\
\hline \multirow[t]{3}{*}{$65 \mathrm{~W}$} & $1 a$ and $b$ & 0.00062 & 0.000513 & 0.00162 & 0.00024 & 0.034 \\
\hline & 2 & $<$ LOD & - & 0.00043 & 0.00047 & - \\
\hline & 3 & $<L O D$ & - & $<$ LOD & - & - \\
\hline \multicolumn{7}{|c|}{ EC2: Kanger ${ }^{\circledR}$ Protank 2} \\
\hline \multirow[t]{3}{*}{$9 W$} & $1 a$ and $b$ & $<L O D$ & - & 0.0937 & 0.0930 & - \\
\hline & 2 & $<L O D$ & - & 0.0047 & 0.0059 & - \\
\hline & 3 & $\angle L O D$ & - & 0.0030 & 0.0041 & - \\
\hline \multirow[t]{3}{*}{$11 W$} & $1 a$ and $b$ & 0.463 & 0.329 & 1.323 & 0.302 & 0.029 \\
\hline & 2 & 0.208 & 0.119 & 0.519 & 0.134 & 0.044 \\
\hline & 3 & 0.137 & 0.101 & 0.373 & 0.085 & 0.036 \\
\hline
\end{tabular}


Table S2. Mass of e-liquid consumed for each sample collected.

\begin{tabular}{|c|c|c|c|c|}
\hline \multicolumn{5}{|c|}{ EC1: SMOK Baby Q2 } \\
\hline Power setting & $\begin{array}{l}\text { E-liquid } \\
\text { solution }\end{array}$ & $\begin{array}{l}\text { Initial mass of } \\
\text { cartomizer (g) }\end{array}$ & $\begin{array}{l}\text { Final mass of } \\
\text { cartomizer (g) }\end{array}$ & $\begin{array}{l}\text { Mass e-liquid } \\
\text { consumed (g) }\end{array}$ \\
\hline \multirow[t]{6}{*}{$55 W$} & \multirow[t]{3}{*}{$\mathrm{PG} / \mathrm{GL}$} & 49.5742 & 49.1751 & 0.3991 \\
\hline & & 49.5742 & 49.1751 & 0.3991 \\
\hline & & 49.5051 & 49.1576 & 0.3475 \\
\hline & \multirow[t]{3}{*}{ TA/PG/GL } & 49.7639 & 49.4324 & 0.3315 \\
\hline & & 49.6284 & 49.3175 & 0.3109 \\
\hline & & 49.4698 & 49.1166 & 0.3532 \\
\hline \multirow[t]{7}{*}{$65 W$} & \multirow[t]{3}{*}{ PG/GL } & 49.5416 & 49.1049 & 0.4367 \\
\hline & & 49.7651 & 49.3618 & 0.4033 \\
\hline & & 49.5471 & 49.1750 & 0.3721 \\
\hline & \multirow[t]{4}{*}{ TA/PG/GL } & 49.6309 & 49.2638 & 0.3671 \\
\hline & & 49.6385 & 49.2717 & 0.3668 \\
\hline & & 49.6965 & 49.3786 & 0.3179 \\
\hline & & 49.4190 & 49.0114 & 0.4076 \\
\hline \multicolumn{5}{|c|}{ EC2: Kanger Protank 2} \\
\hline \multirow[t]{6}{*}{$9 \mathrm{~W}$} & \multirow[t]{3}{*}{ PG/GL } & 42.8153 & 42.7423 & 0.0730 \\
\hline & & 42.9256 & 42.8630 & 0.0626 \\
\hline & & 43.0114 & 42.9397 & 0.0717 \\
\hline & \multirow[t]{3}{*}{ TA/PG/GL } & 43.0143 & 42.8431 & 0.1712 \\
\hline & & 42.8698 & 42.7840 & 0.0858 \\
\hline & & 42.7369 & 42.6343 & 0.1026 \\
\hline \multirow[t]{7}{*}{$11 \mathrm{~W}$} & \multirow[t]{3}{*}{ PG/GL } & 43.1723 & 43.0388 & 0.1335 \\
\hline & & 42.7491 & 42.6496 & 0.0995 \\
\hline & & 42.7623 & 42.6592 & 0.1031 \\
\hline & \multirow[t]{4}{*}{ TA/PG/GL } & 42.8196 & 42.7098 & 0.1098 \\
\hline & & 42.6840 & 42.5752 & 0.1088 \\
\hline & & 42.7170 & 42.6214 & 0.0956 \\
\hline & & 42.3275 & 42.2355 & 0.0920 \\
\hline
\end{tabular}

Reported concentration range of triacetin in e-liquid. Due to the current FDA

regulations e-cigarette liquid manufactures do not need to report the full chemical composition of the e-liquid nor the chemical concentration. To determine the 
concentration that was used for this study, we compiled a list of the few manufacturers that report TA in their e-liquid, as well as one recent published report of TA concentration within e-liquid. Reported in Table S3 is the number of TA containing eliquids that have a concentration level reported at or above $10 \%$ from each source. The $10 \%$ TA concentration used in this study represents a conservative and relevant concentration.

Table S3. Reported concentration range of triacetin in e-liquid.

\begin{tabular}{|c|c|}
\hline & $\begin{array}{l}\text { Number of TA-containing e-liquids } \\
\text { reported with TA levels } \geq 10 \%\end{array}$ \\
\hline Flavor Apprentice ${ }^{35}$ & 7 of 19 \\
\hline Simply Flavors ${ }^{36}$ & 39 of 51 \\
\hline Flavor West ${ }^{36}$ & 13 of 24 (post-dilution) \\
\hline Behar, R. et al. ${ }^{37}$ & 0 of 5 \\
\hline
\end{tabular}

Self-reported users' preferences for power output setting. To determine which battery power settings would be used for this study, we manually recorded users' selfreported preferences from Reddit. Two wattages were chosen for each e-cigarette device which would cover the range of reported preferences. Below is the list used; however, this is not an exhausted search due to the high volume of conversations and responses found on Reddit. 
SMOK Baby, Q2 0.4 ohm coil

- BeholderVee: "Tried a q2 coil on baby on 30-55w..." 38

- [deleted]: "I like to vape around 45-55 watts. (Q2)."39

- Urano_Metria: “...I find the best flavor at 55W and notice I get the best vapor production and temp at around $65 \mathrm{~W}$, I have no problems sacrificing a tiny bit of flavor and vaping it at 60W." 40

- DeadRights: "I usually run it at about 65 - 70 watts."41

- Rezingreenbowl: "...using the Q2 at 65w..."42

- 702jimboslice: "best through 55-65 and that's where it seems to have a sweet spot..." 43

Protank 2, $2.2 \mathrm{ohm}$ coil

- Cravingvapor: "I am normally vaping at 8-10 watts."44

- residualenvy. "...for my liking 2.2 at about $10 \mathrm{~W}$ works great." 45

- kkeeiiggaann: “...don't need to be used above 8-9w to put out a decent vape." 46

- swancitysounds: "I like to stick around 9 watts."47

- BikerKnight: "Would work great on your Protank 2 at 7-12W..." 48

- Okolo: “...depending on the juice I'm using, going up to 11 watts improves the taste..." 49

- NELyon: "I usually have my VV with the MPT2 at around 10.5 or 11 watts..." 50

\section{REFERENCES}

1. Tushar Singh; René A. Arrazola; Catherine G. Corey; Corinne G. Husten; Linda J. Neff; David M. Homa; King, B. A., Tobacco Use among Middle and High School Students - United States, 2011-2015. MMWR; Morbidity and Mortality Weekly Report 2016, 65, 361-367.

2. Bold, K. W.; Kong, G.; Camenga, D. R.; Simon, P.; Cavallo, D. A.; Morean, M. E.; Krishnan-Sarin, S., Trajectories of E-Cigarette and Conventional Cigarette Use among Youth. Pediatrics 2018, 141 (1), e20171832.

3. Patel, D.; Davis, K. C.; Cox, S.; Bradfield, B.; King, B. A.; Shafer, P.; Caraballo, R.; Bunnell, R., Reasons for Current E-Cigarette Use among U.S. Adults. Preventive Medicine 2016, 93, 14-20.

4. Zare, S.; Nemati, M.; Zheng, Y., A Systematic Review of Consumer Preference for E-Cigarette Attributes: Flavor, Nicotine Strength, and Type. PLoS ONE 2018, 13 (3).

5. Bold, K. W.; Kong, G.; Cavallo, D. A.; Camenga, D. R.; Krishnan-Sarin, S., Reasons for Trying E-Cigarettes and Risk of Continued Use. Pediatrics 2016, 138 (3), e20160895.

6. Kinouani, S.; Pereira, E.; Tzourio, C., Electronic Cigarette Use in Students and Its Relation with TobaccoSmoking: A Cross-Sectional Analysis of the I-Share Study. International Journal of Environmental Research and Public Health 2017, 14 (11), 1345. 
7. Berg, C. J., Preferred Flavors and Reasons for E-Cigarette Use and Discontinued Use among Never, Current, and Former Smokers. International Journal of Public Health 2016, 61 (2), 225-236.

8. Vaporizers, E-Cigarettes, and Other Electronic Nicotine Delivery Systems (Ends). https://www.fda.gov/TobaccoProducts/Labeling/ProductsIngredientsComponents/ucm456610.htm (accessed January 10, 2018).

9. Info Electronic Cigarettes. The Safety of E-Liquid, What We Know Now. https://info-electroniccigarette.com/e-juice/e-liquid-safety (accessed April 12, 2018).

10. Better Than Food-Grade in Everything You Need to Know About Vaporfi E Juices! . https://www.vaporfi.com/blog/everything-you-need-to-know-about-vaporfi-e-juices/ (accessed April 16, 2018).

11. Khlystov, A.; Samburova, V., Flavoring Compounds Dominate Toxic Aldehyde Production During ECigarette Vaping. Environmental Science \& Technology 2016, 50 (23), 13080-13085.

12. Lerner, C. A.; Sundar, I. K.; Yao, H.; Gerloff, J.; Ossip, D. J.; Mclntosh, S.; Robinson, R.; Rahman, I., Vapors Produced by Electronic Cigarettes and E-Juices with Flavorings Induce Toxicity, Oxidative Stress, and Inflammatory Response in Lung Epithelial Cells and in Mouse Lung. PLoS ONE 2015, 10 (2), e0116732.

13. Muthumalage, T.; Prinz, M.; Ansah, K. O.; Gerloff, J.; Sundar, I. K.; Rahman, I., Inflammatory and Oxidative Responses Induced by Exposure to Commonly Used E-Cigarette Flavoring Chemicals and Flavored E-Liquids without Nicotine. Frontiers in physiology 2018, 8, 1130.

14. Gerloff, J.; Sundar, I. K.; Freter, R.; Sekera, E. R.; Friedman, A. E.; Robinson, R.; Pagano, T.; Rahman, I., Inflammatory Response and Barrier Dysfunction by Different E-Cigarette Flavoring Chemicals Identified by Gas Chromatography-Mass Spectrometry in E-Liquids and E-Vapors on Human Lung Epithelial Cells and Fibroblasts. Applied in Vitro Toxicology 2017, 3 (1), 28-40.

15. Leigh, N. J.; Lawton, R. I.; Hershberger, P. A.; Goniewicz, M. L., Flavourings Significantly Affect Inhalation Toxicity of Aerosol Generated from Electronic Nicotine Delivery Systems (Ends). Tobacco Control 2016, 25 (Suppl 2), ii81-ii87.

16. Farsalinos, K. E.; Voudris, V., Do Flavouring Compounds Contribute to Aldehyde Emissions in ECigarettes? Food and Chemical Toxicology 2018, 115, 212-217.

17. Eddingsaas, N.; Pagano, T.; Cummings, C.; Rahman, I.; Robinson, R.; Hensel, E., Qualitative Analysis of E-Liquid Emissions as a Function of Flavor Additives Using Two Aerosol Capture Methods. International Journal of Environmental Research and Public Health 2018, 15 (2), 323.

18. Soussy, S.; EL-Hellani, A.; Baalbaki, R.; Salman, R.; Shihadeh, A.; Saliba, N. A., Detection of 5Hydroxymethylfurfural and Furfural in the Aerosol of Electronic Cigarettes. Tobacco Control 2016, 25, ii88-ii93.

19. Farley, S. M.; Schroth, K. R.; Grimshaw, V.; Luo, W.; DeGagne, J. L.; Tierney, P. A.; Kim, K.; Pankow, J. F., Flavour Chemicals in a Sample of Non-Cigarette Tobacco Products without Explicit Flavour Names Sold in New York City in 2015. Tobacco Control 2018, 27 (2), 170-176.

20. E-Cig Express. Comments on Mts Vape Wizard by Flavourart. http://www.ecigexpress.com/diy-eliquid/diy-e-liquid-flavors/flavourart-usa/flavourart-tobacco/mts-vape-wizard-by-flavourart.html (accessed April 12, 2018).

21. Perfumers Apprentice. Flavors - Non Pg. https://shop.perfumersapprentice.com/c-133-flavors-nonpg.aspx (accessed April 12, 2018).

22. Vreeke, S.; Korzun, T.; Luo, W.; Jensen, R. P.; Peyton, D. H.; Strongin, R. M., Dihydroxyacetone Levels in Electronic Cigarettes: Wick Temperature and Toxin Formation. Aerosol Science and Technology 2018, $52(4), 370-376$.

23. Laino, T.; Tuma, C.; Moor, P.; Martin, E.; Stolz, S.; Curioni, A., Mechanisms of Propylene Glycol and Triacetin Pyrolysis. Journal of Physical Chemistry A 2012, 116 (18), 4602-4609.

24. Formaldehyde, 2-Butoxyethanol and 1-Tert-Butoxy-2-Propanol. IARC Monographs on the Evaluation of Carcinogenic Risks to Humans 2006, 88, 39-325. 
25. O Faroon; N Roney; J Taylor; A Ashizawa; MH Lumpkin; Plewak, D., Acrolein Health Effects. Toxicology and Industrial Health 2008, 24 (7), 43.

26. Jensen, R. P.; Strongin, R. M.; Peyton, D. H., Solvent Chemistry in the Electronic Cigarette Reaction Vessel. Scientific Reports 2017, 7, 42549.

27. Jensen, R. P.; Luo, W.; Pankow, J. F.; Strongin, R. M.; Peyton, D. H., Hidden Formaldehyde in E-Cigarette Aerosols. New England Journal of Medicine 2015, 372 (4), 392-394.

28. Korzun, T.; Lazurko, M.; Munhenzva, I.; Barsanti, K. C.; Huang, Y.; Jensen, R. P.; Escobedo, J. O.; Luo, W.; Peyton, D. H.; Strongin, R. M., E-Cigarette Airflow Rate Modulates Toxicant Profiles and Can Lead to Concerning Levels of Solvent Consumption. ACS Omega 2018, 3 (1), 30-36.

29. Tuma, C.; Laino, T.; Curioni, A.; Jochnowitz, E.; Stolz, S., Reaction Pathways for the Pyrolysis of Glycerol, Propylene Glycol and Triacetin in the Gas Phase and at Solid Surfaces. In Car-Parrinello Molecular Dynamics 2011, Barcelona, Spain, 2011.

30. Clifton, J. R.; RossiterJr, W. J.; Brown, P. W., Degraded Aqueous Glycol Solutions: Ph Values and the Effects of Common Ions on Suppressing Ph Decreases. Solar Energy Materials 1985, 12, 77-86.

31. Nimlos, M. R.; Blanksby, S. J.; Qian, X.; Himmel, M. E.; Johnson, D. K., Mechanisms of Glycerol Dehydration. Journal of Physical Chemistry A 2006, 110 (18), 6145-6156.

32. Salamanca, J. C.; Munhenzva, I.; Escobedo, J. O.; Jensen, R. P.; Shaw, A.; Campbell, R.; Luo, W.; Peyton, D. H.; Strongin, R. M., Formaldehyde Hemiacetal Sampling, Recovery, and Quantification from Electronic Cigarette Aerosols. Scientific Reports 2017, 7 (1), 11044.

33. Pankow, J. F., Calculating Compound Dependent Gas-Droplet Distributions in Aerosols of Propylene Glycol and Glycerol from Electronic Cigarettes. Journal of Aerosol Science 2017, 107, 9-13.

34. Thomsen, V.; Schatzlein, D.; Mercuro, D., Limits of Detection in Spectroscopy. Spectroscopy (Santa Monica) 2003, 18, 112-114.

35. Products with Cas \# 102-76-1 : Triacetin. Perfumers Apprentice. https://shop.perfumersapprentice.com/specsheetlist.aspx (accessed June 04, 2018).

36. Search Results for "Triacetin.". Flavor West http://flavorwest.com/index.php/catalogsearch/result/?q=triacetin (accessed June 04, 2018).

37. Behar, R. Z.; Luo, W.; McWhirter, K. J.; Pankow, J. F.; Talbot, P., Analytical and Toxicological Evaluation of Flavor Chemicals in Electronic Cigarette Refill Fluids. Scientific Reports 2018, 8 (1), 8288.

38. BeholderVee. Comment on Smok Tfv8 Burnt Taste. Reddit https://www.reddit.com/r/electronic_cigarette/comments/5g52hy/smok_tfv8_burnt_taste/ (accessed Aug 11, 2017).

39. Deleted. Comment on Best Settings to Use the Smok Alien At? Reddit https://www.reddit.com/r/Vaping/comments/5jvanx/best_settings_to_use_the_smok_alien_at/ (accessed Aug 11, 2017).

40. Urano_Metria. Comment on What Settings Do I Need to Set My Alien to for the V8 Baby Q2 Coils? . Reddit https://www.reddit.com/r/electronic_cigarette/comments/6a79nu/what_settings_do_i_need_to_set _my_alien_to_for/ (accessed Aug 11, 2017).

41. DeadRights. Comment on I Need Some Help Avoiding the Burnt Hits on My Smok Tfv8 Cloud Beast Tank. . Reddit https://www.reddit.com/r/electronic_cigarette/comments/7500wn/i_need_some_help_avoiding_the _burnt_hits_on_my/ (accessed Aug 11, 2017).

42. Rezingreenbowl. Comment on Best Settings to Use the Smok Alien At? . Reddit https://www.reddit.com/r/Vaping/comments/5jvanx/best_settings_to_use_the_smok_alien_at/ (accessed Aug 11, 2017).

43. 702jimboslice. Comment on Best Settings to Use the Smok Alien At? Reddit https://www.reddit.com/r/Vaping/comments/5jvanx/best_settings_to_use_the_smok_alien_at/ (accessed Aug 11, 2017). 
44. Cravingvapor. Comment on I Have a Couple of Protank 2 Questions If You Don't Mind! . Reddit https://www.reddit.com/r/electronic_cigarette/comments/1mdnrt/i_have_a_couple_of_protank_2_q uestions_if_you/ (accessed Aug 09, 2017).

45. Residualenvy. Comment on I Have a Couple of Protank 2 Questions If You Don't Mind! . Reddit https://www.reddit.com/r/electronic_cigarette/comments/1mdnrt/i_have_a_couple_of_protank_2_q uestions_if_you/\#bottom-comments (accessed Aug 09, 2017).

46. Kkeeiiggaann. Comment on Pro Tank 2 Help!! Please. . Reddit https://www.reddit.com/r/electronic_cigarette/comments/2ppk4g/pro_tank_2_help_please/ (accessed Aug 09, 2017).

47. Swancitysounds. Comment on What Wattage or Voltage to Use on a $1.1 \mathrm{Ohm}$ Coil in a Kanger Protank 2 ? Reddit https://www.reddit.com/r/electronic_cigarette/comments/1zlli7/what_wattage_or_voltage_to_use_ on_a_11_ohm_coil/\#bottom-comments (accessed Aug 09, 2017).

48. BikerKnight. Comment on Transitioning from Analogs: Few Questions on 1.8-2.2 Ohm Atomizers + Variable Voltage-Wattage Batteries + Nicotine Level/E-Juice Blends for My Protank 2. . Reddit https://www.reddit.com/r/electronic_cigarette/comments/3gwkvc/transitioning_from_analogs_few_ questions_on_1822/ (accessed Aug 09, 2017).

49. Okolo. Comment on Need Help with Wattage Settings on My Itaste Vv 3.0. . Reddit https://www.reddit.com/r/electronic_cigarette/comments/2440bm/need_help_with_wattage_setting s_on_my_itaste_vv_30/(accessed Aug 09, 2017).

50. NELyon. Comment on Need Help with Wattage Settings on My Itaste Vv 3.0. . Reddit https://www.reddit.com/r/electronic_cigarette/comments/2440bm/need_help_with_wattage_setting s_on_my_itaste_vv_30/(accessed Aug 09, 2017). 


\section{Chapter 5: Conclusion}

Electronic cigarettes have grown in popularity against a backdrop of misinformation and a lack of scientific knowledge of their health effects. ${ }^{1}$ While touting the message as a safer alternative to cigarettes, they are being marketed to youth who have never smoked and are more susceptible to nicotine addiction and long-term health consequences. ${ }^{2}$ As more cases of lung damage from vape users appear, the public and policy makers are turning towards scientific research for answers. However, due to the complexity of e-cigarette products and the decades needed to complete epidemiological studies, there is still little known about their health hazards. State and local regulatory agencies have enacted flavor bans, some temporary, until more knowledge becomes available and/or more regulations are legislated. ${ }^{3}$ It is thus necessary for researchers to study, analyze and report their findings on the various characteristics of e-cigarettes.

Components that may impact their health risks are device design, solvent matrices and varying additives. All three components mentioned, among others, can affect the levels of toxins produced. Common chemical degradants include the carcinogens formaldehyde and acetaldehyde, and the toxins acrolein and acetone. Each compound has been detected at levels above OSHA workplace limits in the aerosols of e-cigarettes. Additionally, dihydroxyacetone (DHA) was detected in e-cigarette aerosols. DHA is the active ingredient in sunless tanner; while it may be approved for topical applications, there are only two known studies on its inhalation toxicity. ${ }^{4-5}$ Preliminary data shows that at real world aerosol concentrations DHA induced cell death after one 
exposure. ${ }^{5}$ The detection of DHA in e-cigarette aerosols is important due to the frequency of vaping; users could be exposed to millimolar levels each day.

Toxin production was found to vary by device. Power settings correlate well to degradation levels within the same device; however the situation is more complex when comparing inter-device levels. Heat is applied to the e-liquid in order to deliver the sample to the user as an aerosol. Degradation of the e-liquid occurs when an excess amount of heat is applied to the system. Since device design and coil styles are wide ranging, there are many components that could affect how efficient aerosolization occurs. The ability to correlate varying components to relative toxin levels can be used to predict each device's corresponding risk. The ability of the wicking material to deliver a supply of e-liquid to the heating coil in order to outcompete evaporation assists in lowering excess heat and preventing degradation. ${ }^{6}$ This is inversely proportional to coil length, which is relative to heat being supplied to the system. Lastly, the number of wraps of the coil indicates how evenly applied the heat from the coil is to the wick. After factoring in these e-cigarette design characteristics, the model coil length/(SA wick*wraps), is a good predictive tool for determining relative aldehyde levels in the aerosol across many different devices $\left(R^{2}=0.69\right)$. This model performed the best among 13 total models. Interestingly, models that accounted for nominal device power performed poorly as predictors of total carbonyl yields.

Additionally, additives may cause negative health effects when delivered to the body through inhalation or via their degrading into new toxic compounds. There are 
over 150 different flavorants and additives present in e-liquids. ${ }^{7}$ Most of them are "generally recognized as safe", which does not account for inhalation toxicity. ${ }^{8}$ Researchers have identified that different flavored e-liquids produce varying levels of toxins; however, very few have identified which individual chemical is responsible, or how they are interacting to produce more toxins. The additive triacetin (TA) led to a significant increase in formaldehyde, acetaldehyde and acrolein among all power settings tested. Using isotopically labeled TA, analysis by ${ }^{1} \mathrm{H} N M R$ and ${ }^{13} \mathrm{C}$ NMR was used to identify loss of acetic acid, which catalyzed the degradation reactions of the solvents $P G / G L$.

The field of e-cigarettes is very broad and continued research in fundamental chemistry, biology and public health is needed to more completely understand the impact they will have on society. There are characteristics uniquely inherent to ecigarettes that need to be taken into account when comparing them to combustible cigarettes. Flavorants and other additives play a role in toxin formation in a concentration dependent manner. Limiting flavorants and their concentrations may assist in harm reduction. Identifying the pathway of TA degradation and the interaction of the products formed with the carrier solvents can be a predictor of the impact of other ester containing flavor molecules on toxin formation. Esters account for over $50 \%$ (by frequency) of e-liquid additives. ${ }^{7}$

Designing e-cigarettes with high wicking efficiency could help decrease carbonyl emissions 10 -fold (see Chapter 3). By accounting for the relationship of the coil and wick 
(model 1), it may be possible to significantly reduce the chance of over-heating the eliquid. Model 1 is the first predictive tool that can assess aerosol product profiles across several different device styles. Researchers can use this model to show that devices they test are representative of the wide array of available devices. The model can aid manufacturers in creating safer products and assist regulatory agencies in developing policies.

Future work is needed to validate model 1 beyond the 12 devices tested, as well as with emerging devices that are yet to be developed. In addition to carbonyl formation, developing a model to predict total aerosol mass would be beneficial. As more evidence of flavorant toxicity emerges there will be a need to predict e-liquid consumption, since that will inform dosage levels. Additionally, more individual flavorants need to be tested for reactivity upon aerosolization. Recent publications have analyzed the prevalence of over 150 different flavor chemicals found in e-liquids. ${ }^{7}$ Using this data, researchers can analyze which compounds pose a higher risk based on their occurrence in e-liquids.

In conclusion, e-cigarettes can generate toxins such as dihydroxyacetone with preliminary inhalation toxicity. ${ }^{5}$ The frequency of exposure makes such toxins dangerous to e-cigarette users. Such exposure levels can be predicted by utilizing the theories of wicking efficiency and heat transfer. While increasing power will increase degradation intra-device, power alone cannot be used to compare various devices. A simple model was developed using the relationship of coil length to wick surface area and coil wraps. 
Model 1 performed within the moderate to substantial range as a predictor of e-liquid solvent degradation $\left(R^{2}=0.69\right)$. When compared to twelve alternative models it displayed better predictability, including models that contained nominal power as a variable. Additives in the e-liquid also affect aerosol toxin levels. Triacetin, an additive found in e-liquids as well as combustible cigarettes, increased the production of formaldehyde, acetaldehyde and acrolein levels by up to $185 \%$. By utilizing carbon-13 labeling the pathway of ester hydrolysis from TA to form acetic acid was identified. The acetic acid acts as a catalyst in the degradation of PG/GL. This is the first work to identify the chemical reactivity of an individual e-liquid additive. This work can educate the public on the risks of e-cigarettes, inform manufacturers' on how their designs effect aerosol properties and aid regulatory agencies in developing new policies.

\section{REFERENCES}

1. Alcalá, H. E.; Shimoga, S. V., It Is About Trust: Trust in Sources of Tobacco Health Information, Perceptions of Harm, and Use of E-Cigarettes. Nicotine and Tobacco Research 2019.

2. Siqueira, L. M., Nicotine and Tobacco as Substances of Abuse in Children and Adolescents. Pediatrics 2017, 139 (1).

3. Foden-Vencil, K., Oregon Governor Announces Temporary Ban on Flavored Vaping Products. OPB 10/04/19, 2019.

4. Wang, Y. Y.; Wu, Q. G.; Muskhelishvili, L.; Davis, K.; Bryant, M.; Cao, X. F., Assessing the Respiratory Toxicity of Dihydroxyacetone Using an in Vitro Human Airway Epithelial Tissue Model. Toxicology In Vitro 2019, 59, 78-86.

5. Srnith, K. R.; Hayat, F.; Andrews, J. F.; Migaud, M. E.; Gassman, N. R., Dihydroxyacetone Exposure Alters $\mathrm{Nad}(\mathrm{P}) \mathrm{H}$ and Induces Mitochondrial Stress and Autophagy in Hek293t Cells. Chemical Research in Toxicology 2019, 32 (8), 1722-1731.

6. Luikov, A. V., Heat and Mass Transfer in Capillary-Porous Bodies. In Advances in Heat Transfer, Irvine, T. F.; Hartnett, J. P., Eds. Elsevier: 1964; Vol. 1, pp 123-184.

7. Omaiye, E. E.; McWhirter, K. J.; Luo, W.; Tierney, P. A.; Pankow, J. F.; Talbot, P., High Concentrations of Flavor Chemicals Are Present in Electronic Cigarette Refill Fluids. Scientific Reports 2019, 9 (1), 2468.

8. Hallaghan, J. The Safety Assessment and Regulatory Authority to Use Flavors: Focus on E-Cigarettes. https://

www.femaflavor.org/member-update/safety-assessment-and-regulatory-authority-use-flavorsfocus-e-cigarettes. 